Historic, archived document

Do not assume content reflects current scientific knowledge, policies, or practices. 
United States

Department of

Agriculture

Forest Service

Intermountain

Research Station

Ogden, UT 84401

Research Paper

INT-350

October 1985

Uis
Recreational Trampling Effects on Six Habitat Types in Western Montana

David N. Cole
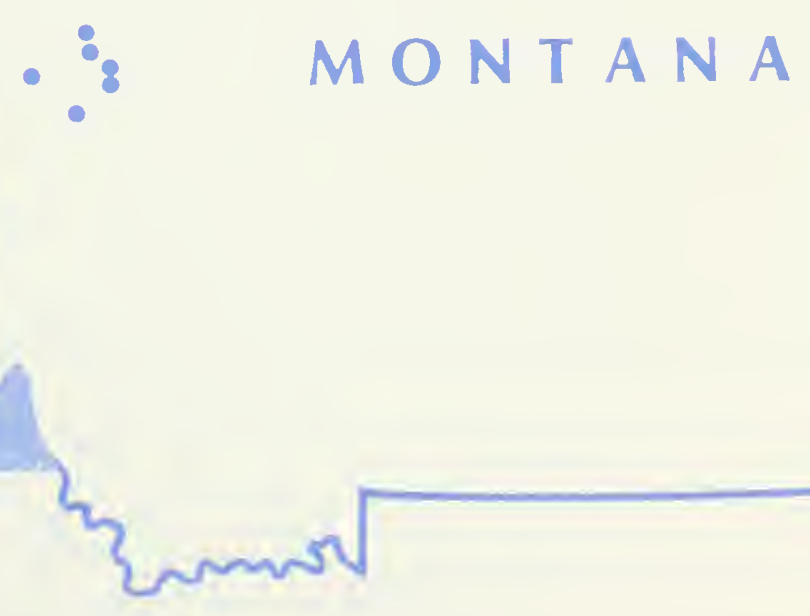


\section{THE AUTHOR}

DAVID N. COLE is a research scientist with Systems for Environmental Management, P.O. Box 8868,

Missoula, MT. He is working cooperatively with the Intermountain Station's Wilderness Management Research Work Unit at the Forestry Sciences Laboratory on the University of Montana campus, Missoula. Dr. Cole received his B.A. degree in geography from the University of California, Berkeley, in 1972. He received his Ph.D., also in geography, from the University of Oregon in 1977. He has written several papers on the ecological effects of wilderness recreation.

\section{ACKNOWLEDGMENTS}

I am grateful to many people for help on this project. Robert Christian, Susan Kerns, Jeffrey Marion, and Margaret Petersen endured the tedium of trampling. Margaret Petersen provided computer assistance. Peter Stickney confirmed species identifications for many of the more difficult plants. Scott Beckett dug and described the soil profiles.

\section{RESEARCH SUMMARY}

This study examined the response of six vegetation types in western Montana to experimental trampling. The types selected were representative of those most frequently used recreationally in the neighboring Bob Marshall Wilderness: the Abies lasiocarpa/Clintonia uniflora (subalpine fir/queencup beadlily), Abies lasiocarpa/Clintonia uniflora-Vaccinium caespitosum phase (subalpine fir/queencup beadlily-dwarf huckleberry), Abies lasiocarpa/Vaccinium caespitosum (subalpine fir/dwarf huckleberry), Abies lasiocarpal Xerophyllum tenax (subalpine fir/beargrass), Pseudotsuga menziesii/Symphoricarpos albus (Douglas-fir/snowberry), and Festuca scabrella-F. idahoensis (rough fescue-Idaho fescue) habitat types. Results are compared with findings from similar experiments in other vegetation types.

All of the forested habitat types showed a curvilinear relationship between amount of trampling and loss of vegetation cover, loss of plant species, and soil compaction. The effect of any incremental increase in amount of trampling decreases as trampling intensity increases. This indicates that trampling damage will generally be minimized when concentrated in space rather than dispersed over large areas. The Abies lasiocarpa/Xerophyllum tenax habitat type was the most resistant forest type studied, suggesting that it would be worthwhile encouraging campers to select sites in this type.

The grassland proved to be much more resistant to vegetation loss than any of the forested types. Here no significant cover loss occurred until after a total of 1,600 trampling passes had been administered. In such a resistant vegetation type, dispersal of use may be advantageous.
In contrast to vegetation loss and soil compaction, trampling intensities had to be very high before much bare mineral soil was exposed. The habitat with the thickest organic horizons (Abies lasiocarpa/Clintonia uniflora) experienced the least soil exposure. If heavy enough to kill most vegetation, use should be directed to sites with thick organic horizons.

Managers of wildernesses and other dispersed recreation areas with similar vegetation can utilize these data to estimate the effects of various use levels. It was possible, for example, to estimate the amount of use that sites in these habitat types could receive and still maintain 50 percent vegetation cover and experience mineral soil exposure of no more than 5 percent. For a party of three backpackers, these frequencies range from no use in Abies lasiocarpal Clintonia uniflora to 5 to 8 nights in Abies lasiocarpa/Xerophyllum tenax, and 10 to 15 nights in Festuca scabrella-F. idahoensis. These latter two are some of the most resistant natural vegetation types ever studied; use frequencies for vegetation types studied elsewhere can be estimated, with caution, from several tables that compare the resistance of types studied here to types studied elsewhere.

The resistance of the major plant species on these sites is assessed. This information can also be used to evaluate the relative durability of alternative recreation sites.

\section{CONTENTS}

Introduction .......................

Previous Studies ......................

Relation Between Amount of Trampling and Amount of Vegetation Loss ............... 3

Relative Resistance of Different Plant Community Types ................... 4

Relative Resistance of Different Growth Forms . . 4

Effects of Frequency and Timing of Trampling on Vegetation Loss ................... 5 Western Montana Study Area ...............6 6 Field Techniques ........................ 11 Effects of Trampling on Vegetation Cover ........ 12

Effect of Trampling Frequency ............. 12

Effect of Trampling Intensity .............. 13

Relative Resistance of Different Habitat Types .. 16

Effect of Local Variations in Species

Composition ...................... 18 Effect of Trampling on Number of Plant Species . . 2 20 Response of Individual Species to Trampling .....21 Effect of Trampling on Mineral Soil Exposure ..... 28 Effect of Trampling on Soil Compaction ........29 29 Conclusions and Management Implications ..... . 31

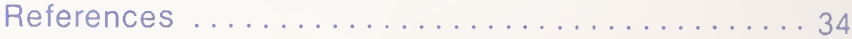
Appendix 1: Soil Profiles ................. 36 Appendix 2: Mean Cover and Frequency Values .... 39 


\section{Recreational Trampling Effects on Six Habitat Types in Western Montana

\author{
David N. Cole
}

\section{INTRODUCTION}

Wilderness and similar areas, ostensibly managed to perpetuate natural ecosystems, are often compromised by recreational use. The most pronounced and obvious impact of recreational use occurs on trails and at campsites. In 1980, managers of about two-thirds of the areas in the National Wilderness Preservation System reported excessive impacts to vegetation and soil on campsites and trails (Washburne and Cole 1983).

Some of this disturbance, such as trees damaged by chopping or tying horses to them, can be eliminated through programs that educate users about minimumimpact camping. Nevertheless, much of the vegetation and soil change on trails and campsites is inevitable. Wherever trampling occurs, vegetation and soil are disturbed. The amount of change is a function of amount and frequency of trampling, type of use, season of use, and site conditions. For most areas, amount and frequency of use and site conditions are the most important of these variables and the most amenable to control by the manager attempting to limit site damage. Where use of pack and saddle stock is significant, managers must be aware that trampling by stock has much more impact than trampling by humans (Weaver and Dale 1978). Trampling is also generally more damaging when soils are water-saturated, as they often are during early season, than when they are dry (Edmond 1966; Willard and Marr 1970).

Many studies have documented the effects of trampling on backcountry trails and campsites; some of these have related amount of change to amount of use and site conditions (Cole and Schreiner 1981). The most effective approach for isolating the effect of these two variables on amount of impact is through experimental application of controlled amounts of trampling on previously undisturbed sites. This approach has been adopted in a number of studies and is the approach taken in the study reported here.

To truly simulate the trampling pressure placed on recreation sites, controlled trampling needs to be applied for a number of years until a new equilibrium between ongoing trampling and vegetation/soil conditions can be established. Unfortunately, in all but one of the experimental studies conducted so far-one by Schreiner (1980)-trampling has been applied for only 1 year. This limits conclusions to initial deterioration; no conclusions about long-term deterioration are possible. To provide a better understanding of these long-term processes, I initiated a study in which trampling is being applied year after year until conditions have a chance to equilibrate (that is, until year-to-year change in vegetation and soil conditions becomes minimal).
Nevertheless, because past studies have applied trampling for only one season, and because little attempt has been made to integrate the results of these studies, it seemed worthwhile to report the initial results of this study (after one season of trampling) and interpret them in light of earlier comparable work. The objectives of this paper, then, are to (1) review and integrate the results of previous single-season studies of trampling and (2) describe the effects of one season of experimental trampling on six vegetation types in western Montana.

\section{PREVIOUS STUDIES}

The results of about 30 experimental trampling studies have been published. Most of these have been concerned primarily with vegetation change, although a few have focused on changes in soil condition and increases in runoff and erosion.

It is difficult to generalize from these results about the relationship between amount of trampling and impact for two reasons. First, a wide variety of vegetation types throughout Europe and North America have been examined, and the effects of trampling are different for each type. This does, however, allow comparisons of the relative resistance of different vegetation types and permits us to gain some insight into what species, growth forms, soil conditions, and so on, tolerate trampling better than others.

The second (and more important) reason is the lack of uniformity in methods. Some of the more important differences include:

1. Amount of trampling. - The number of trampling passes administered varies greatly. Comparability can usually be achieved by interpolating or cautiously extrapolating results.

2. Characteristics of tramplers.-The type of footwear and weight of the tramplers vary, influencing both the amount and nature of the stresses applied. In several cases the effects of different types of footwear have been carefully examined; in general, the effects of different types of footwear have been similar (Saunders and others 1980; Kuss 1983). Others have argued that because recreationists vary in weight and use a variety of footwear types, simulated trampling should also incorporate this variability.

3. Trampling method.-A few studies have used artificial "trampling machines"; in one study (Hartley 1976) a person systematically trampled until the entire sample area was trampled uniformly once; and in another, trampling stress was calculated in terms of "standard steps" (Holmes and Dobson 1976). These studies provide some insights, particularly into the resistance of certain vegetation types, but cannot be directly compared with the 
vast majority of studies in which tramplers walked along each treatment lane, using a natural gait, for a predetermined number of passes.

4. Sampling procedures.-Most treatment lanes are sampled and the size of the sampling unit varies. Because trampling stress is most highly concentrated in the center of each lane, narrow sampling units in the center of the lane will experience more overall trampling stress than a wider unit that includes some of the lesstrampled edge of the lane.

5. Timing of trampling.--Some studies spread the trampling over a season, while others apply all of the
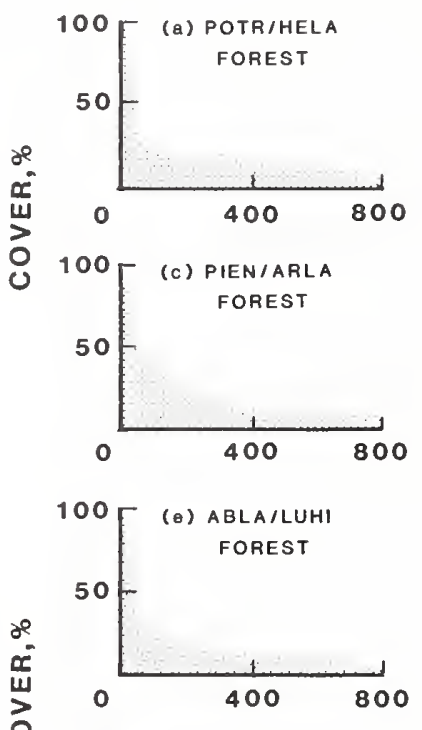

trampling at once. Some have examined the importance of the period of time over which trampling occurs by comparing the effects of the same number of passes applied either all at once or spread over the season. Such a comparison is difficult to interpret because (1) the effect of one-time trampling varies with the time of year the trampling is applied, and (2) in many cases the period of time between trampling application and measurement has varied, so more recovery is possible in some cases than in others.

6. Basis of comparison.-Several studies have not measured the pretrampling condition of treatment lanes.
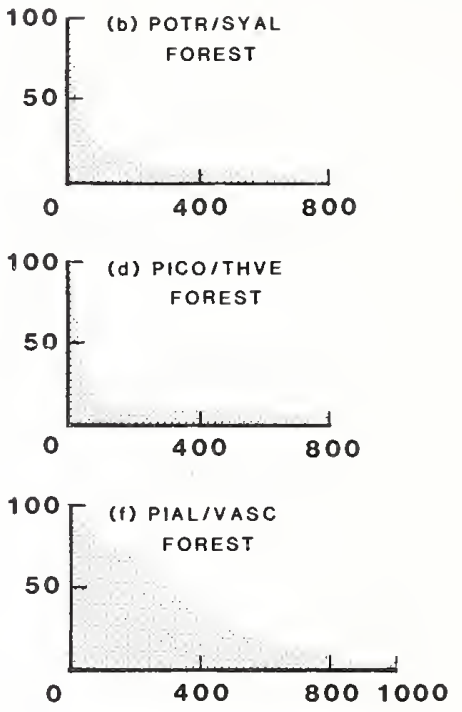
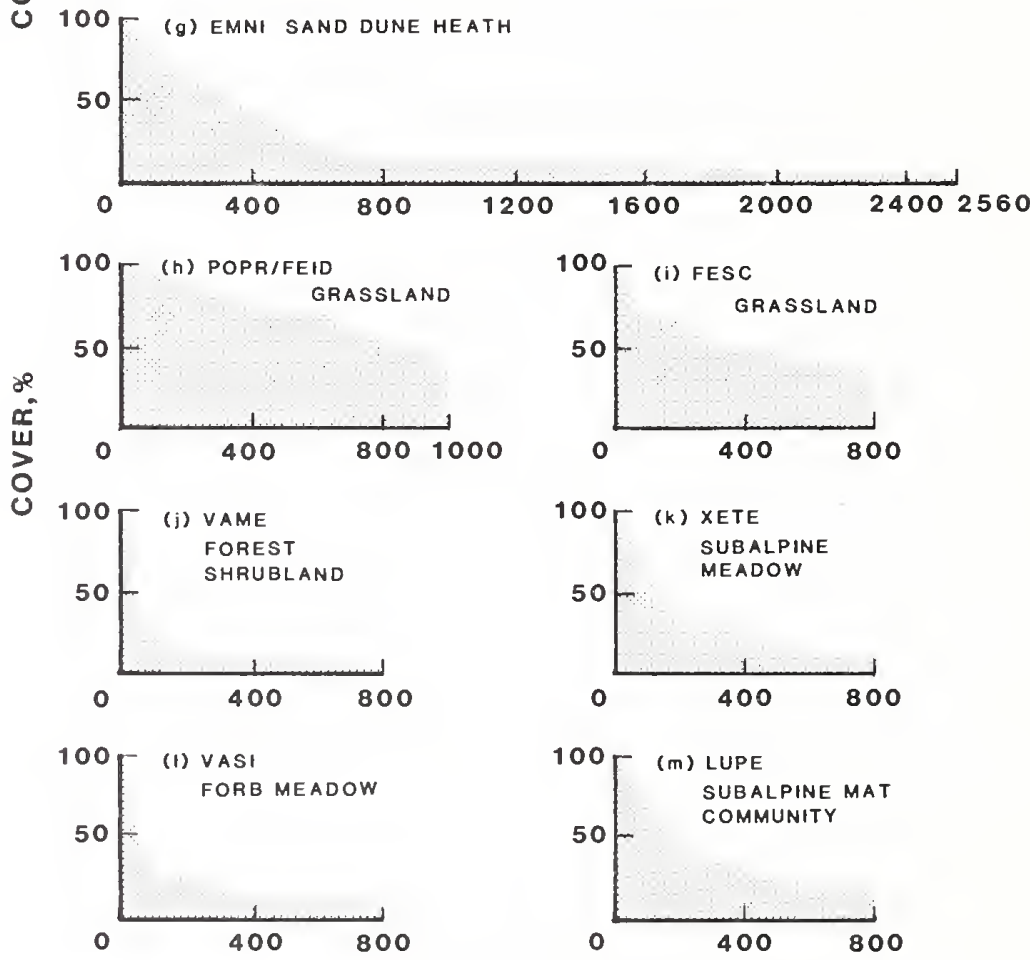

NUMBER OF PASSES

Figure 1.- The relationship between vegetation cover (see text for definitions of relative and estimated relative cover) and amount of trampling (number of passes) for previously studied vegetation types. An asterisk by the source indicates that relative cover was estimated (refer to text for definitions). 
Instead, they rely on a control lane as an estimate of pretrampling conditions. Most plant communities are so heterogeneous that this introduces significant loss of precision. The preferred design, used in many studies, utilizes control and treatment lanes and includes preand posttreatment measurements on each.

The implications of these variations in study design need to constantly be kept in mind. Nevertheless, many studies are directly comparable and with others some generalization is possible. Questions that can be partially answered at this time are: (1) What is the nature of the relationship between amount of trampling and vegetation and soil disturbance? (2) Which plant community types and growth forms are more resistant to damage than others? (3) How does the timing and frequency of trampling affect amount of disturbance?

\section{Relation Between Amount of Trampling and Amount of Vegetation Loss}

All studies show that increased trampling leads to a general increase in cover loss; however, for each plant community the curve that describes this relationship varies in shape. Figure 1 presents curves relating surviving cover to number of passes for the 22 plant communities where this relationship can be described. In some of these, the dependent variable is "relative cover," defined as the percentage of original cover remaining after trampling, adjusted for any changes that occurred on control
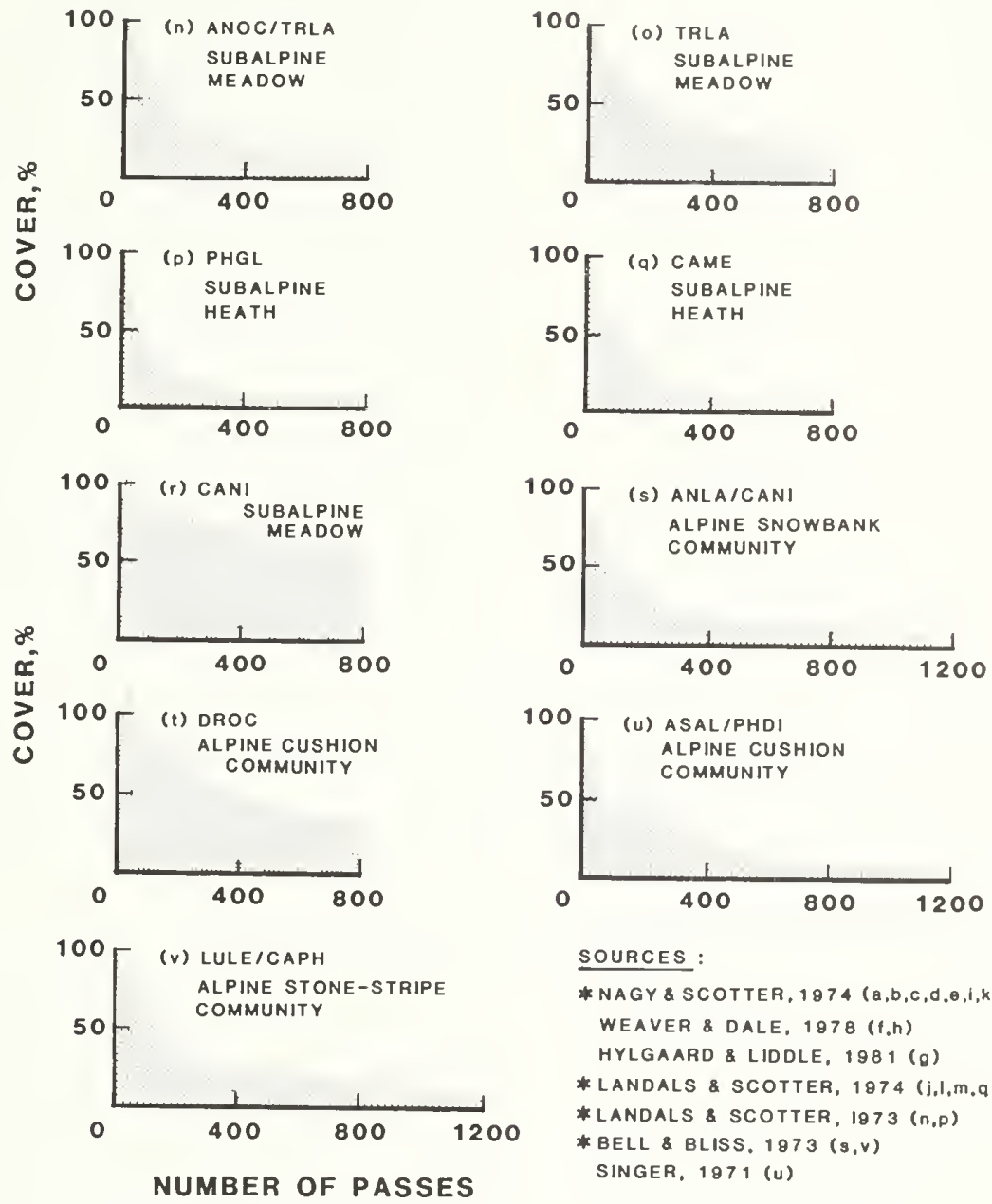

SOURCES:

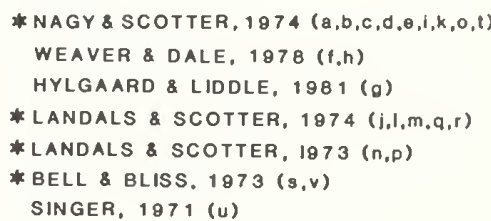

Key to Species Abbreviations:

\begin{tabular}{|c|c|c|}
\hline ABLA = Abies lasiocarpa & FEID = Festuca idahoensis & PICO = Pinus contorta \\
\hline ANOC $=$ Anemone occidentalis & FESC = Festuca scabrella & $P O P R=$ Poa pratensis \\
\hline ANLA = Antennaria lanata & HELA = Heracleum lanatum & POTR $=$ Populus tremuloides \\
\hline ARLA = Arnica latifolia & LUPE = Luetkea pectinata & SYAL = Symphoricarpos albus \\
\hline ASAL = Aster alpigenus & LULE = Lupinus lepidus & THVE $=$ Thalictrum venulosum \\
\hline CANI = Carex nigricans & LUHI = Luzula hitchcockii & TRLA $=$ Trollius laxus \\
\hline CAPH = Carex phaeocephala & PHDI = Phlox diffusa & VAME $=$ Vaccinium membranaceum \\
\hline CAME $=$ Cassiope mertensiana & PHGL = Phyllodoce glanduliflora & VASC $=$ Vaccinium scoparium \\
\hline DROC $=$ Dryas octopetala & PIEN = Picea engelmannii & VASI = Valeriana sitchensis \\
\hline EMNI = Empetrum nigrum & PIAL = Pinus albicaulis & XETE = Xerophyllum tenax \\
\hline
\end{tabular}

Figure 1.-(con.) 
lanes (Bayfield 1979). What I have called "estimated relative cover" is a less precise measure of change; in this case, original cover was not reported, so estimated relative cover is the surviving cover on the trampled lane expressed as a percentage of cover on the control lane. To be as accurate as relative cover, the original cover on controls and all trampled lanes would have to be identical. Although this is unlikely to be the case, differences are seldom substantial enough to create a large problem. For some studies, I reanalyzed original data to convert them to these two consistently defined variables. They are generally arranged from forested to nonforested communities and, within these classes, from low to high elevation.

Almost without exception, these graphs illustrate the curvilinear relationship between amount of use and amount of vegetation loss. Vegetation is lost most rapidly following the initial application of trampling; successive incremental increases in amount of trampling have progressively less effect on vegetation cover. This corroborates the conclusions of several studies of the relationship between use and impact on existing trails and campsites (for example, Dale and Weaver 1974; Cole and Fichtler 1983). Only the most resistant of these vegetation types, the Poa pratensis-Festuca idahoensis grassland, does not lose cover most rapidly at low levels of trampling.

\section{Relative Resistance of Different Plant Community Types}

Of the many potential means available for evaluating the resistance of different plant communities, three seem particularly useful:

1. Liddle (1975a) suggested evaluating resistance on the basis of the number of passes required to reduce cover to 50 percent of its original value. This provides a useful index of how rapidly cover is lost after the introduction of trampling. Such an index does not, however, indicate how well a community type will stand up to either prolonged or heavy amounts of trampling.

2. Although none of these 1-year studies can be used to estimate the effects of prolonged trampling, most studies report the effects of at least 800 passes. Therefore relative cover after 800 passes can be used as an index for resistance to heavy trampling.

3. The most useful index would reflect resistance to a broad range of trampling intensities. The curves in figure 1 can be used to provide such an index. To facilitate comparison, an index was calculated that expressed the area under each curve (up to 800 passes) as a percentage of the entire graphed area. In effect, this integrates the effects of trampling across the range from 0 to 800 passes, expressing surviving cover as a mean percentage of control conditions. Table 1 categorizes 32 plant communities on the basis of these three alternative indices.

Several conclusions can be drawn from table 1. First, the relative resistance of a community type to heavy trampling is similar to its resistance to light trampling. Although some changes in order exist (for example, ericaceous undergrowth is usually more sensitive to heavy than to light trampling), the rankings based on these three indices of resistance are generally similar. Thus, any single index (such as the number of passes it takes to reduce cover to 50 percent of its original value) can be used as a rough index of initial resistance. It is important to remember that resistance to prolonged trampling and ability to recover are not reflected in any of these indices.

Second, there is little relationship between elevational zone and resistance. Alpine communities, even within the same general area, range from very susceptible (Phyllodoce glanduliflora) to very resistant (Carex nigricans); the same is true of low elevation types.

Third, most of the very resistant types are dominated by grasses, sedges, and rushes. But not all grasslands are highly resistant. Some have only a moderate level of resistance, and the sedge marsh (type 6) is one of the least resistant vegetation types. This resistance gradient may reflect, in part, the abundance of moisture. As mentioned, the initial effects of trampling are generally most profound on moist sites and the sedge marsh is inun. dated by water for much of the year (Nagy and Scotter 1974).

Finally, with one exception, the forested sites examined are quite susceptible to trampling damage. Most of these forests occupy mesic sites and have a ground cover dominated by lush forbs. The whitebark pine forest, with a ground cover dominated by the ericaceous shrub Vaccinium scoparium (grouse whortleberry), is considerably more resistant. Some of this apparent resistance may be a result of study method. In this study, trampling treatments and measurements were completed all at once. Vaccinium spp. often die slowly after trampling (Bayfield 1979), so by immediately measuring survival, cover loss of Vaccinium scoparium may have been underestimated. In studies of existing recreation sites, most researchers have found Vaccinium scoparium to be a fragile ground cover (see, for example, Dale and Weaver 1974; Cole 1982a,b).

\section{Relative Resistance of Different Growth Forms}

Morphological characteristics of plants that influence resistance to trampling include location, size, erectness and strength of leaves, strength of petioles and nodes, woodiness and erectness of stems, extent and type of root system, and bud location. Characteristics found to be common to resistant species in experimental studies are short, procumbent, and/or flexible stems (Schreiner 1974), a low-growing, matted or tufted growth form (Singer 1971; Holmes and Dobson 1976), basal leaves (Holmes and Dobson 1976; Rogova 1976), and leaves that are pliable, folded, and either thick or narrow and wiry (Schreiner 1974; Holmes and Dobson 1976). Particularly fragile plants usually have tall, caulescent (obviously leafy), succulent stems and thin leaves, or brittle, low-growing woody stems and branches (Singer 1971; Holmes and Dobson 1976; Rogova 1976).

Studies of campsites and trails have consistently found graminoids (grasses and grasslike plants) to be particularly resistant to trampling (see, for example, Cole 1982a). This has also been confirmed in experimental studies (Wagar 1964; Nagy and Scotter 1974; Schreiner 1980). Forbs and shrubs are more variable in 


\begin{tabular}{|c|c|c|c|}
\hline \multirow[b]{2}{*}{ Plant community types ${ }^{1}$} & \multicolumn{3}{|c|}{ Resistance to: } \\
\hline & $\begin{array}{l}\text { Light }^{2} \\
\text { trampling }\end{array}$ & $\begin{array}{l}\text { Heavy }{ }^{3} \\
\text { trampling }\end{array}$ & Both ${ }^{4}$ \\
\hline 1. Pinus contorta/Thalictrum venulosum (lodgepole pine forest) & VS & VS & VS \\
\hline 2. Populus tremuloides/Heracleum lanatum (aspen forest) & VS & SS & VS \\
\hline 3. Populus tremuloides/Symphoricarpos albus (aspen forest) & VS & SS & VS \\
\hline 4. Vaccinium membranaceum (subalpine huckleberry shrubland) & SS & VS & VS \\
\hline 5. Phyllodoce glanduliflora (subalpine heath) & SS & VS & VS \\
\hline 6. Carex rostrata-C. aquatilis (sedge marsh) & VS & SS & - \\
\hline 7. Cassiope mertensiana (subalpine heath) & SS & VS & SS \\
\hline 8. Abies lasiocarpa/Luzula hitchcockii (subalpine fir forest) & SS & SS & SS \\
\hline 9. Aster alpigenus-Phlox diffusa (alpine cushion community) & SS & SS & SS \\
\hline 10. Picea engelmannii/Arnica latifolia (Engelmann spruce forest) & SS & $N$ & SS \\
\hline 11. Valeriana sitchensis (subalpine forb meadow) & SS & N & SS \\
\hline 12. Picea lauca/Vaccinium uliginosum (boreal spruce forest) & SS & - & - \\
\hline 13. Antennaria lanata-Carex nigricans (alpine snowbank community) & SS & $N$ & $N$ \\
\hline 14. Holcus lanatus-Agrostis stoloniferus (acid grassland) & N & SS & - \\
\hline 15. Deschampsia flexuosa-Holcus lanatus (acid grassland) & $N$ & SS & - \\
\hline 16. Xerophyllum tenax (subalpine beargrass meadow) & $\mathrm{N}$ & SS & $\mathrm{N}$ \\
\hline 17. Lupinus lepidus-Carex phaeocephala (alpine stone-stripe community) & $N$ & $\mathrm{~N}$ & $\mathrm{~N}$ \\
\hline 18. Anemone occidentalis-Trollius laxus (subalpine forb meadow) & $N$ & $\mathrm{~N}$ & N \\
\hline 19. Antennaria lanata-Hieracium gracile (subalpine forb meadow) & $N$ & - & - \\
\hline 20. Phlox diffusa-Carex phaeocephala (subalpine cushion community) & $\mathrm{N}$ & - & - \\
\hline 21. Empetrum nigrum (sand dune heath) & $\mathrm{N}$ & $\mathrm{N}$ & SR \\
\hline 22. Arrhenatherum elatius-Holcus lanatus (neutral grassland) & $N$ & SR & - \\
\hline 23. Trollius laxus-Aster foliaceus (subalpine forb meadow) & $N$ & SR & SR \\
\hline 24. Luetkea pectinata (subalpine mat plant community) & $N$ & SR & SR \\
\hline 25. Calluna vulgaris-Deschampsia flexuosa (heath-grassland) & SR & $N$ & - \\
\hline 26. Pinus albicaulis/Vaccinium scoparium (whitebark pine forest) & SR & $N$ & SR \\
\hline 27. Arctostaphylos uva-ursi-Carex eburnea (heath-grassland) & SR & - & - \\
\hline 28. Dryas octopetala (alpine cushion community) & SR & SR & VR \\
\hline 29. Aster alpigenus-Festuca idahoensis (subalpine meadow) & VR & - & - \\
\hline 30. Festuca scabrella-Danthonia intermedia (prairie grassland) & VR & VR & VR \\
\hline 31. Poa pratensis-Festuca idahoensis (grassland) & VR & VR & VR \\
\hline 32. Carex nigricans (subalpine sedge meadow) & VR & VR & VR \\
\hline
\end{tabular}

${ }^{1}$ Sources are as follows: Nagy and Scotter $1974(1,2,3,6,8,10,16,23,28,30) ;$ Landals and Scotter $1974(4,7,11,24,32) ;$ Landals and Scotter 1973 (5,18); Singer 1971 (9); Schreiner 1980 (12); Bell and Bliss 1973 (13,17); Harrison 1981 (14,15,22,25); Schreiner 1974 (19,20,29); Hylgaard and Liddle 1981 (21); Weaver and Dale 1978 (26,31); Bowles and Maun 1982 (27).

${ }^{2}$ The index for resistance to light trampling is the number of passes required to reduce cover to 50 percent of original conditions. Classes are as follows: very susceptible (VS) (0-25 passes); somewhat susceptible (SS) (26 to 100 passes); neither susceptible nor resistant (N) (101 to 250 passes); somewhat resistant (SR) (251 to 500 passes); very resistant (VR) (more than 500 passes).

${ }^{3}$ The index for resistance to heavy trampling is relative or estimated relative cover after 800 passes. Classes are as follows: VS $(0$ to 3 percent); SS ( 4 to 7 percent); N ( 8 to 15 percent); SR ( 16 to 35 percent); VR (more than 35 percent).

${ }^{4} \mathrm{~T}$ he index for both is the percentage of area under the curves in figure 1 -essentially the mean relative or estimated relative cover across the range from 0 to 800 passes. Classes are as follows: VS $(0$ to 15 percent); SS (16 to 25 percent); N (26 to 35 percent); SR ( 36 to 50 percent); VR (more than 50 percent).

response, depending upon many of the factors listed above. Bryophytes have generally been found to be quite resistant to damage (Schreiner 1974, 1980; Holmes and Dobson 1976; Studlar 1980), although certain mosses (Sphagnum spp., for example) may be sensitive. Lichens are usually sensitive to trampling (Bell and Bliss 1973; Kellomäki and Saastamoinen 1975; Schreiner 1974, 1980).

\section{Effects of Frequency and Timing of Trampling on Vegetation Loss}

Clearly, at very high levels of trampling-where all vegetation is destroyed-trampling frequency, whether a given number of passes is spread over a long period of time or concentrated all at once, is irrelevant. Rogova
(1976) found that it made no difference if 1,500 passes were applied at a rate of 50 per day every day or 175 per day twice a week.

At lower trampling intensities, however, frequency may make a difference. Hylgaard and Liddle (1981) found that spreading passes over a 4 -week period caused more vegetation loss on an Empetrum nigrum sand dune heath than concentrating those passes at one time. Singer (1971), Landals and Scotter (1973, 1974), and Nagy and Scotter (1974) also found that in most cases a given number of passes causes less damage at one time than when spread over a long period. In each of these studies, however, confounding factors cloud the picture. In the three latter studies the time between treatment and measurement-a period in which recovery could occur-was longer on the more concentrated treatments; 
the phenological stages at which trampling occurred were also different. Hylgaard and Liddle's (1981) onetime treatment occurred at a late date (August 21), when vulnerability may have been low and, as they acknowledge, the time between treatment and measurement was not sufficient to observe the delayed damage that occurs to the dominant plant, Empetrum nigrum.

Where recovery of vegetation trampled at different frequencies has been followed for a year or more, making recovery periods approximately equivalent, differences related to frequency of trampling have been minimal (Campbell and Scotter 1975; Douglas and others 1975; Bayfield 1979). Type of vegetation and intensity of tram. pling had a much greater effect on vegetation cover.

It is difficult, then, to form conclusions about the effect of trampling frequency. Effects are probably different in different vegetation types and they certainly vary with differences in number of passes and the period of time over which use is spread. When the number of passes per period of time is high, the effects of trampling frequency diminish because alteration reaches maximum limits. Common sense suggests that at the other extreme-where a small number of tramples are spread over a very long period of time-concentrated trampling would be more destructive than trampling spread over time. Yet, all studies of trampling frequency have found the opposite. Spreading the trampling out over a growing season causes more damage than concentrating it at one time, even at trampling levels as low as 25 passes per year. Even here, however, the consistent effect of frequency is much less important than other factors.

The effect of seasonality of trampling is also complex and difficult to determine. Again the effect probably varies with such factors as number of passes, morphology and phenology of the constituent plant species, and the seasonality of soil moisture. For example, trampling grasses late in the season, after they have completed their annual growth and reproduction, may have little effect compared to early trampling. Low-growing shrubs, in contrast, are often more susceptible to late-season trampling, because they become increasingly brittle as the season progresses.

Singer (1971) found that vegetation cover was not significantly affected by the time of summer (July 3August 13) at which trampling occurred. Nagy and Scotter (1974) also found no consistent difference between trampling in early season (early June-early July) and midseason (late July-early August). If pretreatment measurements had been taken and differences in recovery periods had been accounted for, however, it might have been possible to identify meaningful differences for individual species. Holmes and Dobson (1976) found that late season trampling (early September) caused much more cover loss than midseason trampling (early August) for nine of the 14 species that they studied. They attribute this higher vulnerability in late season to reduced plant vigor and drier, more brittle, plant parts. There may, however, be little relationship between cover loss immediately after trampling and cover at some time in the future. Early-season trampling may, for example, have a more profound effect on the stored reserves and reproductive success of the plants, changes that will have a greater effect on future conditions.

\section{WESTERN MONTANA STUDY AREA}

The study reported here attempts to extend our knowledge of the relationships discussed in the preceding review. Originally five habitat types were selected for study. The types chosen were those most commonly used for camping at low elevations to midelevations in the Bob Marshall Wilderness. Four of these are forested: Abies lasiocarpa/Clintonia uniflora (subalpine fir/queencup beadlily), Abies lasiocarpa/Vaccinium caespitosum (subalpine fir/dwarf huckleberry), Abies lasiocarpal Xerophyllum tenax (subalpine fir/beargrass), and Pseudotsuga menziesii/Symphoricarpos albus (Douglasfir/snowberry) (Pfister and others 1977); the other is a grassland: Festuca scabrella-F. idahoensis (rough fescueIdaho fescue) (Mueggler and Stewart 1980). Two replicate experimental plots were established in each type. Following initial sampling, it became clear that the two Abies lasiocarpa/Clintonia uniflora plots were different. The ground cover of one was predominantly lush forbs, particularly Thalictrum occidentale. This is the Clintonia uniflora phase of the type, called ABLA/CLUN hereafter. The other was predominantly low shrubs, such as Linnaea borealis and Arctostaphylos uva-ursi. This is the Vaccinium caespitosum phase of the type, called ABLA/ CLUN-VACA hereafter.

All of the experimental plots were located close to roaded access on the fringes of the Bob Marshall Wilderness (fig. 2). The forested plots were all on the Seeley Lake District of the Lolo National Forest; the grassland was on the Montana Department of Fish, Wildlife and Parks' Blackfoot-Clearwater Game Range. All of the plots are located at elevations of 4,200 to $4,400 \mathrm{ft}$ (1 260 to $1320 \mathrm{~m}$ ). They are all essentially flat (slopes of 0 to 7 percent), except for the Pseudotsuga menziesii/ Symphoricarpos albus (PSME/SYAL) plots, which are on a 20 to 25 percent southwest slope.

The ABLA/CLUN plot is located on a stream terrace above Dunham Creek, in a slight concavity at the base of a toe slope. The soil is a Eutric Glossoboralf, with thick organic horizons -4.3 inches $(11 \mathrm{~cm})$, a silty loam surface mineral horizon, and an absence of coarse fragments throughout the soil profile. Soil profiles for this and the other habitat types are described in appendix 1.

The overstory on the plot is a dense stand, predominantly of large Larix occidentalis and Picea engelmannii. Pinus contorta, Abies lasiocarpa, and Pseudotsuga menziesii are also present. Spherical densitometer readings indicate a canopy cover of about 90 percent. The ground cover is dominated by lush forbs, particularly Thalictrum occidentale, Arnica latifolia, Smilacina stellata, and Clintonia uniflora (fig. 3). Various shrubs, of which Berberis repens is most abundant, are also present. Tables giving cover and frequency for each species on this and other habitat types are in appendix 2 . 


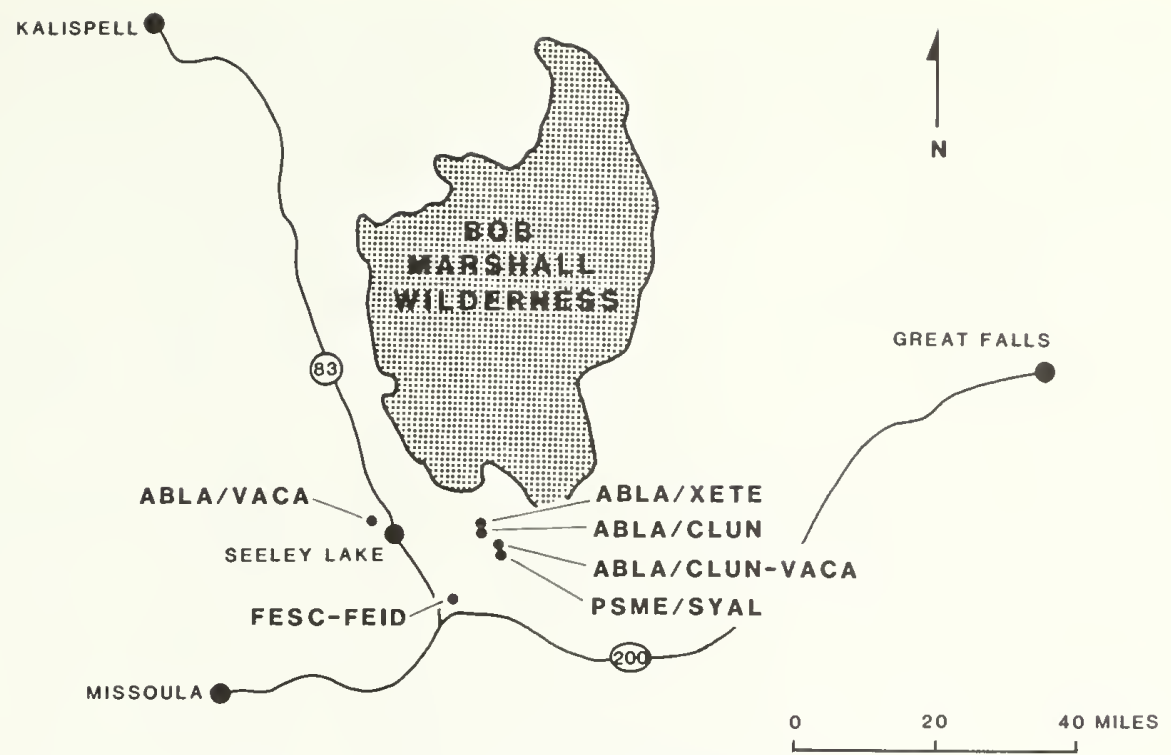

Figure 2.-Location in western Montana of the experimental plots for each of the six habitat types.

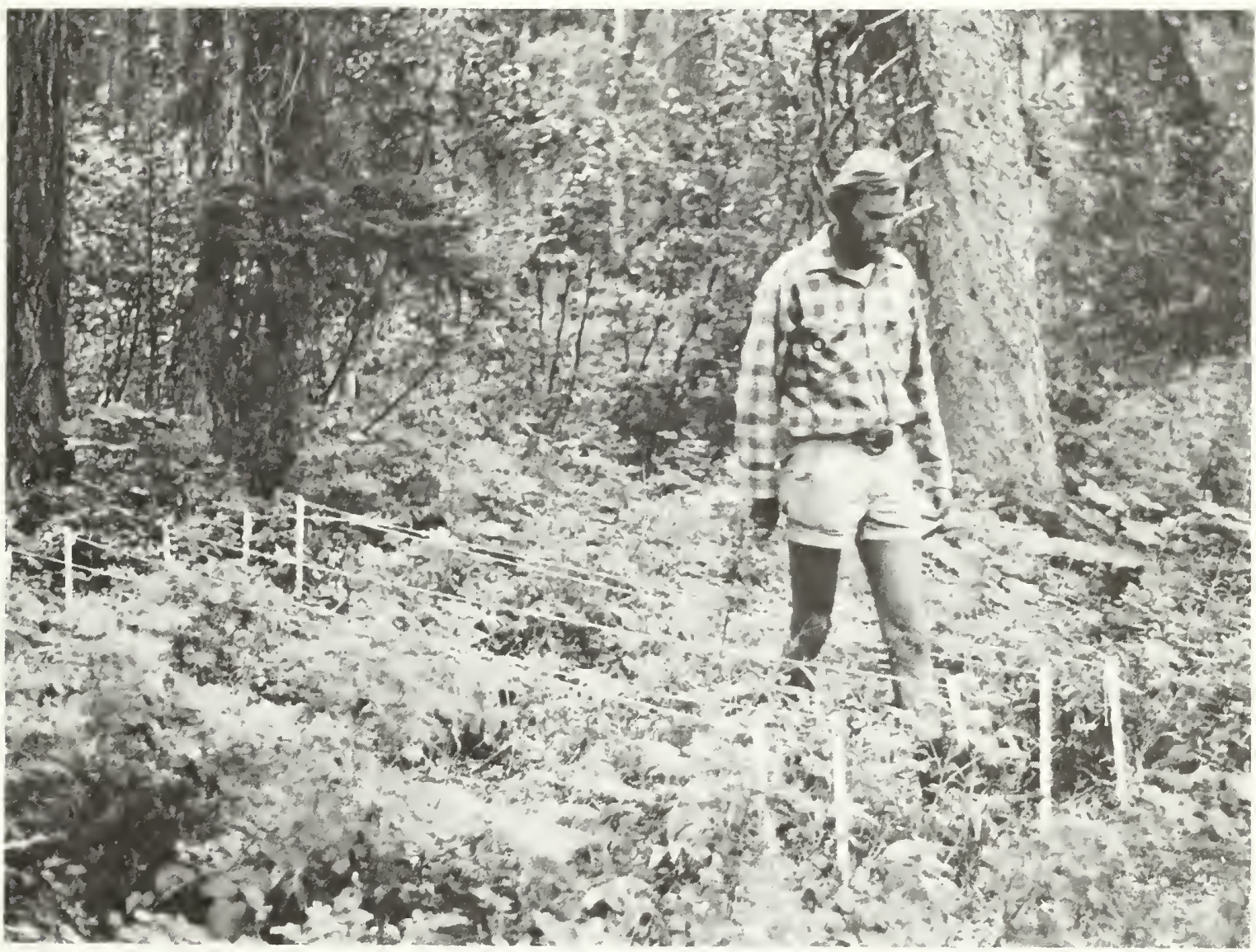

Figure 3.-Closeup of the lush, forb-dominated undergrowth of the Abies lasiocarpa/Clintonia uniflora plot. 
The ABLA/CLUN-VACA plot is located on a broad flat terrace of glacial outwash near Monture Creek Campground. The soil is a Typic Udorthent, with moderately thick organic horizons -2.4 inches $(6 \mathrm{~cm})$, a cobbly sandy loam surface mineral horizon, and 85 percent angular gravel and cobbles throughout the soil profile.

The overstory on the plot is a dense stand, predominantly of moderate-sized Larix occidentalis, Pseudotsuga menziesii, and Pinus contorta. Pinus ponderosa and Picea engelmannii are also present. Canopy cover is about 90 percent. The ground cover is dominated by low woody species, particularly Linnaea borealis (fig. 4). Berberis repens, Spiraea betulifolia, and Calamagrostis rubescens are also abundant.

The Abies lasiocarpa/Vaccinium caespitosum (ABLA/VACA) habitat type plots are located on a hummocky bench northwest of Seeley Lake. The soil is an Andic Dystrochrept, with thin organic horizons-1.4 inches $(3.5 \mathrm{~cm})$, a cobbly fine sandy loam surface mineral horizon, and gravel and cobbles constituting from 20 percent of the surface horizon to 60 percent of the lower horizons.

On one plot about two-thirds of the mature trees are Pinus contorta; the rest are Larix occidentalis. Canopy

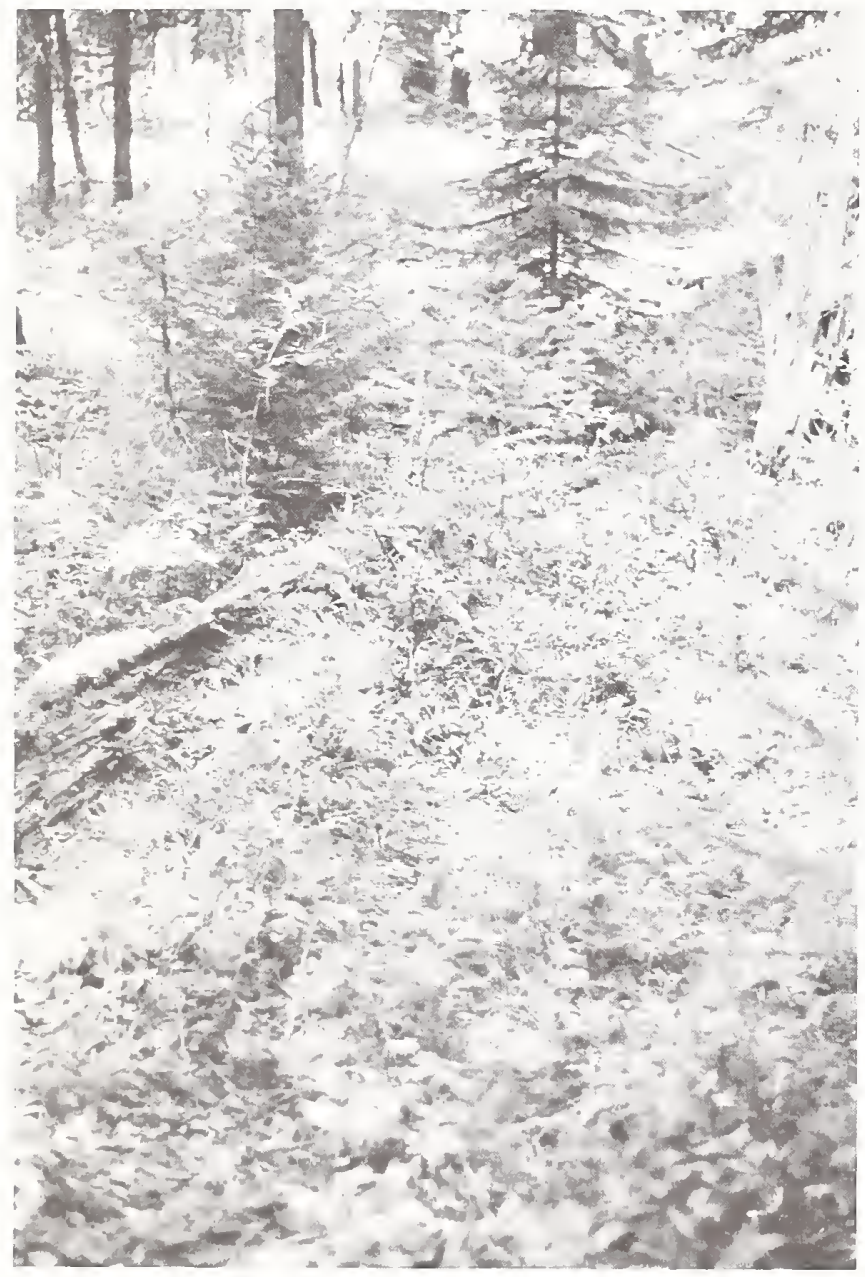

Figure 4.-General view of the vegetation near the Abies lasiocarpa/Clintonia uniflora-Vaccinium caespitosum phase plot. cover is about 65 percent. The other plot is entirely polesized Pinus contorta, with a canopy coverage of 85 percent. Abies lasiocarpa is the most abundantly reproducing tree species. The ground cover of the two plots is similar; they have 21 of 26 species in common and a similarity index, based on relative cover (Bray and Curtis 1957), of 69 percent. Vaccinium caespitosum is dominant on both plots. Other abundant species include Arctostaphylos uva-ursi, Xerophyllum tenax,

Calamagrostis rubescens, and Lupinus argenteus (fig. 5). Mosses, primarily species of Brachythecium, are abundant.

The Abies lasiocarpa/Xerophyllum tenax-Vaccinium globulare phase (ABLA/XETE-VAGL) habitat type plots are located on a stream terrace close to the ABLA/CLUN plot above Dunham Creek. The soil is an Andic Dystrochrept, with very thin organic horizons-0.3 inch $(0.7 \mathrm{~cm})$, a silt loam surface mineral horizon, and coarse fragment content that increases from 5 percent gravel close to the surface, to 85 percent gravel and cobbles below 11 inches $(28 \mathrm{~cm})$.

The overstory on both plots is predominantly polesized Pinus contorta, with lesser amounts of Pseudotsuga menziesii, Abies lasiocarpa, and Larix occidentalis. Canopy coverage is about 70 percent. The ground cover of the two plots is very similar; 14 of 19 species are shared and the similarity index is 81 percent. Vaccinium scoparium, Xerophyllum tenax, and Vaccinium globulare are the most abundant vascular plants and together comprise about 90 percent of the total vascular plant cover (fig. 6). Mosses, particularly species of Brachythecium and Dicranum, and lichens, mostly Cladonia spp., are especially abundant on these plots.

The Pseudotsuga menziesii/Symphoricarpos albusCalamagrostis rubescens phase (PSME/SYAL-CARU) habitat type plots are located on a side slope about 100 yards $(100 \mathrm{~m})$ above Monture Creek. The soil is a Eutric Glossoboralf, with moderately thick organic horizons2.4 inches $(6 \mathrm{~cm})$, a fine gravelly silty loam surface horizon, and coarse fragment content that increases from 30 percent gravel in the surface horizon to 80 percent gravel and cobbles in the lower horizons.

The overstory on both plots is predominantly moderate-sized Pseudotsuga menziesii and Pinus contorta, with some Larix occidentalis. Canopy cover is about 80 percent. The ground cover of the two plots is quite similar (similarity index $=76$ percent), although the plots have only 21 of 33 species in common.

Calamagrostis rubescens is the most abundant plant on both plots. Medium-sized shrubs (<3 ft [1 m] tall) characterize this habitat type (fig. 7). Spiraea betulifolia, Berberis repens, and Symphoricarpos albus are particularly abundant.

The Festuca scabrella-F. idahoensis (FESC-FEID) habitat type plots are located on a hilltop and a flat bench $100 \mathrm{ft}(30 \mathrm{~cm})$ below the hilltop. The soil is a Typic Haploboroll, with thin organic horizons -1.2 inches $(3 \mathrm{~cm})$, a gravelly silty loam surface horizon, and a gravel content of about 45 percent. 


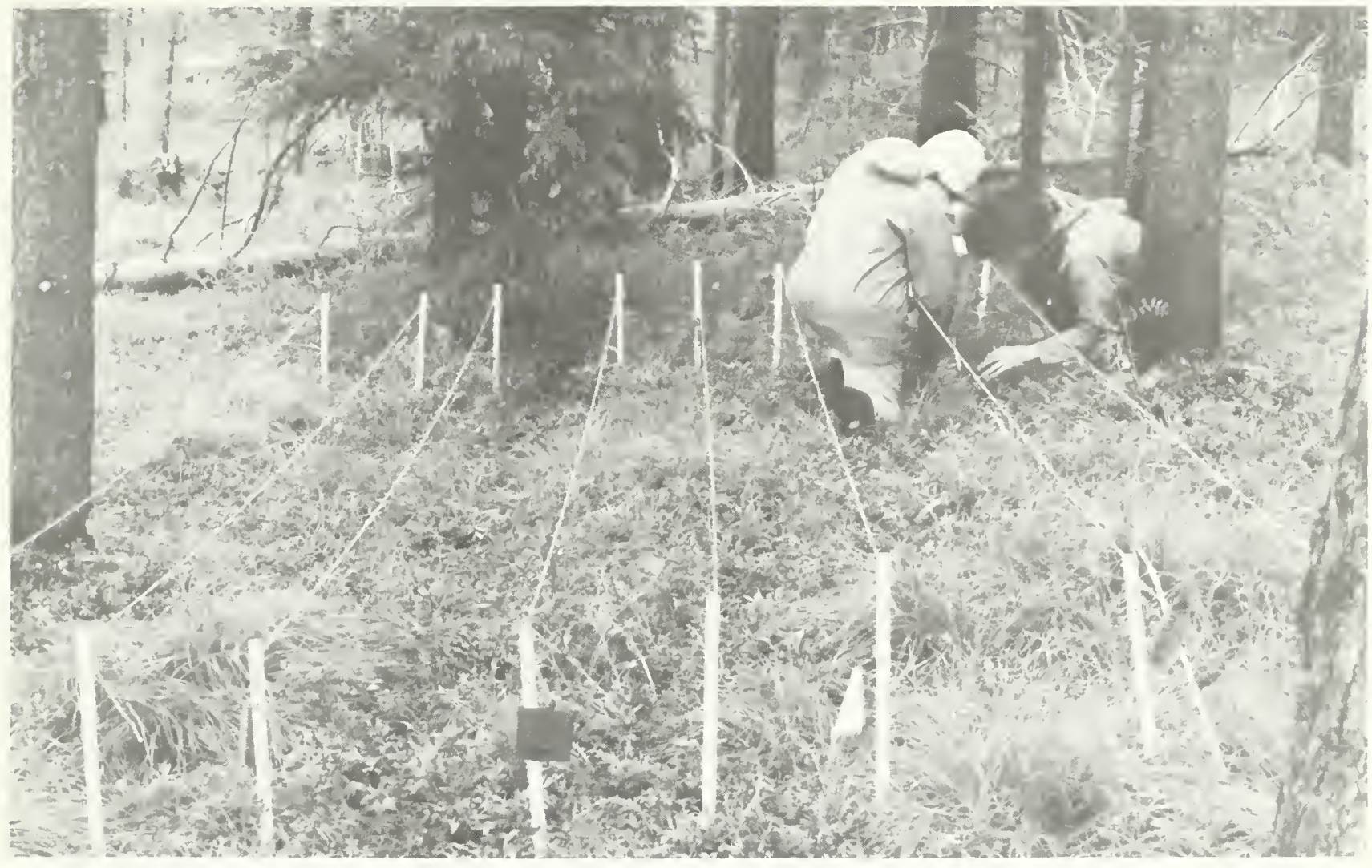

Figure 5.-Treatment lanes in the Abies lasiocarpa/Vaccinium caespitosum type.

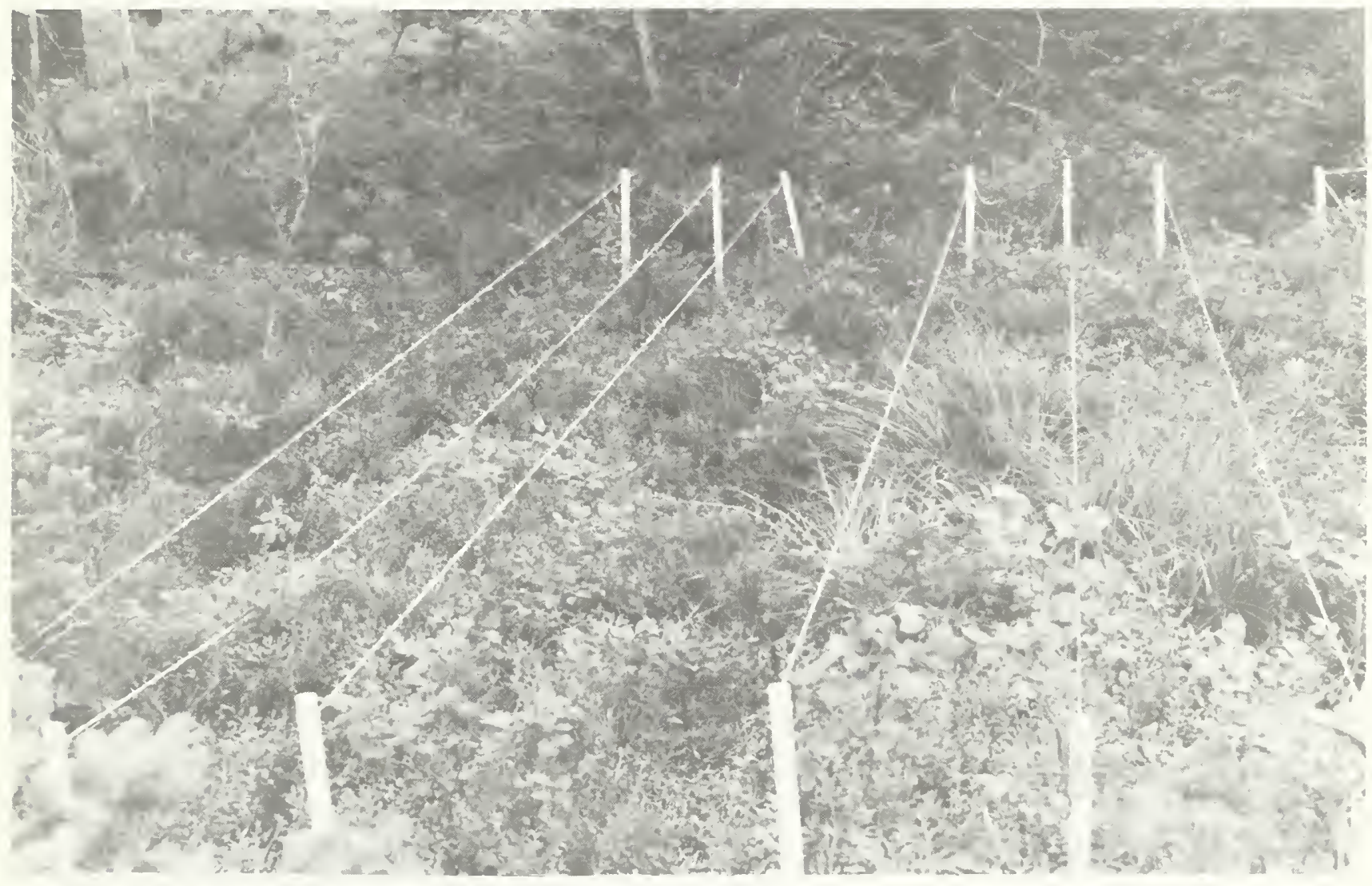

Figure 6. - Treatment lanes in the Abies lasiocarpa/Xerophyllum tenax type. 
Grasses dominate the vegetation of both plots (fig. 8). In addition to the two dominants, Festuca scabrella and F. idahoensis, Koeleria cristata and Agropyron spicatum are the most abundant grasses. Lupinus sericeus,
Achillea millefolium, and Solidago missouriensis are common on both plots, but many of the less common species were only found on one or the other of the plots. Despite a similarity index of 65 percent, the two plots have only 15 of 35 species in common.

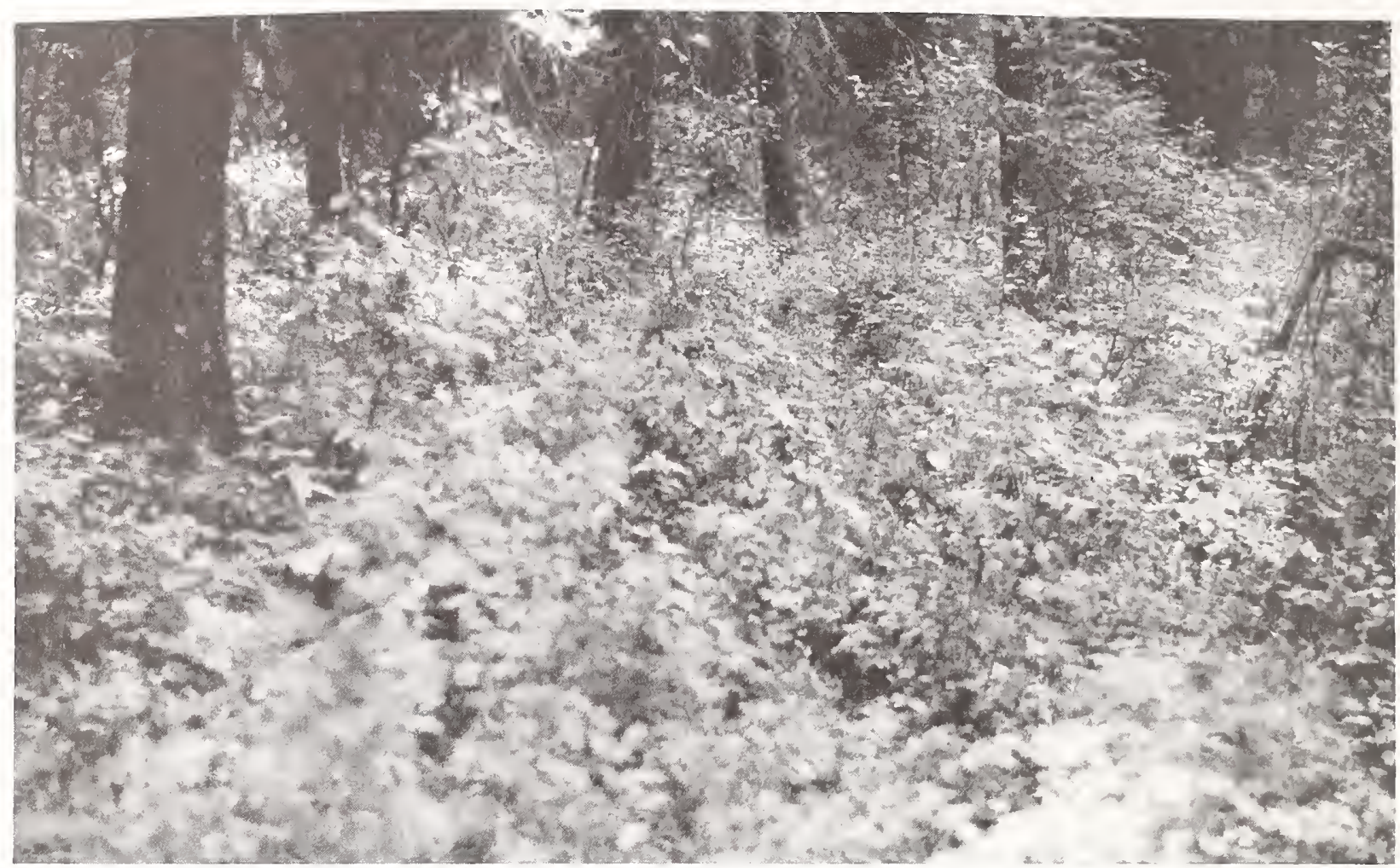

Figure 7.-General view of the vegetation near the Pseudotsuga menziesii/Symphoricarpos albus plots.

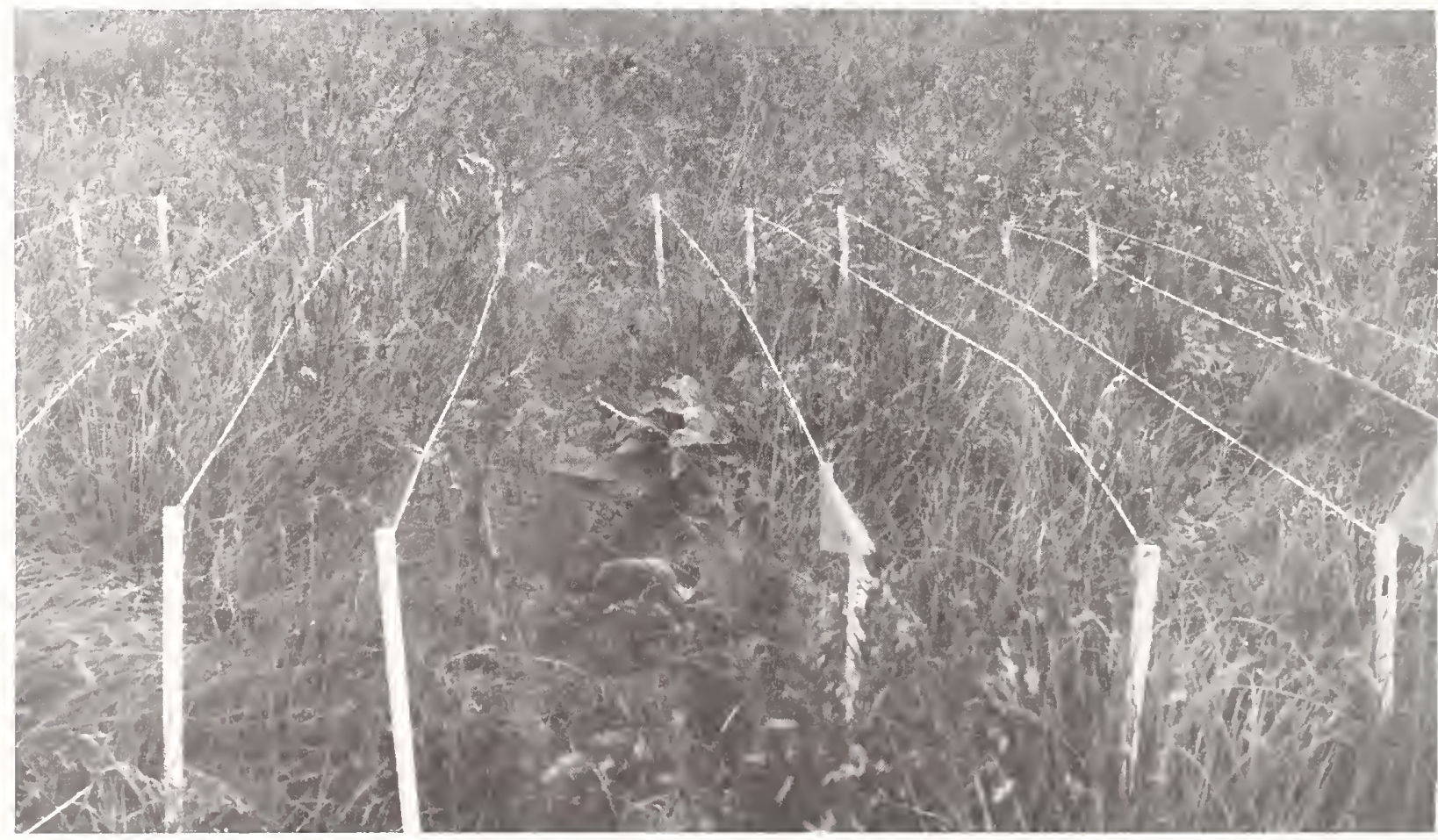

Figure 8-Treatment lanes in the Festuca scabrella.F. idahoensis type. 


\section{FIELD TECHNIQUES}

At each plot, 17 treatment lanes, each $1 \mathrm{ft}(0.3 \mathrm{~m})$ wide and about $16 \mathrm{ft}(5 \mathrm{~m})$ long, were delineated. Each set of two treatment lanes was separated by a 1.6 - by $16-\mathrm{ft}$ (0.5- by $5-\mathrm{m}$ ) buffer strip to permit sampling without disturbance of the treatment lanes. Where the land sloped, the lanes were oriented parallel to the contours.

One of the treatment lanes was a control; it was never trampled. The other treatments consisted of four sets of four lanes trampled at the following frequencies throughout the 8-week season: once (1X), three times (3X), eight times (once per week-8X), and 16 times (twice per week $-16 \mathrm{X})$. The numbers of passes administered each time to the $1 \mathrm{X}$ and $3 \mathrm{X}$ lanes were $5,25,100$, and 300 . The $8 \mathrm{X}$ and $16 \mathrm{X}$ lanes received $5,25,75$, and 100 passes each time (fig. 9). One pass is a one-way walk along the lane. The total number of passes per season is trampling frequency $(1,3,8$, or 16$)$ times the number of passes. For example, total passes on the four $8 \mathrm{X}$ lanes were 40 $(8 \times 5), 200(8 \times 25), 600(8 \times 75)$, and $800(8 \times 100)$. In each plot, then, one lane received $0,5,15,25,40,75,80,100$, $200,400,600,800,900,1,200$, and 1,600 total passes per season and two lanes received 300 passes-one in a single treatment and one in three treatments of 100 passes. The treatment assigned to each lane was randomized. All treatments were replicated in a second plot in each habitat type with the exception of the ABLA/CLUN and ABLA/CLUN-VACA types.

Initial measurements were taken on each lane in midJune 1981. Measurements were taken in four 0.66 - by $1.64-\mathrm{ft}(2-$ by 5 -dm) subplots, systematically placed-in the center of each lane-3.3,6.5, 9.8, and $13.1 \mathrm{ft}(1,2,3$, and $4 \mathrm{~m}$ ) from one end of the lanes. In each subplot the cover of total vegetation, exposed mineral soil, each vascular plant species, and mosses and lichens, each as a group, was estimated to the nearest percent if under 10 percent or in 10-percent coverage classes between 10 and 100 percent.

Trampling commenced the last week of June and continued for 8 weeks until late August. The $1 \mathrm{X}$ treatment occurred in late July. The $3 \mathrm{X}$ treatments occurred at

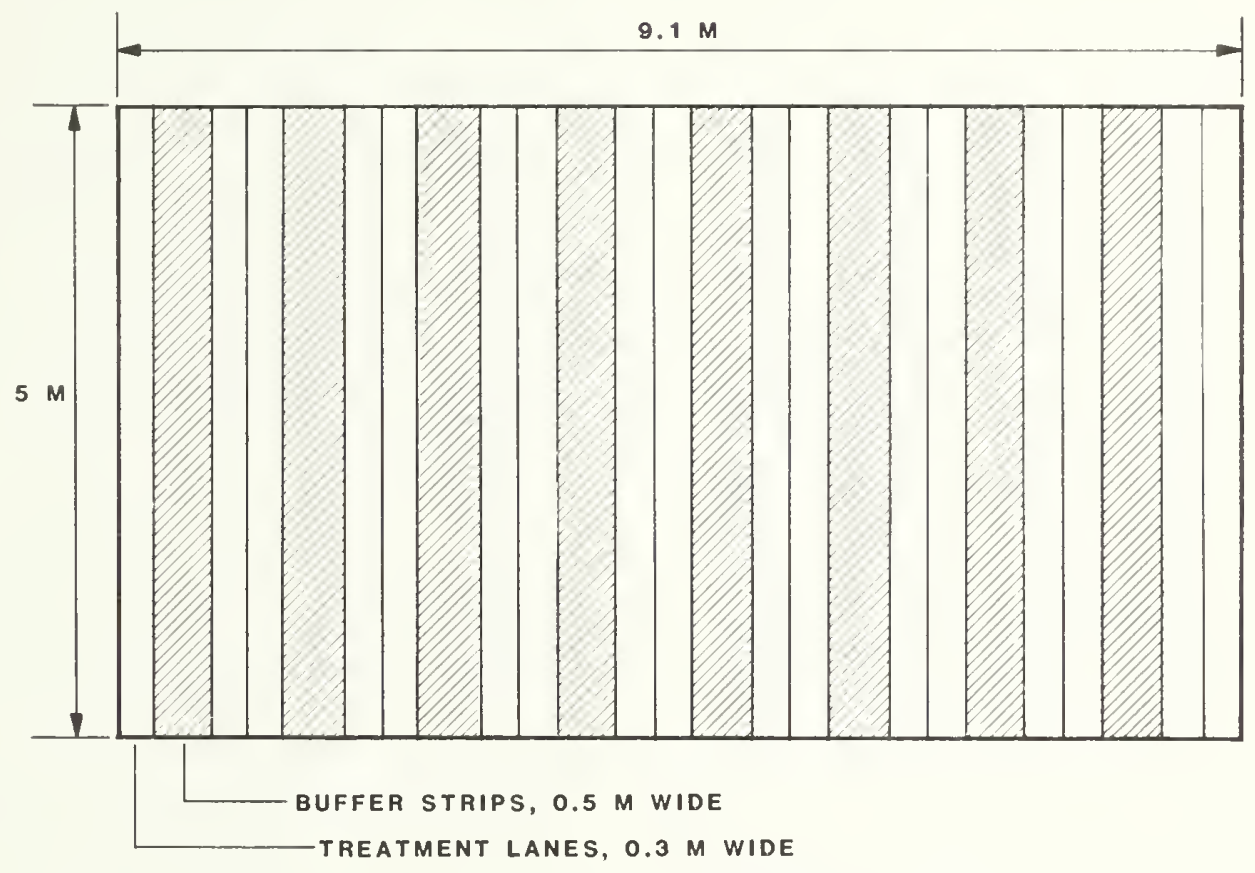

16 TREATMENTS, PLUS A CONTROL, WERE RANDOMLY ASSIGNED TO LANES
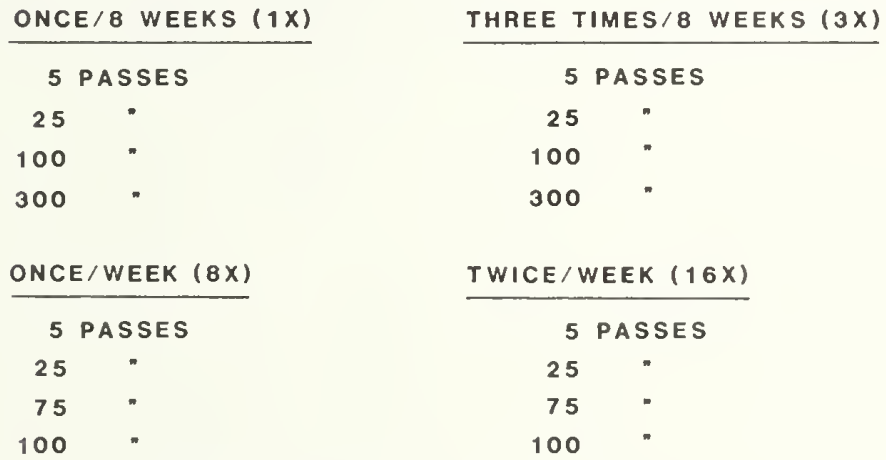

Figure 9. - Layout of the experimental plot and treatments. 
2 -week intervals throughout the summer. The twice-perweek (16X) treatments never occurred on consecutive days. Four people, ranging in weight from about $130 \mathrm{lb}$ $(60 \mathrm{~kg})$ to $190 \mathrm{lb}(85 \mathrm{~kg})$. did the trampling; they all wore lug-soled boots. Followup measurements were taken by the end of August. These were identical to those taken initially. Penetration resistance was measured beneath the unconsolidated surface organic litter layer with a pocket soil penetrometer on each subplot. On the FESCFEID habitat type, it was so difficult to identify individual grass species after trampling that only the cover of all graminoids combined and of Festuca scabrella were recorded.

\section{EFFECTS OF TRAMPLING ON VEGETATION COVER}

Change in vegetation cover as a result of trampling was expressed as relative cover. This measure, first sug. gested by Bayfield (1979), utilizes a correction factor to compensate for inherent variability in cover between treatment lanes and account for changes in cover which occur over the trampling period but which are not caused by trampling. Relative cover is the percentage of original cover that survives trampling, adjusted for any changes occurring on control lanes. It is calculated as follows:

Relative cover $=$ $\frac{\text { surviving cover on each trampled subplot }}{\text { initial cover on each trampled subplot }} \times \mathrm{cf} \times 100 \%$,

where

mean initial cover on four control subplots

mean surviving cover on four control subplots.

The effects on relative cover of the two major controlled variables-amount of trampling and habitat type-were analyzed in a two-way analysis of variance using a factorial design (Steel and Torrie 1960). It was necessary to utilize an inverse sine transformation of the relative cover data to reduce the heterogeneity of variances. With four subplots in each lane and one replication for most habitat types, there were usually eight observations for each treatment in each habitat type.
Both of these main effects were significant ( $p<0.001)$, as was the interaction between these two variables.

\section{Effect of Trampling Frequency}

As reviewed at the beginning of this report, some previous studies have suggested that the effect of a given number of passes varies with trampling frequency. This possibility was examined with an analysis of covariance that tested whether or not relative cover differed significantly with trampling frequency, after statistically controlling differences in the total number of passes. Only in the ABLA/VACA type did frequency of trampling make a significant difference at the 0.05 level (table 2). Here the most concentrated trampling did the least amount of damage. This would corroborate the conclusions of Singer (1971) and Hylgaard and Liddle (1981). Nevertheless, the effects are not pronounced. Even for the ABLA/VACA type, the percentage of variation in relative cover $\left(\mathrm{r}^{2}\right)$ explained by both frequency and total number of passes. (41 percent) is only 4 percent greater than the $\mathrm{r}^{2}$ value for just total number of passes.

Another line of evidence supports the conclusion that the effect of trampling frequency is both inconsistent and not a profound factor. Lanes trampled 300 times, once per season (abbreviated 1-300) had the same total number of passes -300 -as lanes trampled 100 times, three times per season $(3-100)$. Table 3 presents relative cover after each of these treatments and two other comparisons.

For all habitat types combined, there is a slight, but insignificant (t-test, $\alpha=0.05$ ), tendency for concentrated trampling to be more damaging. This tendency, the opposite of what the literature reports, is significant, in all three comparisons, only on the PSME/SYAL type. Most of this difference, however, appears to result from a coincidental greater abundance of resistant species on the lanes that received more frequent trampling. For example, mean moss cover before trampling was 23 percent on the 3-100 lane and 2 percent on the $1-300$ lane. Most of the surviving vegetation on the $3-100$ lane was moss. Similar differences in species composition

Table 2.-Mean relative cover on lanes treated 1, 3, 8, and 16 times during the season. Means were adjusted, through analysis of covariance, to compensate for differences in the total number of passes they received

\begin{tabular}{|c|c|c|c|c|c|c|}
\hline \multirow[b]{2}{*}{ Habitat type } & \multicolumn{4}{|c|}{$\begin{array}{l}\text { Trampling } \\
\text { frequency }\end{array}$} & \multirow[b]{2}{*}{$\mathbf{F}$} & \multirow{2}{*}{$\begin{array}{c}\text { Level } \\
\text { of } \\
\text { significance }\end{array}$} \\
\hline & $1 \mathrm{X}$ & $3 x$ & $8 X$ & $16 x$ & & \\
\hline & \multicolumn{4}{|c|}{$\begin{array}{c}\text { Adjusted mean }---- \\
\text { relative cover } \\
\text { (percent) }\end{array}$} & & \\
\hline Abies lasiocarpa/Clintonia uniflora & 43 & 34 & 27 & 28 & 0.75 & 0.53 \\
\hline Abies lasiocarpa/Clintonia uniflora- & & & & & & \\
\hline Vaccinium caespitosum phase & 49 & 46 & 37 & 58 & 1.59 & 20 \\
\hline Abies lasiocarpa/Vaccinium caespitosum & 73 & 50 & 41 & 50 & 4.77 & .004 \\
\hline Abies lasiocarpa/Xerophyllum tenax & 73 & 81 & 76 & 59 & 2.09 & .11 \\
\hline Pseudotsuga menziesii/Symphoricarpos albus & 36 & 47 & 32 & 48 & 2.30 & .08 \\
\hline Festuca scabrella-F. idahoensis & 99 & 100 & 100 & 100 & .08 & .97 \\
\hline All habitat types & 70 & 68 & 60 & 64 & 1.41 & .24 \\
\hline
\end{tabular}


Table 3.-Comparisons of mean relative cover for three pairs of treatments with different trampling frequencies but approximately the same number of total passes ${ }^{1}$

\begin{tabular}{|c|c|c|c|c|c|c|c|c|}
\hline \multirow[b]{2}{*}{ Habitat type } & \multicolumn{8}{|c|}{ Compared treatments } \\
\hline & $1-100$ & & $16-5$ & $3-25$ & $16-5$ & $1-30 c$ & & $3-100$ \\
\hline Abies lasiocarpa/ & \multicolumn{4}{|c|}{ Mean relative cover (percent) } & & & & \\
\hline Clintonia uniflora & 39 & & 37 & 35 & 37 & 6 & & 10 \\
\hline $\begin{array}{l}\text { Abies lasiocarpal } \\
\text { Clintonia uniflora. }\end{array}$ & & & & & & & & \\
\hline Vaccinium caespitosum phase & 53 & $<$ & 82 & 79 & 82 & 23 & & 19 \\
\hline $\begin{array}{l}\text { Abies lasiocarpal } \\
\text { Vaccinium caespitosum }\end{array}$ & 78 & & 63 & 53 & 63 & 59 & $>$ & 16 \\
\hline $\begin{array}{l}\text { Abies lasiocarpal } \\
\text { Xerophyllum tenax }\end{array}$ & 77 & $>$ & 60 & 96 & 60 & 38 & $<$ & 71 \\
\hline $\begin{array}{l}\text { Pseudotsuga menziesiil } \\
\text { Symphoricarpos albus }\end{array}$ & 38 & $<$ & 73 & 50 & 73 & 10 & $<$ & 50 \\
\hline Festuca scabrella. & & & & & & & & \\
\hline F. idahoensis & 99 & & 100 & 100 & 100 & 99 & & 99 \\
\hline All habitat types & 67 & & 71 & 71 & 71 & 44 & & 49 \\
\hline
\end{tabular}

The 1-100 treatment, for example, indicates that 100 passes were administered once during the season. < and > symbols between pairs indicate that the more concentrated treatment was more or less damaging, respectively; no symbol indicates no significant difference (t-test; $\alpha=0.05$ ).

between treatment lanes-differences that existed prior to treatment-proved to be a major source of uncontrollable variation throughout this experiment.

This study could not prove that frequency of trampling had no effect on amount of impact. However, one can conclude that frequency of trampling has no consistent effect and is less important than total number of passes, habitat type, and local differences in species composition.

\section{Effect of Trampling Intensity}

A one-way analysis of variance was used to examine the effect of number of passes on relative cover for each vegetation type (fig. 10). Significant differences between treatments were identified using Duncan's multiple range test $(\alpha=0.05)$ (Steel and Torrie 1960). In each habitat type, cover generally decreased as trampling increased. For some habitat types, however, the rate of decrease was much more rapid than for others. In addition, the general decrease was erratic on some types, namely ABLA/VACA (fig. 10c), ABLA/XETE (fig. 10d), and PSME/SYAL (fig. 10e). These types have patchy representation of particularly resistant species. Lanes in which resistant species were particularly abundant frequently lost less cover than other lanes despite receiving higher levels of trampling.

The relationship between trampling intensity and relative cover is distinctly curvilinear for all five forested habitat types; most of the cover loss occurred after a small number of passes. Increases in trampling beyond 200 to 300 passes caused little additional loss of cover. The data for these types fit closely to a regression line with the form

$$
\mathrm{Y}=\mathrm{a}+\mathrm{b} \log \mathrm{X}
$$

where $\mathrm{Y}$ is transformed (inverse sine) relative vegetation cover and $\mathrm{X}$ is number of passes. This corroborates the findings, reviewed earlier, of most other studies.

Of the forested types, cover loss was least rapid in the ABLA/XETE type. In this type more than 75 passes were required to cause a statistically significant reduction in cover (fig. 10d). Beyond this level cover loss was rapid; over 50 percent of the original cover was lost after 400 passes. Further losses of cover were minimal; 37 percent cover survived 1,600 passes. In fact, increasing trampling beyond 300 passes caused no statistically significant increases in cover loss. 


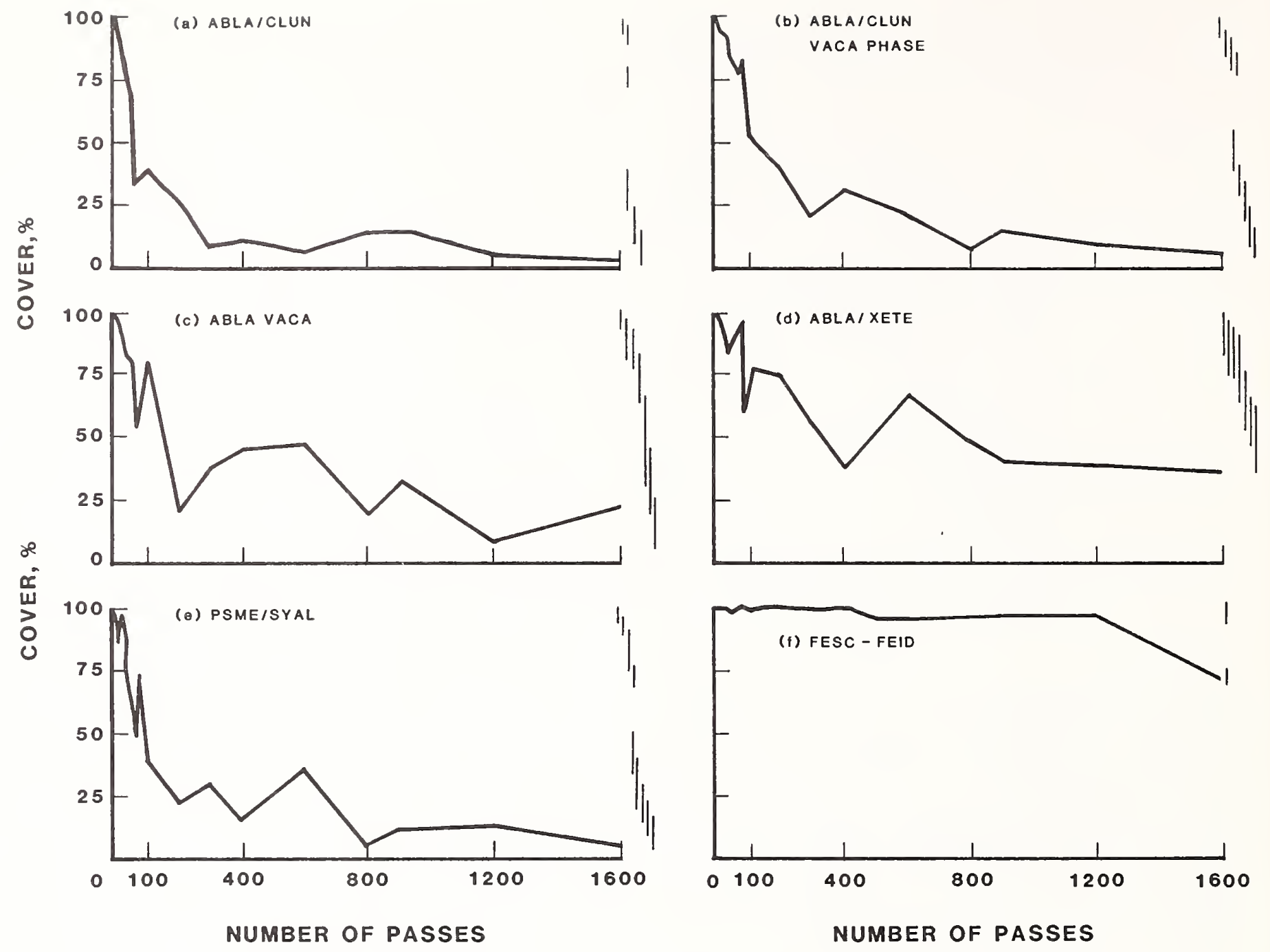

Figure 10. - The relationship between number of passes and relative vegetation cover (percentage of original cover that survives, adjusted for changes on control lanes). Lines at the right of each graph connect values that are not significantly different (Duncan's multiple range test, $\alpha=0.05$ ).

At the other extreme, the most fragile of the forested types was the lush forb-rich ABLA/CLUN type. Here just 15 passes caused a significant loss of cover (fig. 11a, b), and cover loss grew rapidly with increased trampling. Seventy-five passes was sufficient to reduce relative cover to only 35 percent (fig. 11c). Cover was less than 10 percent after 300 passes (fig. 11d), and further increases in trampling caused no significant further reductions in cover (fig. 11e).

In dramatic contrast to the forested types, the FESCFEID grassland tolerated 1,200 tramples without significant cover loss. Biomass was lost and plants were damaged, but nearly total cover remained. Cover was reduced to 72 percent after 1,600 passes. It is not possible to conclude whether or not the shape of the curve of cover loss beyond the 1,200-pass threshold will also approximate a logarithmic curve as the forested types do. 

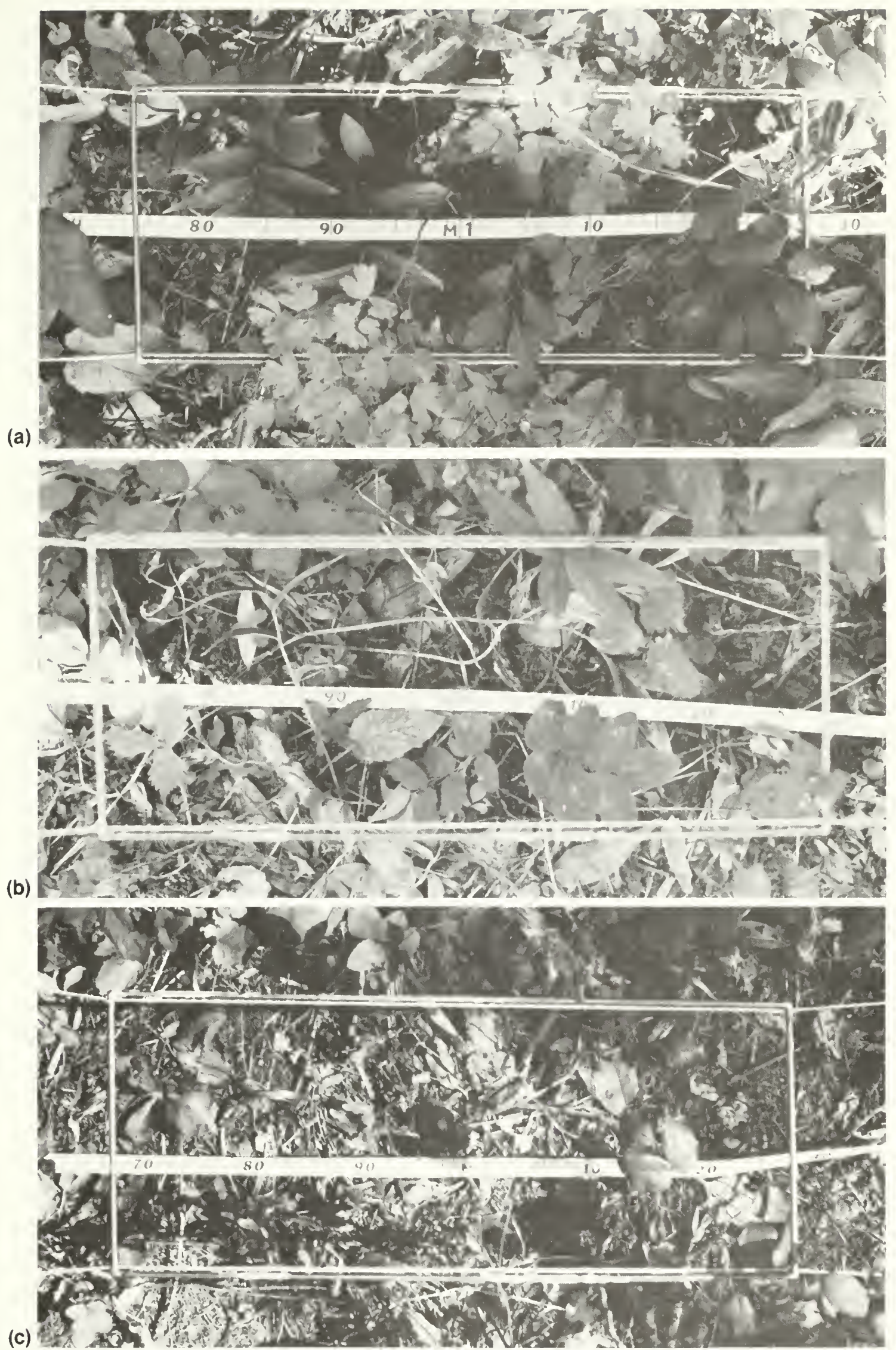

Figure 11.-Vegetation appearance in the Abies lasiocarpa/Clintonia uniflora habitat

type on (a) the control lane and after (b) 15 passes, (c) 75 passes, (d) 300 passes,

and (e) 1,200 passes. 


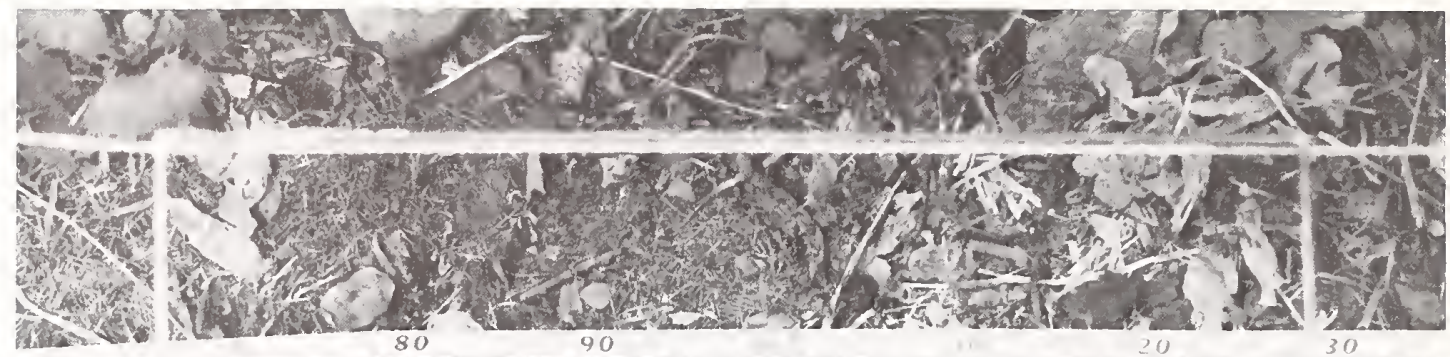

(d)
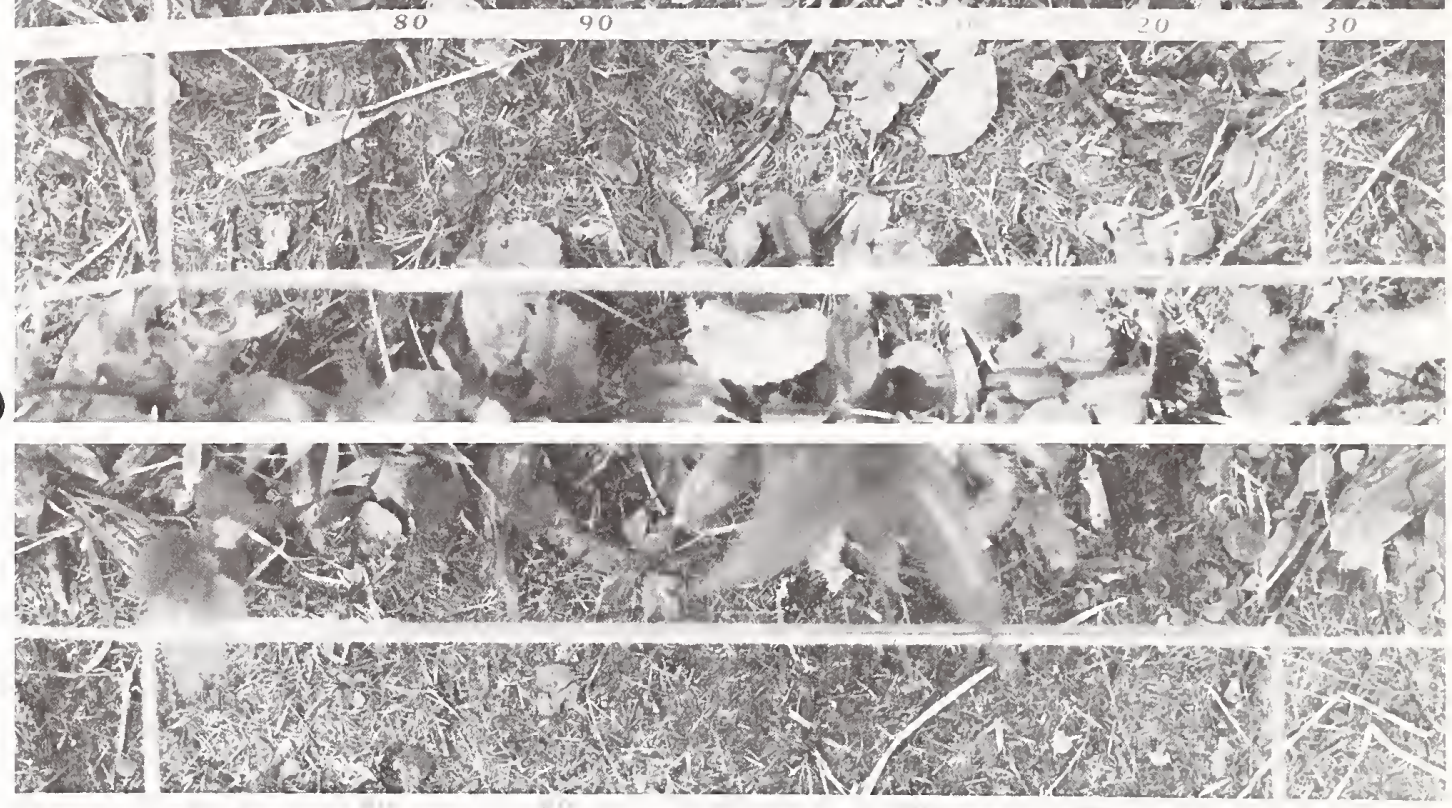

(e)

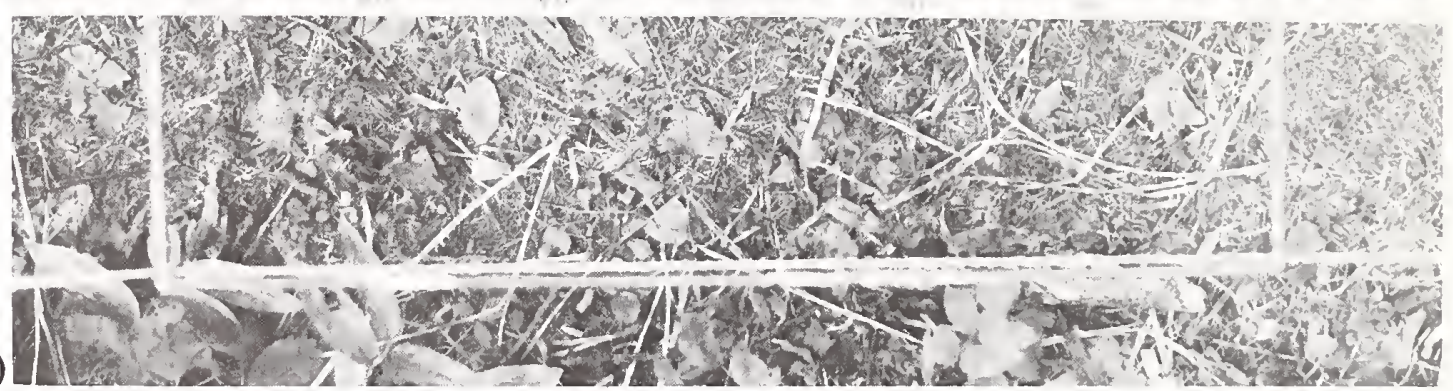

Figure 11. (Con.)

\section{Relative Resistance of Different Habitat Types}

A one-way analysis of variance was used to examine the significance of differences in relative cover resulting from differences in the resistance of the six habitat types. Duncan's multiple range test $(\alpha=0.05)$ was used again to identify significant differences between types. Table 4 displays the relative resistance of these types after different numbers of passes.

After as few as 25 passes, some of the more fragile forested types had lost significantly more cover than the FESC-FEID grassland had. Above 75 passes, FESCFEID was significantly more resistant than all of the forested types, and the most resistant of the forested types, ABLA/XETE, had significantly more cover than
ABLA/CLUN, the least resistant habitat type. After 200 passes, ABLA/XETE generally retained significantly more cover than all of the other forested types. Differences between the four least resistant habitat types were most pronounced between 300 and 900 passes. Above 900 passes, cover loss was so great on these four latter types that differentiation diminished.

As indicated in the discussion of previous studies, there are many possible ways of ranking habitat types according to their relative resistance. The number of passes it takes to eliminate more than 50 percent cover was more than 1,600 for FESC-FEID; 400 to 800, depending upon local differences in species composition, for ABLA/XETE; 200 for ABLA/VACA and ABLA/CLUNVACA; 100 for PSME/SYAL; and 75 for ABLA/CLUN. 
Table 4.- Mean percentage relative vegetation cover after various amounts of trampling for each habitat type and for all habitat types combined ${ }^{1}$

\begin{tabular}{|c|c|c|c|c|c|c|c|}
\hline \multirow{2}{*}{$\begin{array}{c}\text { Number } \\
\text { of } \\
\text { passes }\end{array}$} & \multicolumn{6}{|c|}{ Habitat type ${ }^{2}$} & \multirow{2}{*}{$\begin{array}{c}\text { All } \\
\text { habitat } \\
\text { types }\end{array}$} \\
\hline & $\begin{array}{l}\text { FESC- } \\
\text { FEID }\end{array}$ & $\begin{array}{l}\text { ABLAI } \\
\text { XETE }\end{array}$ & $\begin{array}{l}\text { ABLAI } \\
\text { VACA }\end{array}$ & $\begin{array}{l}\text { ABLA/CLUN. } \\
\text { VACA phase }\end{array}$ & $\begin{array}{l}\text { PSMEI } \\
\text { SYAL }\end{array}$ & $\begin{array}{l}\text { ABLA/ } \\
\text { CLUN }\end{array}$ & \\
\hline 5 & $102 \mathrm{a}$ & $99 a$ & $99 a$ & $98 a$ & $90 b$ & $97 a$ & 97 \\
\hline 15 & $100 a$ & $93 a$ & $95 a$ & $95 a$ & $96 a$ & $92 a$ & 95 \\
\hline 25 & $102 a$ & $83 b$ & $83 b$ & $93 a b$ & $76 b$ & $79 b$ & 86 \\
\hline 40 & $99 a$ & $89 a b$ & $81 b$ & $85 b$ & $75 b$ & $71 b$ & 84 \\
\hline 75 & $100 \mathrm{a}$ & $96 a$ & $53 c$ & $79 b$ & $50 c$ & $35 c$ & 71 \\
\hline 80 & $100 \mathrm{a}$ & $60 \mathrm{bc}$ & $63 b$ & $82 b$ & $73 b$ & $37 \mathrm{c}$ & 71 \\
\hline 100 & $99 a$ & $77 b$ & $78 b$ & $53 c$ & $38 \mathrm{c}$ & $39 c$ & 67 \\
\hline 200 & $100 a$ & $74 b$ & $20 c$ & $41 \mathrm{c}$ & $22 \mathrm{c}$ & $26 c$ & 50 \\
\hline 300 & $99 a$ & $54 b$ & $37 c$ & $21 \mathrm{~cd}$ & $30 \mathrm{c}$ & $8 d$ & 47 \\
\hline 400 & $100 a$ & $39 b c$ & $44 b$ & $31 \mathrm{bc}$ & $16 \mathrm{c}$ & $12 \mathrm{c}$ & 44 \\
\hline 600 & $95 a$ & $67 b$ & $46 c$ & $22 \mathrm{~cd}$ & $35 \mathrm{~cd}$ & $7 d$ & 51 \\
\hline 800 & $96 a$ & $48 b$ & $19 c$ & $8 c$ & $6 c$ & $15 \mathrm{c}$ & 36 \\
\hline 900 & $97 a$ & $41 b$ & $37 b c$ & $15 \mathrm{~cd}$ & $12 d$ & $15 \mathrm{~cd}$ & 40 \\
\hline 1,200 & $96 a$ & $38 b$ & $8 c$ & $10 \mathrm{c}$ & $14 \mathrm{c}$ & $5 c$ & 32 \\
\hline 1,600 & $72 a$ & $37 b$ & $22 b c$ & $6 c$ & $7 c$ & $4 \mathrm{C}$ & 29 \\
\hline \multicolumn{8}{|l|}{$\begin{array}{l}\text { Mean } \\
\text { of all }\end{array}$} \\
\hline amounts & $97 a$ & $68 b$ & $54 \mathrm{c}$ & $51 \mathrm{~cd}$ & $45 d$ & $38 d$ & 62 \\
\hline
\end{tabular}

${ }^{1}$ Any two relative vegetation cover values in the same row followed by the same letter are not significantly different (Duncan's multiple range test, $\alpha=0.05$ )

${ }^{2}$ Habitat types are:

FESC-FEID = Festuca scabrella-F. idahoensis

ABLA/XETE = Abies lasiocarpa/Xerophyllum tenax

ABLA/VACA = Abies lasiocarpa/Vaccinium caespitosum

ABLA/CLUN-VACA = Abies lasiocarpa/Clintonia uniflora.Vaccinium caespitosum phase

PSME/SYAL = Pseudotsuga menziesii/Symphoricarpos albus

ABLA/CLUN = Abies lasiocarpa/Clintonia uniflora

Table 5.-Relative resistance of the six types ${ }^{1}$

\begin{tabular}{lccc}
\hline \multicolumn{1}{c}{ Habitat type } & \multicolumn{3}{c}{ Resistance to: } \\
\cline { 2 - 4 } & $\begin{array}{c}\text { Light } \\
\text { trampling }\end{array}$ & $\begin{array}{c}\text { Heavy } \\
\text { trampling }\end{array}$ & Both \\
\hline Abies lasiocarpa/Clintonia uniflora & $\mathrm{SS}$ & $\mathrm{N}$ & $\mathrm{SS}$ \\
$\begin{array}{l}\text { Pseudotsuga menziesii/Symphoricarpos albus } \\
\text { Abies lasiocarpa/Clintonia uniflora. }\end{array}$ & $\mathrm{SS}$ & $\mathrm{SS}$ & $\mathrm{N}$ \\
Vaccinium caespitosum phase & $\mathrm{N}$ & $\mathrm{N}$ & $\mathrm{N}$ \\
Abies lasiocarpa/Vaccinium caespitosum & $\mathrm{N}$ & $\mathrm{SR}$ & $\mathrm{SR}$ \\
Abies lasiocarpa/Xerophyllum tenax & $\mathrm{VR}$ & $\mathrm{VR}$ & VR \\
Festuca scabrella-F. idahoensis & $\mathrm{VR}$ & $\mathrm{VR}$ & VR \\
\end{tabular}

${ }^{1}$ The indices used here are the same as those in table 1, permitting the resistance of these vegetation types to be compared with types studied previously.

Table 5 summarizes the rankings of the habitat types using the same indices and classes used in table 1 to classify previously studied vegetation types. The FESCFEID grassland was more resistant than any vegetation type previously studied. The ABLA/XETE type was more resistant than any forested type previously studied. The moderately resistant ABLA/VACA type responded in a manner similar to the Pinus albicaulis/ Vaccinium scoparium forest (Weaver and Dale 1978), the most resistant forest type studied before this. The three least resistant habitat types, ABLA/CLUN, ABLA/ CLUN-VACA, and PSME/SYAL, were about as resis- tant as the somewhat sensitive Abies lasiocarpa/Luzula hitchcockii and Picea engelmannii/Arnica latifolia forests of Waterton Lakes National Park (Nagy and Scotter 1974). They were considerably more resistant than some of the most fragile types previously examined.

Two other statistics provide a useful overview of the difference in resistance of these six habitat types. These are the mean relative cover across all of the treatment lanes-the last number in each column in table 4 -and the slope of lines regressing transformed relative cover on the logarithm of the number of passes (table 6). Both 
Table 6. - Slopes of lines regressing relative vegetation cover on number of passes for each habitat type ${ }^{1}$

\begin{tabular}{|c|c|c|c|c|c|}
\hline Habitat type & $\begin{array}{l}\text { Intercept } \\
\text { (a) }\end{array}$ & $\begin{array}{l}\text { Slope } \\
\text { (b) }\end{array}$ & $r^{2}$ & SEE & $\begin{array}{l}\text { Signif- } \\
\text { icance }\end{array}$ \\
\hline $\begin{array}{l}\text { Festuca scabrella- } \\
\text { F. idahoensis }\end{array}$ & 95.2 & $-4.3 a$ & 0.15 & 8.9 & $<0.001$ \\
\hline $\begin{array}{l}\text { Abies lasiocarpal } \\
\text { Xerophyllum tenax }\end{array}$ & 99.3 & $-18.7 b$ & .40 & 19.8 & $<.001$ \\
\hline $\begin{array}{l}\text { Abies lasiocarpal } \\
\text { Vaccinium caespitosum }\end{array}$ & 98.4 & $-23.5 c$ & .57 & 17.7 & $<.001$ \\
\hline $\begin{array}{l}\text { Pseudotsuga menziesiil } \\
\text { Symphoricarpos albus } \\
\text { Abies lasiocarpal } \\
\text { Clintonia uniflora. }\end{array}$ & 93.2 & $-24.5 c$ & .73 & 12.8 & $<.001$ \\
\hline $\begin{array}{l}\text { Vaccinium caespitosum phase } \\
\text { Abies lasiocarpal }\end{array}$ & 102.7 & $-27.2 \mathrm{~cd}$ & .83 & 10.6 & $<.001$ \\
\hline Clintonia uniflora & 98.2 & $-28.8 d$ & .86 & 10.0 & $<.001$ \\
\hline
\end{tabular}

${ }^{1}$ The exact form of the regression equation used was $Y=a+b \log X$, where $Y$ is relative cover (inverse sine transformed) and $X$ is number of passes. The most resistant habitat types have the least negative slope values. Two slope values followed by the same letter are not significantly different $(\alpha=0.05)$. SEE is the standard error of the estimate.

show the high resistance of FESC-FEID (fig. 12a, b) and the relatively high resistance of ABLA/XETE. The other four types are similar enough in response to make differentiation difficult. Of these four, ABLA/VACA seems to be somewhat more resistant than the rest and ABLA/CLUN seems to be more fragile, but the differences are too slight to have any real significance to management.

One question of considerable interest is whether differences in habitat type or differences in amount of trampling are more important determinants of amount of vegetation loss. Clearly the answer would depend upon the habitat types being compared and the range of trampling pressure applied. If similar vegetation types are subjected to a wide range of use, amount of use will be the more important factor. In contrast, if quite different vegetation types are compared across a narrow range of use-such as 100 versus 200 passes-habitat type is likely to make more difference. The importance of amount of trampling is also highly dependent upon the number of passes. For example, in most habitat types differences in amount of trampling would be much more important when comparing the effects of five and 200 passes than when comparing the effects of 600 and 800 passes.

Across the range of trampling from zero to 1,600 passes, the difference between the grassland and any of the forested types explained more of the variation in relative cover than differences in amount of trampling. That is, in a multiple regression with pairs of habitat types and number of passes as independent variables and relative cover as the dependent variable, the $r^{2}$ contribution of habitat type was higher 10.31 to 0.63 depending upon which forested type the grassland was compared to) than the $\mathrm{r}^{2}$ contribution of number of passes $(0.14$ to 0.19$)$.

Amount of trampling was more important than differences between any of the forested types across this wide range of trampling intensity. If narrower ranges of trampling are compared, however, some forested habitat type differences become more important. From figures $10 \mathrm{a}$ and $10 \mathrm{~d}$, it can be seen that between 300 and 1,600 passes, the difference in relative cover related to a difference in number of passes is 11 percent in the ABLA/CLUN type and 17 percent in the ABLA/XETE type. The difference in relative cover between these two types varies from 26 to 60 percent, between 300 and 1,600 passes. This suggests that whether use occurs in ABLA/CLUN or ABLA/XETE has a more profound influence on amount of cover loss than whether amount of trampling is 300 or 1,600 passes. Numerous similar interpretations can be made from these data.

\section{Effect of Local Variations in Species Composition}

As mentioned previously, local variations in the initial species composition of different treatment lanes on the same plot appear to have a significant effect on cover loss. Unfortunately, this variability could not be controlled and instead appears as "noise," making it more difficult to interpret the effects of the controlled variables. Nevertheless, the nature and magnitude of this variability is of considerable interest itself.

Let us assume that any time relative cover increases with an incremental increase in number of passes (refer to fig. 10), this increase-the opposite of the general trend-is primarily a result of proportionally more resistant species on the more heavily trampled lane. This is a reasonable assumption given that the major variables affecting cover loss should be amount of trampling and the resistance of the plants being trampled. Moreover, most of the treatments with unexpectedly high cover values did have large percentages of resistant species. For example, an analysis of covariance for the ABLA/ $\mathrm{XETE}$ type showed the amount of variation in relative 

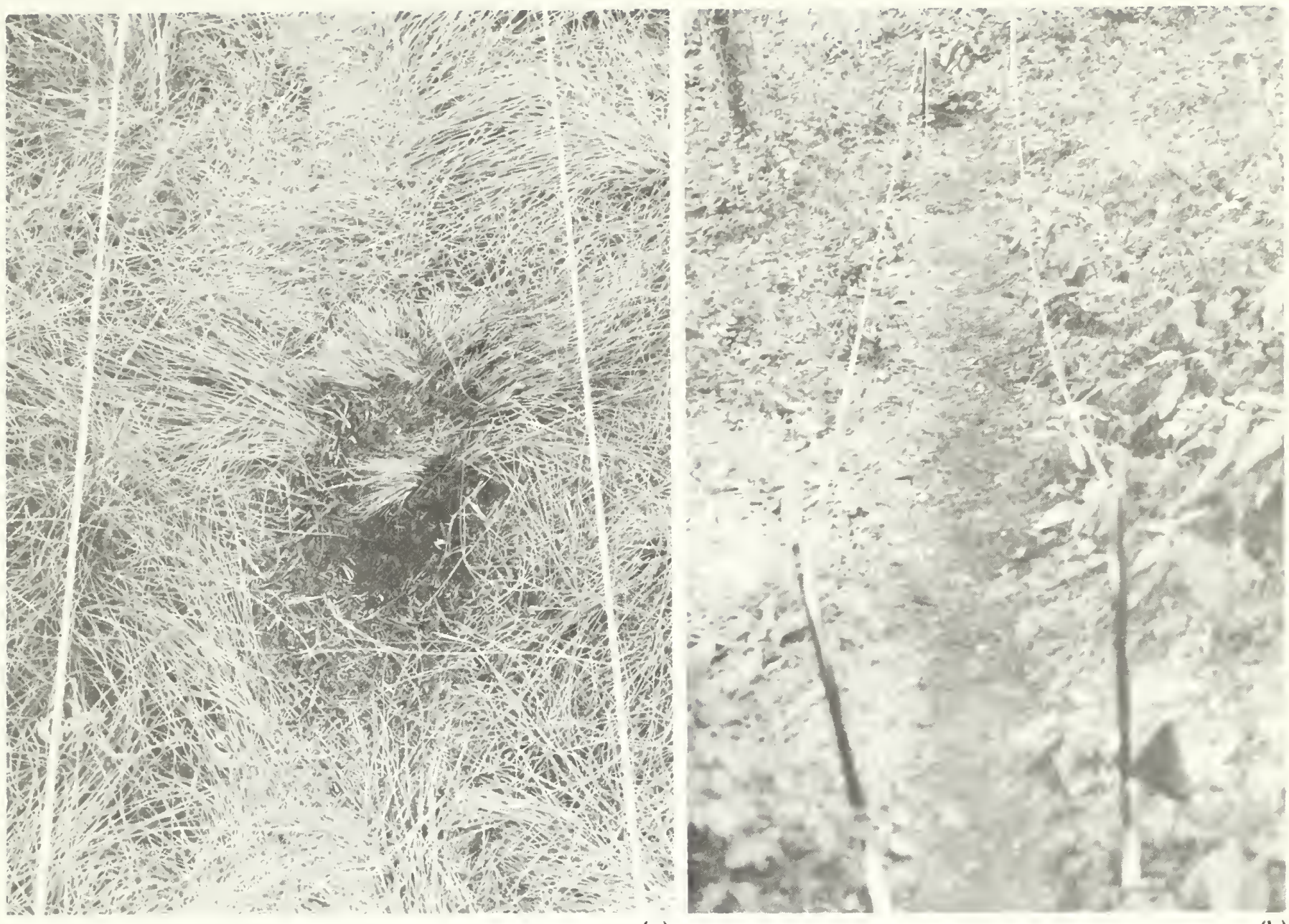

(a)

(b)

Figure 12. - The effect of 1,600 passes in (a) the resistant Festuca scabrella.F idahoensis habitat type and (b) the susceptible Pseudotsuga menziesii/ Symphoricarpos albus habitat type.

cover explained by number of passes increased from 52 percent (eta $\left.{ }^{2}=0.52\right)$ to 72 percent $\left(\mathrm{r}^{2}=0.72\right)$ when pretreatment differences in cover of two resistant plants, Xerophyllum tenax and moss, were statistically controlled. In other words, local variation in the distribution of just these two plants accounted for about 40 percent of the variation in cover not explained by trampling intensity. Differences in the distribution of other species probably accounted for much of the rest.

If this assumption about the cause of erratic relative cover values is accepted, then local variations in species distributions-on a scale of a few meters or less-can account for differences in relative cover of as much as 25 percent in the ABLA/VACA, ABLA/XETE, and PSME SYAL types (fig. 10). Xerophyllum tenax and/or mosses are resistant and patchily distributed in these habitat types. The relative importance of these two plants in the treatment lane can often have a greater influence on cover loss than differences in trampling intensity on the order of many hundred passes. For the ABLA/CLUN, ABLA/CLUN-VACA, and FESC-FEID types, local variation in species distribution is not very important. In the first two types, no resistant species are abundant enough to dampen the effect of a given number of passes. In the grassland, resistant species are so abundant and evenly distributed that no lane was inherently more resistant than any other. 


\section{EFFECT OF TRAMPLING ON NUMBER OF PLANT SPECIES}

Loss of species after trampling was assessed by calculating

Species $=$

loss

number of species before trampling - number after trampling number of species before trampling.

This loss of species varies significantly both with number of passes and between habitat types; interaction between these two major effects is also significant (twoway analysis of variance; $\mathrm{p}<0.001$ ).
The graphs in figure 13 show that as number of passes increased from zero to 1,600 , loss of species was initially rapid and then leveled off. Most habitat types lost the first quarter of their species by 75 to 100 passes and the second quarter by 400 passes; a further increase in trampling to 1,600 passes caused an additional loss of only 10 to 15 percent.

Initial loss of species was most rapid in the ABLA/ VACA (fig. 13c) and PSME/SYAL (fig. 13e) types; it was least rapid in the FESC-FEID (fig. 13f) and ABLA/XETE (fig. 13d) types. Generally. the initial rapid loss of species began to abate after 25 passes, increasing more slowly to 400 passes. In the ABLA/CLUN type (fig. 13a), the initial rapid loss continued unabated to 300 passes,

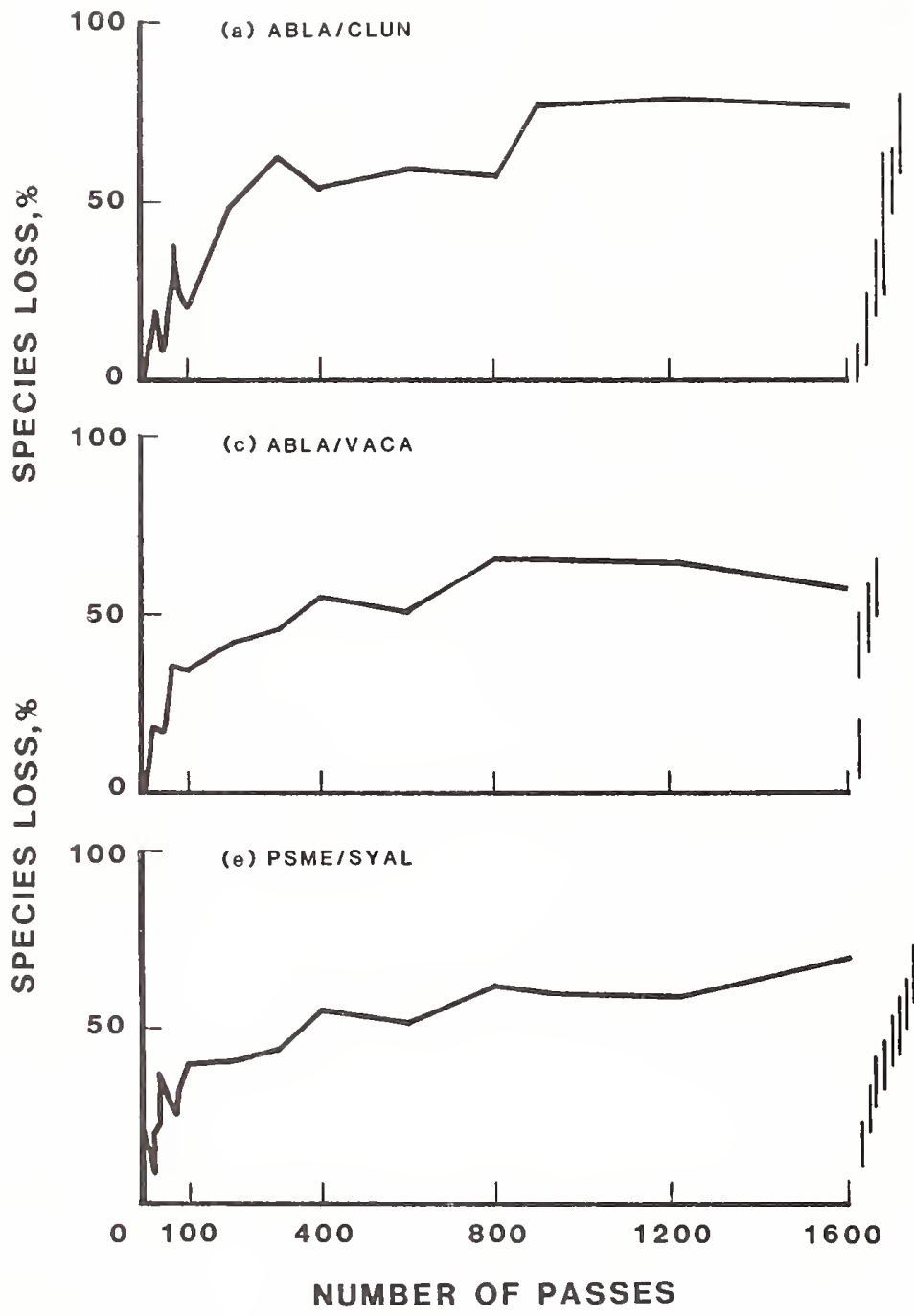

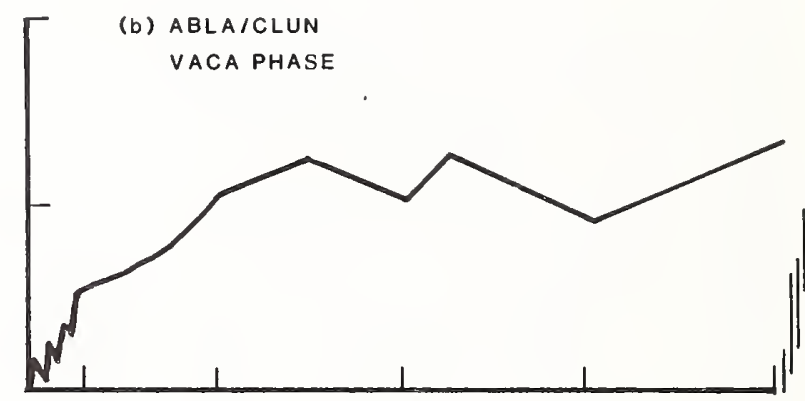
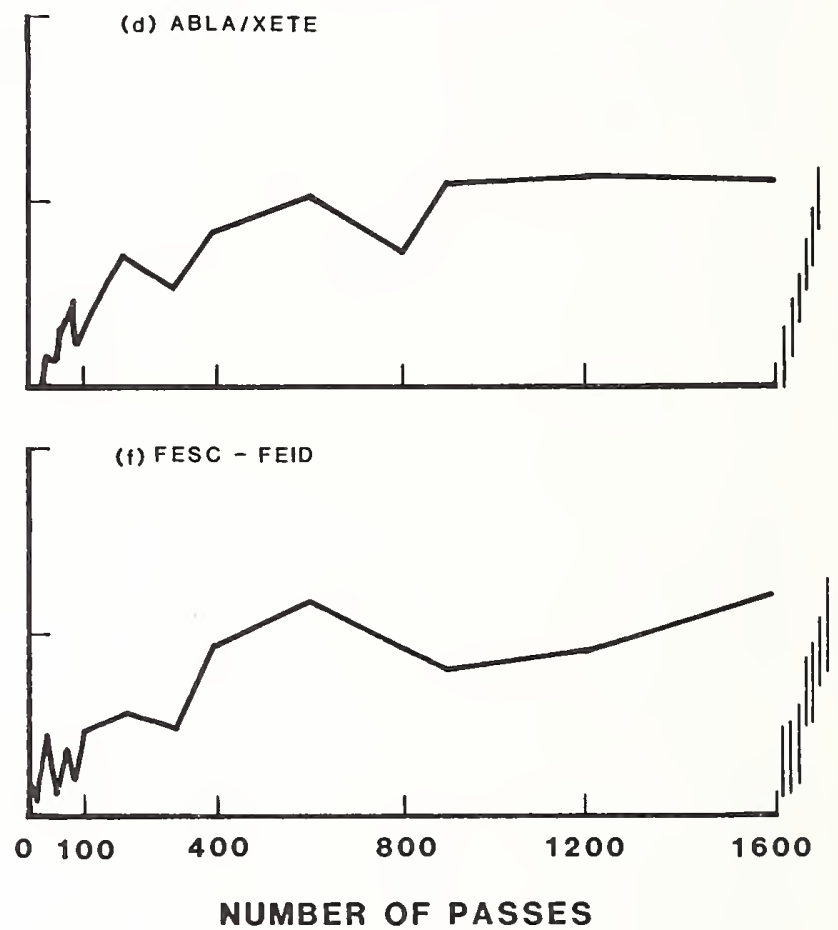

Figure 13. - The relationship between number of passes and species loss (percentage of species originally present that were absent after trampling). Lines at the right of each graph connect values that are not significantly different (Duncan's multiple range test, $\alpha=0.05$ ). 
Table 7.-Mean percentage species loss after various amounts of trampling for each habitat type and for all habitat types combined ${ }^{1}$

\begin{tabular}{|c|c|c|c|c|c|c|c|}
\hline \multirow{2}{*}{$\begin{array}{c}\text { Number } \\
\text { of } \\
\text { passes }\end{array}$} & \multicolumn{6}{|c|}{ Habitat type ${ }^{2}$} & \multirow{2}{*}{$\begin{array}{c}\text { All } \\
\text { habitat } \\
\text { types }\end{array}$} \\
\hline & $\begin{array}{l}\text { ABLA/ } \\
\text { XETE }\end{array}$ & $\begin{array}{l}\text { FESC. } \\
\text { FEID }\end{array}$ & $\begin{array}{l}\text { ABLA/CLUN. } \\
\text { VACA phase }\end{array}$ & $\begin{array}{l}\text { ABLAI } \\
\text { VACA }\end{array}$ & $\begin{array}{l}\text { PSMEI } \\
\text { SYAL }\end{array}$ & $\begin{array}{l}\text { ABLA/ } \\
\text { CLUN }\end{array}$ & \\
\hline 5 & $0 \mathrm{a}$ & $5 a$ & $7 a$ & $9 a$ & $10 a$ & $7 a$ & 6 \\
\hline 15 & $8 a$ & $23 a$ & $2 a$ & $17 a$ & $20 a$ & $8 a$ & 15 \\
\hline 25 & $8 a$ & $20 a$ & $8 a$ & $18 \mathrm{a}$ & $22 a$ & $20 \mathrm{a}$ & 16 \\
\hline 40 & $10 \mathrm{a}$ & $11 \mathrm{a}$ & $7 a$ & $17 a$ & $33 b$ & $10 \mathrm{a}$ & 16 \\
\hline 75 & $19 a$ & $17 a$ & $16 \mathrm{a}$ & $35 a$ & $26 a$ & $38 \mathrm{a}$ & 25 \\
\hline 80 & $23 a b c$ & $14 a$ & $16 a b$ & $35 c$ & $33 b c$ & $24 a b c$ & 25 \\
\hline 100 & $14 a$ & $24 a b$ & $27 a b$ & $35 b$ & $38 \mathrm{~b}$ & $21 a b$ & 27 \\
\hline 200 & $37 a$ & $28 a$ & $32 a$ & $42 a$ & $39 a$ & $50 a$ & 37 \\
\hline 300 & $29 a b$ & $24 a$ & $40 a b c$ & $46 c$ & $42 b c$ & $64 d$ & 39 \\
\hline 400 & $44 a$ & $47 a$ & $53 a$ & $55 a$ & $54 a$ & $56 a$ & 51 \\
\hline 600 & $53 a$ & $58 a$ & $63 a$ & $51 a$ & $51 a$ & $61 a$ & 55 \\
\hline 800 & $38 a$ & $45 a b$ & $51 a b c$ & $66 c$ & $61 c$ & $59 \mathrm{bc}$ & 53 \\
\hline 900 & $56 b$ & $40 a$ & $64 \mathrm{bc}$ & $65 b c$ & $59 b$ & $79 c$ & 58 \\
\hline 1,200 & $58 a b$ & $43 a$ & $46 a b$ & $66 \mathrm{bc}$ & $58 a b$ & $81 c$ & 58 \\
\hline 1,600 & $57 a$ & $58 a$ & $65 a$ & $58 a$ & $69 a$ & $79 a$ & 63 \\
\hline All & & & & & & & \\
\hline amounts & $28 a$ & $29 a$ & $31 a$ & $39 b$ & $40 b$ & $42 b$ & 35 \\
\hline
\end{tabular}

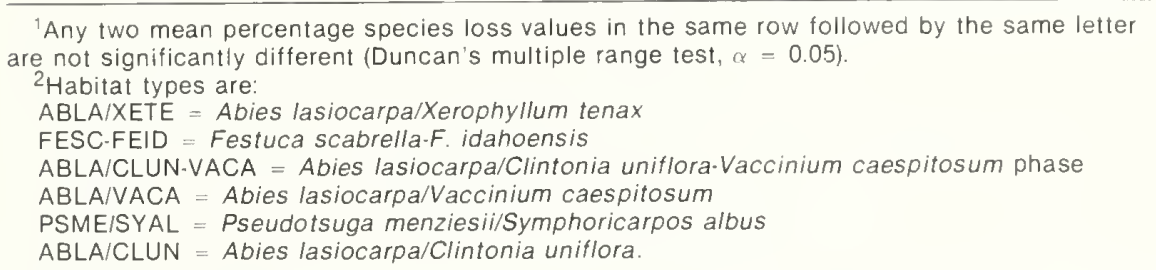

after which 64 percent of the species were lost. This type eventually lost about 80 percent of its species at trampling levels of $900,1,200$, and 1,600 passes.

The relative resistance of these types is displayed in table 7 . Over the entire range of trampling intensity, ABLA/VACA, PSME/SYAL, and ABLA/CLUN were more prone to species loss than ABLA/XETE, FESCFEID, and ABLA/CLUN-VACA; however, differences were not as pronounced as for resistance to cover loss.

\section{RESPONSE OF INDIVIDUAL SPECIES TO TRAMPLING}

We were able to calculate relative cover and to graph response to trampling for species abundant on control lanes and most treated lanes (fig. 14). Cover loss for individual species is generally more rapid than for total cover. The rate for individual species is actually a more accurate reflection of how rapidly vegetation is lost, because pretreatment total cover measures are underestimated on account of multitiered vegetation cover. Median relative cover for the 19 species fell below 50 percent after 40 to 75 passes and below 30 percent after 100 passes. It declined more slowly to 6 to 7 percent after 400 passes and then even more slowly to 1 to 2 percent after 1,600 passes.

The most sensitive species, Thalictrum occidentale, Osmorhiza chilensis, and Melampyrum lineare, all lost most of their cover after 15 passes and were all but eliminated-at least for the season-after 40 passes. They are all forbs adapted to tolerate low sunlight conditions. Such adaptations-thin cuticles, cell walls, and stems, and a large amount of supportive and conductive tissue-make them susceptible to breakage (Cole 1979). 

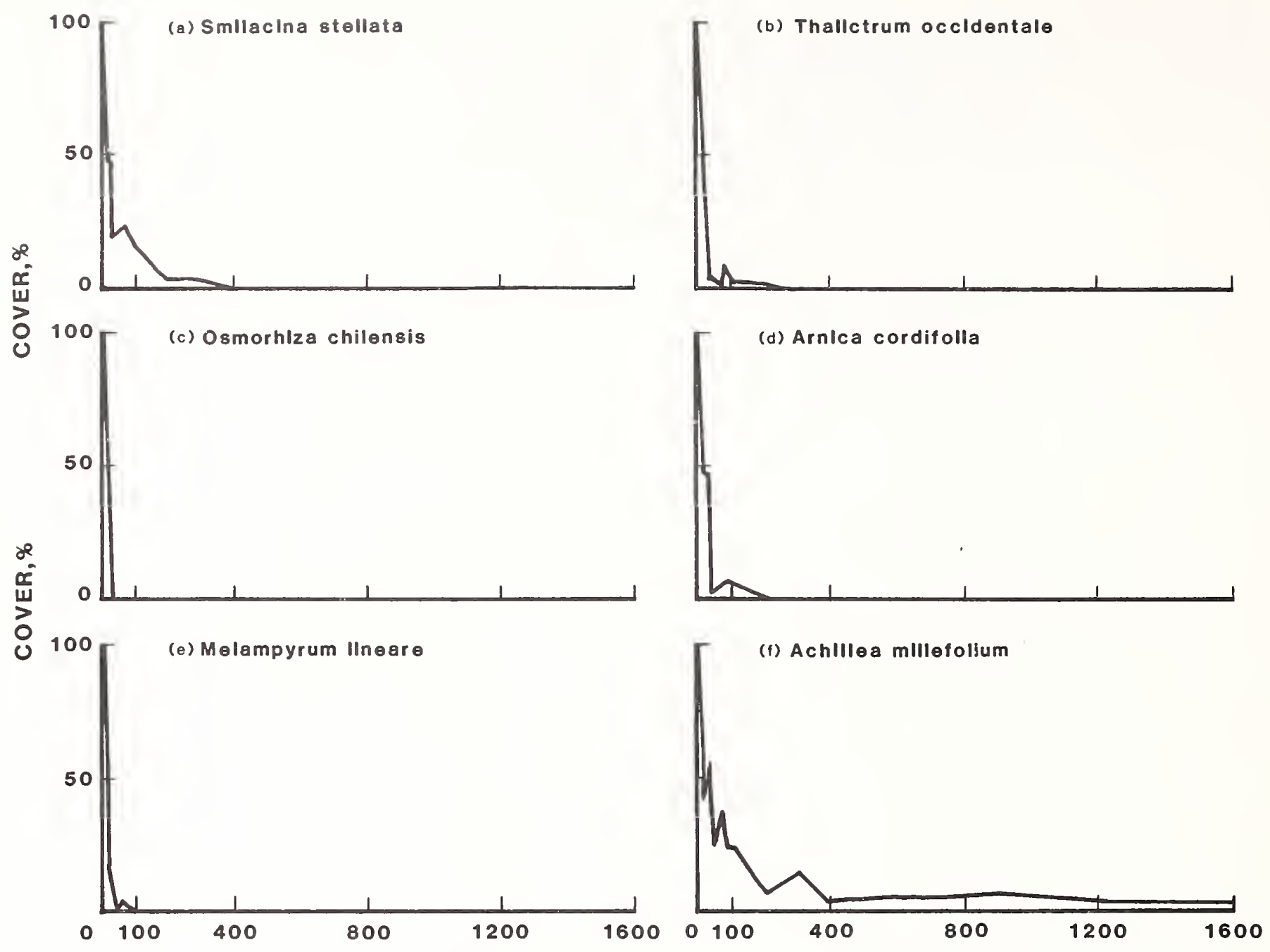

NUMBER OF PASSES

NUMBER OF PASSES

Figure 14. - The relationship between number of passes and relative cover (percentage of original cover that survives, adjusted for changes on control lanes) for the most common vascular species and for mosses and lichens as a group. The * denotes species for which data from more than one habitat type have been averaged. 

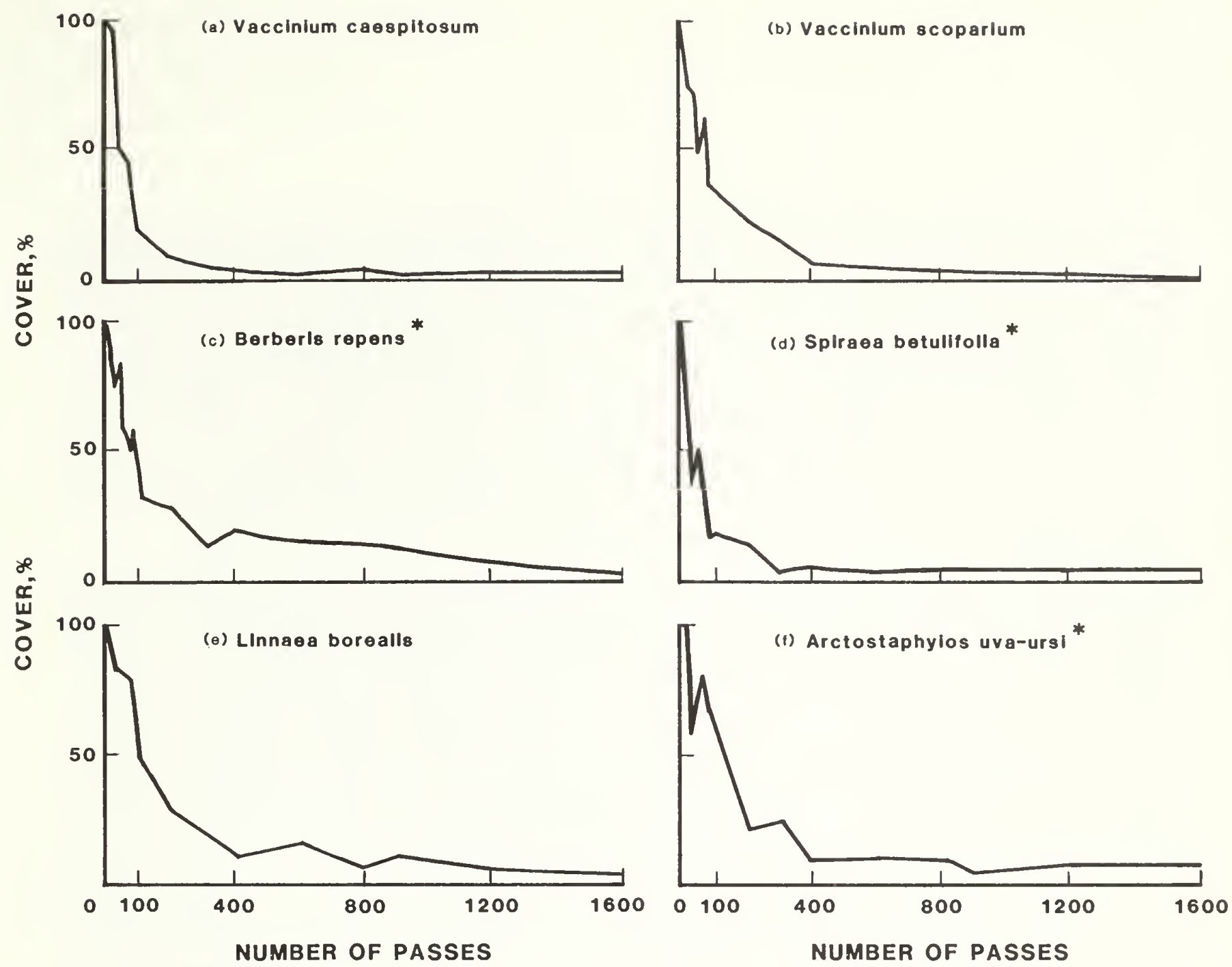

Figure 14. (Con.) 

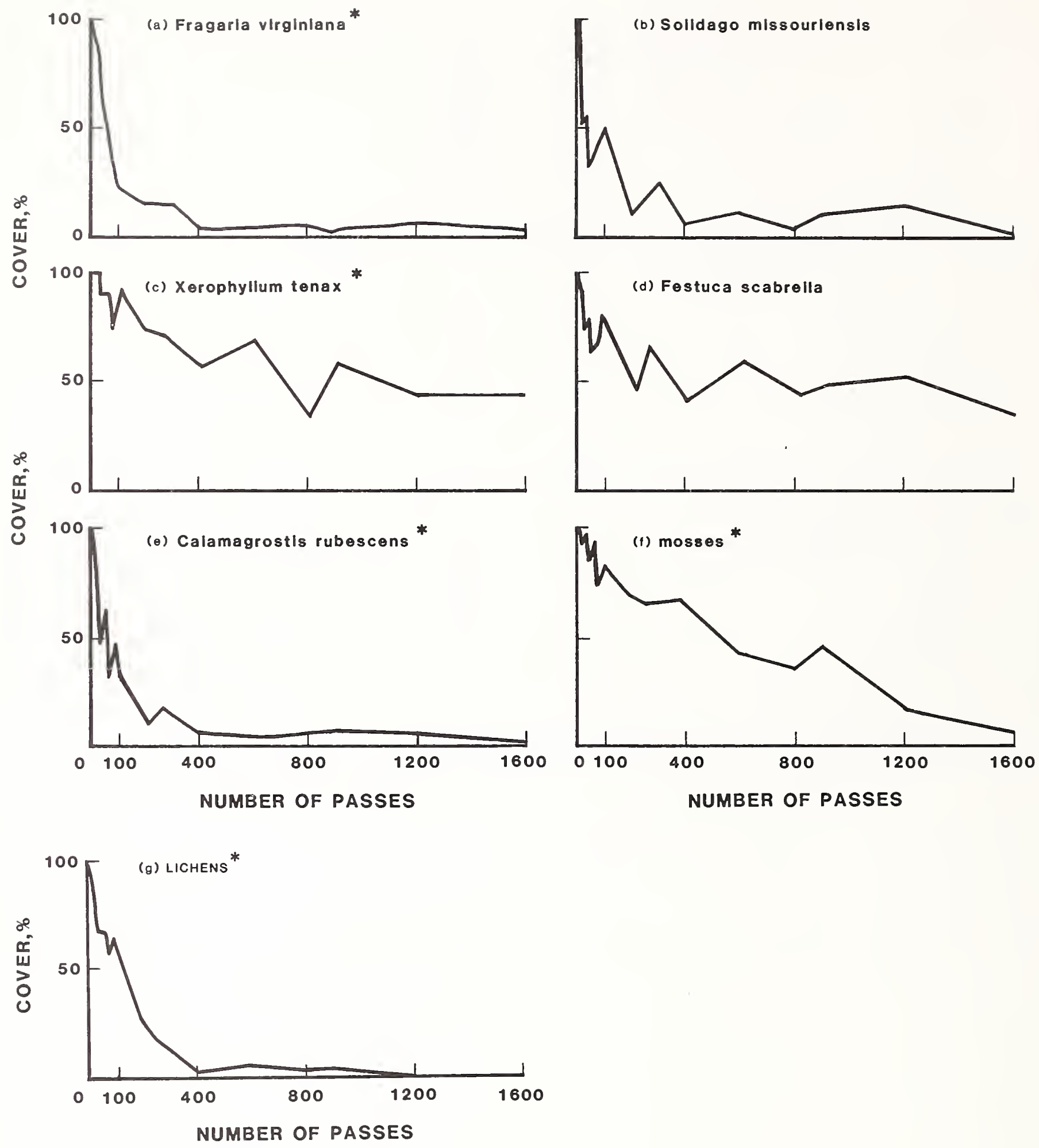

Figure 14. (Con.) 
Achillea millefolium and Fragaria virginiana were less susceptible but were nearly eliminated after 400 passes. Leaves close to the ground allow these two forbs to survive low levels of trampling. Tough, flexible, straplike leaves and a tufted growth form combine to make Xerophyllum tenax, a forb, the most resistant of all plants studied (fig. $15 \mathrm{a}$, b). It is important to note that even this most resistant species exhibited no threshold below which trampling had little effect and above which effects were pronounced. Instead, cover loss was immediate, the rate of loss declining as trampling intensity increased.
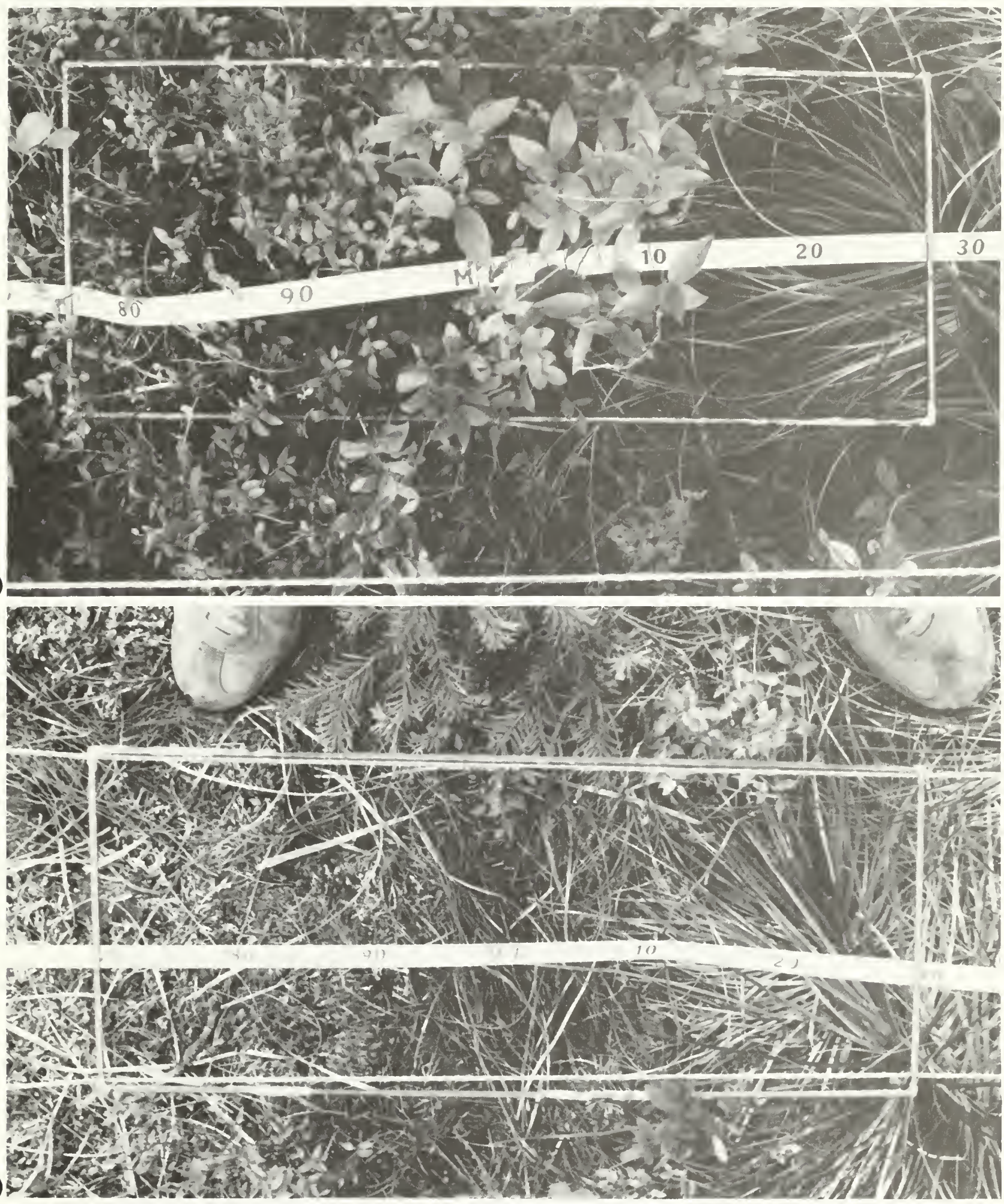

Figure 15.-Vegetation of the 200-pass lane on the Abies lasiocarpa/Xerophyllum tenax habitat type, (a) before and (b) after treatment. Xerophyllum tenax and moss survive, but $\mathrm{V}$ accinium scoparium and $\mathrm{V}$. globulare do not. 
Shrubs generally were more resistant than forbs to the immediate effects of trampling. But, none of the shrubs were highly resistant. The most resistant common shrub, Berberis repens, lost 80 percent of its cover after 300 passes. The reader should remember that these results do not account for susceptibility to prolonged trampling or ability to recover. Studies of established campsites and trails suggest that most shrubs are relatively susceptible to prolonged trampling (Dale and Weaver 1974; Cole 1982a, 1983).

The two graminoids responded quite differently. The bunchgrass, Festuca scabrella, was very resistant. Even after 1,600 tramples, about 35 percent of the plant's cover survived. This was usually the tough core of the tuft (fig. 16). Calamagrostis rubescens, a rhizomatous grass, was not particularly resistant and lost over 90 percent of its cover after 400 passes.

Mosses were very resistant, particularly to low and moderate levels of trampling (fig. 15a, b). This is the one type of plant that did not exhibit a curvilinear relationship between cover loss and amount of trampling. Twothirds of the moss cover survived 400 passes. Beyond this level of trampling, cover loss was rapid and continued unabated; only about 5 percent survived 1,600 passes. Lichens were considerably more sensitive, but, like mosses, consistently survived low levels of trampling. Over 60 percent of the cover survived 100 passes. Beyond this level, cover dropped rapidly to less than 5 percent after 400 passes.

All of these species and 34 less widely distributed species are classified according to their susceptibility in table 8 . This ranking can be used to predict the resistance of vegetation types to the initial effects of trampling. Types dominated by resistant species will obviously be more resistant than those dominated by susceptible species. For example, the most resistant habitat types, FESC-FEID and ABLA/XETE, have 74 and 73 percent cover of very resistant species, compared with 0 and 1 percent cover of very susceptible species. In the PSME/SYAL, ABLA/VACA, and ABLA/CLUN-VACA types, very susceptible species are slightly more abundant than very resistant species. In the ABLA/ CLUN type, very sensitive species contribute 59 percent cover compared to 5 percent for very resistant species.

From table 8, graminoids have been classified as very resistant, resistant, and neutral. The bunchgrass, Festuca scabrella, is most resistant. Previous studies have generally found graminoids to be particularly resistant to trampling (Schreiner 1974, 1980; Nagy and Scotter 1974). These results, along with those of Nagy and Scotter (1974), suggest that graminoids growing under shady forested conditions are generally more sensitive than graminoids growing in the open. Graminoids that evolved under grazing pressure should also be more resistant than those that did not.

Shrubs range from sensitive to resistant; none are exceptionally sensitive or exceptionally resistant. The more resistant shrubs are over $2 \mathrm{ft}(0.6 \mathrm{~m})$ tall (Amelanchier alnifolia), very low-growing (Arctostaphylos uva-ursi, Linnaea borealis), and/or have tough, flexible branches and leaves (Berberis repens). The most susceptible shrubs (Vaccinium caespitosum, V. globulare, Spiraea betulifolia) are short, erect shrubs with brittle stems. Brittleness increases with the season, making these species particularly susceptible to trampling later in the summer.

These results agree with results of a series of Canadian studies (Landals and Scotter 1973, 1974; Nagy and Scotter 1974) in which Berberis repens and Vaccinium scoparium were found more resistant than Symphoricarpos albus, Vaccinium membranaceum-a morphological analog to $V$. globulare-and Spiraea betulifolia. Differences were slight, however, when considering the general susceptibility of these shrubs.

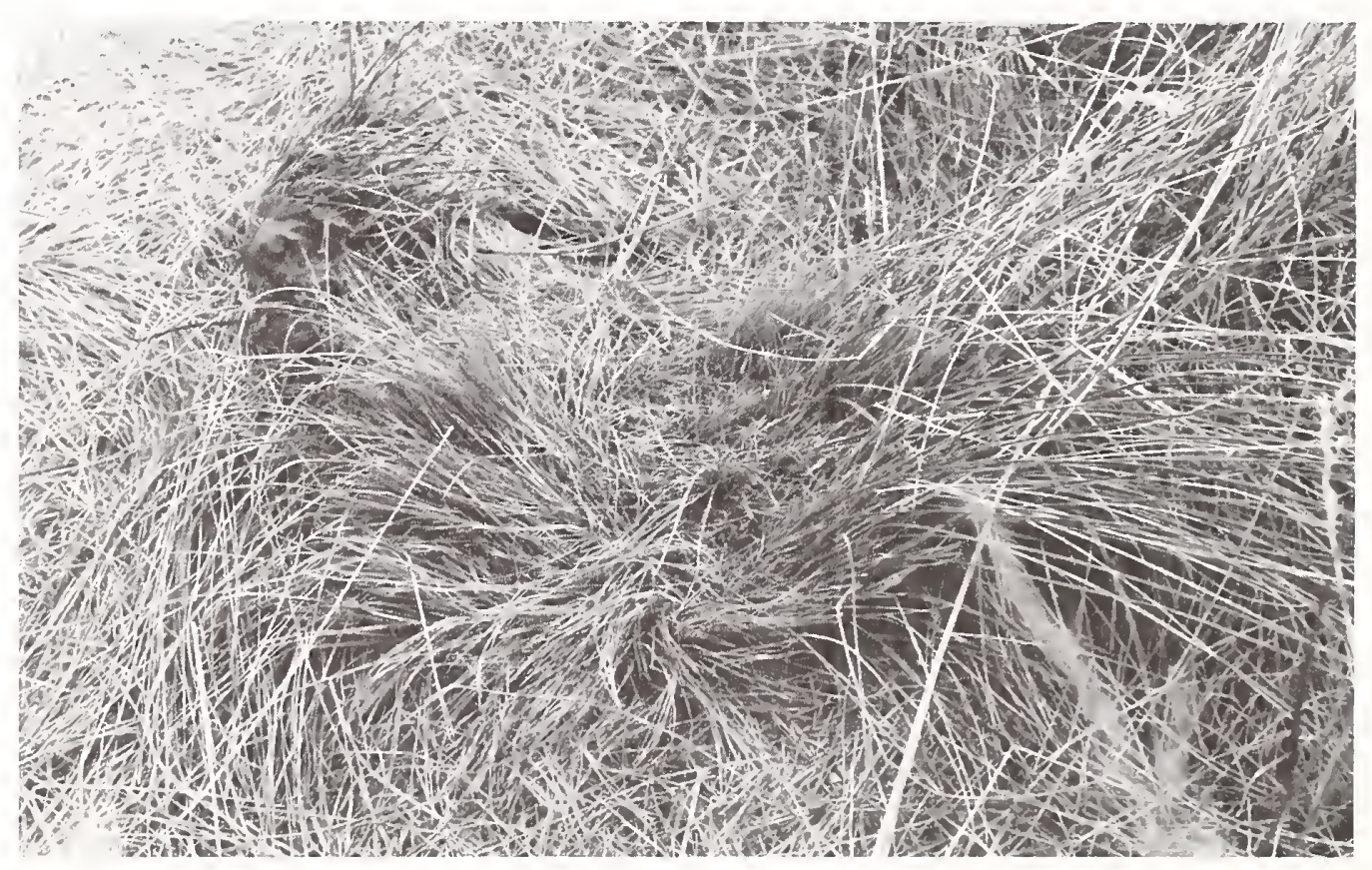

Figure 16. - After 1,200 passes, Festuca scabrella is severely abraded but the

tough core of the tuft survives. 
Table 8.-Classification of the more abundant species according to their sensitivity to trampling ${ }^{3}$

\section{VERY RESISTANT}

Carex geyeri (elk sedge)

Festuca scabrella (rough fescue)

Arenaria congesta (capitate sandwort)

Penstemon confertus/P. procerus (yellow/small-flowered beardtongue) Xerophyllum tenax (beargrass)

mosses

\section{RESISTANT}

Amelanchier alnifolia (western serviceberry)

Arctostaphylos uva-ursi (kinnikinnick)

Berberis repens (creeping Oregongrape)

Linnaea borealis (twinflower)

Rosa acicularis (prickly rose)

Rosa gymnocarpa (baldhip rose)

Carex concinnoides (northwest sedge)

Antennaria microphylla/A. umbrinella (rosy/umber pussy-toes)

Antennaria racemosa (raceme pussy-toes)

Chimaphila umbellata (prince's-pine)

Chrysopsis villosa (hairy golden-aster)

Solidago missouriensis (Missouri goldenrod)

Viola orbiculata (round-leaved violet)

NEITHER RESISTANT NOR SENSITIVE

Pachistima myrsinites (mountain-lover)

Rubus parviflorus (thimbleberry)

Symphoricarpos albus (snowberry)

Vaccinium scoparium (grouse whortleberry)

Bromus vulgaris (Columbia brome)

Calamagrostis rubescens (pine grass)

Achillea millefolium (common yarrow)

Aster foliaceus (leafy aster)

Fragaria virginiana (blueleaf strawberry)

Potentilla gracilis (slender cinquefoil)

tree seedlings

lichens

SENSITIVE

Spiraea betulifolia (shiny-leaf spirea)

Vaccinium caespitosum (dwarf huckleberry)

Vaccinium globulare (globe huckleberry)

Arnica cordifolia/A. latifolia (heartleaf/mountain arnica)

Aster conspicuus (showy aster)

Fragaria vesca (woods strawberry)

Galium boreale (northern bedstraw)

Geranium viscosissimum (sticky purple geranium)

Hieracium albiflorum (white-flowered hawkweed)

Lupinus sericeus (silky lupine)

Smilacina stellata (starry false Solomon's seal)

VERY SENSITIVE

Adenocaulon bicolor (pathfinder)

Clintonia uniflora (queencup beadlily)

Disporum trachycarpum (Sierra ferry-bell)

Epilobium angustifolium (fireweed)

Galium triflorum (fragrant bedstraw)

Hedysarum occidentale (western sweetvetch)

Lupinus argenteus (silvery lupine)

Melampyrum lineare (narrow-leaved cow-wheat)

Osmorhiza chilensis (mountain sweet-root)

Thalictrum occidentale (western meadowrue)

Viola adunca (early blue violet)

${ }^{1}$ Classification guidelines were: very resistant if relative cover was greater than 30 percent after 400 passes; resistant if relative cover was greater than 30 percent after 100 passes and greater than 10 percent after 400 passes; sensitive if relative cover was between 1 and 20 percent after 100 passes; and very sensitive if the plant was usualiy eliminated after 100 passes. Within each class plants are arranged from shrubs and subshrubs to graminoids, forbs, and miscellaneous. 
Forbs are most divergent in their response. All the very sensitive species are forbs, but so are three of the six very resistant species. Tough leaves in a basal rosette or tuft and a woody base are characteristics that make some forbs particularly resistant. Taller, caulescent forbs are most sensitive. Schreiner (1974) found Arenaria capillaris, a species similar morphologically to $A$. congesta, to be resistant. Nagy and Scotter (1974) found Xerophyllum tenax to be resistant and Thalictrum venulosum, Aster conspicuus, and Galium triflorum to be highly sensitive.

The resistance of mosses has been noted many times (Schreiner 1974, 1980; Landals and Scotter 1974; Nagy and Scotter 1974; Holmes and Dobson 1976; Studlar 1980). Lichens have been found to be sensitive when trampled in high-elevation and high-latitude vegetation types (Schreiner 1974, 1980). In the midelevation types trampled in this study, lichens were only moderately susceptible to damage.

With only six exceptions, these fragility ratings (table 8) are comparable to ratings based on a comparison of species response on campsites in the Bob Marshall Wilderness and neighboring undisturbed control plots (Cole 1983). Compared to the study of existing camp. sites, this experimental study overestimates the fragility of Smilacina stellata and Disporum trachycarpum. These species appear to be highly resilient, recovering rapidly after disturbance from rhizomes. The experimental study underestimates the fragility of Carex geyeri,

Arctostaphylos uva-ursi, Linnaea borealis, and mosses. Apparently, the initial resistance of these species declines when subjected to prolonged trampling. These hypotheses will be tested after following the response of these species to subsequent years of trampling.

\section{EFFECT OF TRAMPLING ON MINERAL SOIL EXPOSURE}

In addition to eliminating vegetation cover, trampling also can erode the surface organic horizons of the soil, exposing mineral soil beneath. Before trampling, all of the habitat types had a mean mineral soil exposure of 0 percent, although seven of the 34 subplots on the FESCFEID type and one of the subplots on the PSME/SYAL type had traces of exposed mineral soil. The increase in exposure resulting from trampling was expressed simply as the percentage of exposure after trampling minus the percentage before-usually zero. No correction for changes on the control lanes was necessary because these lanes had no mineral soil exposure.

Table 9 shows the relationship between trampling intensity and increase in mineral soil exposure for each habitat type and for all types combined. Because most values were zeros, the distribution of values was so highly skewed that nonparametric statistics were used to draw inferences about the statistical significance of these results.

A Friedman two-way analysis of variance (Siegel 1956) suggested that increase in exposure differs both with amount of trampling and with habitat type $(\mathrm{p}<0.001)$. Page's test for ordered alternatives based on Friedman rank sums was used to test whether or not mineral soil exposure increased with trampling. Multiple comparisons

Table 9.-The relationship between number of passes and percentage increase in mineral soil exposure for each habitat type and for all types combined ${ }^{1}$

\begin{tabular}{|c|c|c|c|c|c|c|c|c|c|c|c|c|c|c|}
\hline \multirow{3}{*}{$\begin{array}{c}\text { Number } \\
\text { of } \\
\text { passes }\end{array}$} & \multicolumn{12}{|c|}{ Habitat type ${ }^{2}$} & \multirow{2}{*}{\multicolumn{2}{|c|}{$\begin{array}{c}\text { All } \\
\text { types }\end{array}$}} \\
\hline & \multicolumn{2}{|c|}{ ABLA/CLUN } & \multicolumn{2}{|c|}{$\begin{array}{l}\text { ABLA/CLUN- } \\
\text { VACA phase }\end{array}$} & \multicolumn{2}{|c|}{ ABLAIVACA } & \multicolumn{2}{|c|}{ ABLAIXETE } & \multicolumn{2}{|c|}{ PSME/SYAL } & \multicolumn{2}{|c|}{ FESC.FEID } & & \\
\hline & Mean & S.d. & Mean & S.d. & Mean & S.d. & Mean & S.d. & Mean & S.d. & Mean & S.d. & Mean & S.d. \\
\hline 0 & - & - & - & - & - & - & - & - & - & - & - & - & - & - \\
\hline 5 & - & - & - & - & - & - & - & - & - & - & - & - & - & - \\
\hline 15 & - & - & - & - & - & - & - & - & - & - & - & - & - & - \\
\hline 25 & - & - & - & - & 1 & 1 & - & - & - & - & + & 1 & + & 1 \\
\hline 40 & - & - & - & - & - & - & - & - & - & - & - & - & - & - \\
\hline 75 & - & - & - & - & - & - & + & 1 & 3 & 5 & - & - & 1 & 2 \\
\hline 80 & - & - & - & - & - & - & - & - & - & - & + & + & + & 2 \\
\hline 100 & - & - & - & - & - & - & 2 & 5 & 1 & 4 & 1 & 2 & 1 & 3 \\
\hline 200 & - & - & - & - & + & 1 & - & - & - & - & - & - & + & + \\
\hline 300 & - & - & 1 & 4 & 1 & 4 & 2 & 9 & 4 & 8 & + & 1 & 1 & 5 \\
\hline 400 & - & - & - & - & - & - & 1 & 4 & 3 & 6 & - & - & 1 & 3 \\
\hline 600 & - & - & - & - & - & - & 1 & 1 & 7 & 11 & 3 & 9 & 2 & 7 \\
\hline 800 & - & - & - & - & - & - & - & - & 1 & 4 & 3 & 5 & 1 & 3 \\
\hline 900 & - & - & - & - & 3 & 9 & 4 & 5 & 15 & 22 & + & 1 & 4 & 11 \\
\hline 1,200 & - & - & - & - & 6 & 16 & 1 & 1 & 8 & 9 & 3 & 4 & 4 & 8 \\
\hline 1,600 & - & - & - & - & - & - & 1 & 1 & 14 & 21 & 13 & 14 & 6 & 12 \\
\hline Mean & 0 & 0 & 0.5 & 3 & 0.8 & 4.6 & 0.9 & 3.7 & 3.5 & 9.4 & 1.3 & 4.5 & 1.4 & 5.6 \\
\hline
\end{tabular}

${ }^{1}$ Increase in mineral soil exposure is percentage mineral soil exposure after trampling minus percentage mineral soil exposure before trampling. $A+$ indicates less than 0.5 percent.

${ }^{2}$ Habitat types are:

ABLAICLUN = Abies lasiocarpa/Clintonia uniflora

ABLA/CLUN-VACA = Abies lasiocarpa/Clintonia uniflora-Vaccinium caespitosum phase

ABLAIVACA $=$ Abies lasiocarpa/Vaccinium caespitosum

ABLAIXETE = Abies lasiocarpa/Xerophyllum tenax

PSME/SYAL = Pseudotsuga menziesii/Symphoricarpos albus

FESC-FEID = Festuca scabrella-F. idahoensis. 
based on Friedman rank sums were used to identify which of the trampling treatments were different from the control and from each other and which habitat types differed in their response (Hollander and Wolfe 1973).

For all habitat types combined, exposure increased significantly $(p<0.001)$ as number of passes increased. The treatment of 100 passes and treatments of 300 passes and above resulted in significantly more exposure of mineral soil than on the control $(\alpha=0.05)$. Differences in exposure were very small; this is underscored by the result that none of the individual trampling treatments differed significantly.

For individual habitat types, mineral soil exposure increased significantly as trampling increased on the ABLA/XETE, PSME/SYAL, and FESC-FEID habitat types. Although increases were as great as 13 to 15 percent after some treatments, results were so erratic (refer to high standard deviations in table 9) that there were no statistically significant differences between treatments and control or among treatments for any individual habitat type.

The resistance of these habitat types to mineral soil exposure appears to be affected primarily by depth of the organic horizons and the slope of the plot perpendicular to the treatment lanes. Soil exposure was greatest on the PSME/SYAL habitat type, which had a slope of 20 to 25 percent. All of the other habitat types were almost flat. Walking perpendicular to this slope cut terraced paths into the slope, exposing more mineral soil than if there had been no slope. For the other types, those with the deepest organic horizons. ABLA/CLUN and ABLA/CLUN-VACA, had the least exposure; those with the shallowest horizons, ABLA/XETE and FESC-

FEID, had the most. Despite how readily apparent these differences are in the field and from the results in table 9 , the only statistically significant difference between habitat types $(\alpha=0.05)$ is that ABLA/CLUN experienced less mineral soil exposure than PSME/SYAL.

To generalize, 1,600 passes are sufficient to reveal a general tendency for increased trampling to lead to increased exposure of mineral soil. Increases are highly erratic, difficult to predict, and generally not very pronounced. This suggests that, in contrast to vegetation loss, there is considerable resistance to soil exposure and that it would take either prolonged trampling or much higher levels of trampling to cause pronounced increases in mineral soil exposure. This corroborates a study of existing campsites that found soil exposure to be one of only a few types of impact that only become serious after use of campsites exceeds low-use levels (Cole and Fichtler 1983).

\section{EFFECT OF TRAMPLING ON SOIL COMPACTION}

Penetration resistance, as measured with a pocket soil penetrometer, was used as a measure of soil compaction. Penetration resistance readings are affected by a number of soil characteristics, but particularly by differences in soil moisture. Because of this, a comparison of pre- and posttreatment readings would include a sizable component of change that was unrelated to the treatment itself.
Therefore the measure of change used was simply the penetration resistance of the treatment subplot minus the mean penetration resistance of the control lane.

A two-way analysis of variance again showed that both number of passes and habitat type influenced increase in penetration resistance and that there was a significant interaction between these two main effects $(\mathrm{p}<0.001)$. In this case, variances were made more homogeneous with a logarithmic (base 10) transformation. Figure 17 graphs the relationship between compaction and trampling intensity for each habitat type and table 10 shows the resistance of each habitat to each level of trampling.

It is clear that trampling generally increased penetration resistance; only a few values were negative. Moreover, with the exception of the ABLA/CLUN habitat type, there was a clear tendency for resistance to increase as trampling increased. As with vegetation loss, this relationship was a curvilinear one in which the increase in compaction caused by a given increment of trampling decreased as trampling increased. For most habitat types, the most rapid increase occurred with the first 50 to 75 passes. The rate of increase was less, but still rapid, up to 400 passes. Beyond this level of trampling the rate of increase was much less.

Pocket soil penetrometer readings are not very precise and are highly variable (Jones 1978). This variability, which could have been compensated for by making more observations, is probably a major source of the erratic nature of the increases in penetration resistance apparent in figure 17.

Another factor that contributed to the erratic nature of these increases is variability in amount of surviving vegetation on treatment lanes. Vegetation apparently cushions the impact of trampling, because compaction was usually less on lanes with high relative cover values. For example, the unexpectedly high penetration resistance value after 800 passes in ABLA/CLUN.VACA (fig. 17b) coincides with an unusually low relative cover value of 8 percent (fig. 10b).

Compaction from trampling was least pronounced on the ABLA/CLUN and ABLA/CLUN-VACA types. In fact, in the ABLA/CLUN type none of the treatments were significantly different $(\alpha=0.05)$ from the control. The least resistant types were ABLA/VACA and ABLA/XETE. Generally it appears that those types with the thickest organic horizons are least susceptible. Theoretically this would be expected because, in most situations, organic matter cushions the mineral soil from compaction (Lunt 1937; Lutz 1945; Lull 1959).

Differences between types in resistance to soil compaction were considerably less pronounced than differences in resistance to vegetation loss. Across the range of trampling from zero to 1,600 passes, no differences between habitat types explain as much of the variation in penetration resistance increase as differences in amount of trampling. In multiple regressions with pairs of habitat types and number of passes as independent variables and increase in penetration resistance as the dependent variable, the $r^{2}$ contribution of number of passes 10.15 to 0.50 , depending upon which types were compared) was always higher than the $\mathrm{r}^{2}$ contribution of habitat type (0.003 to 0.14$)$. 

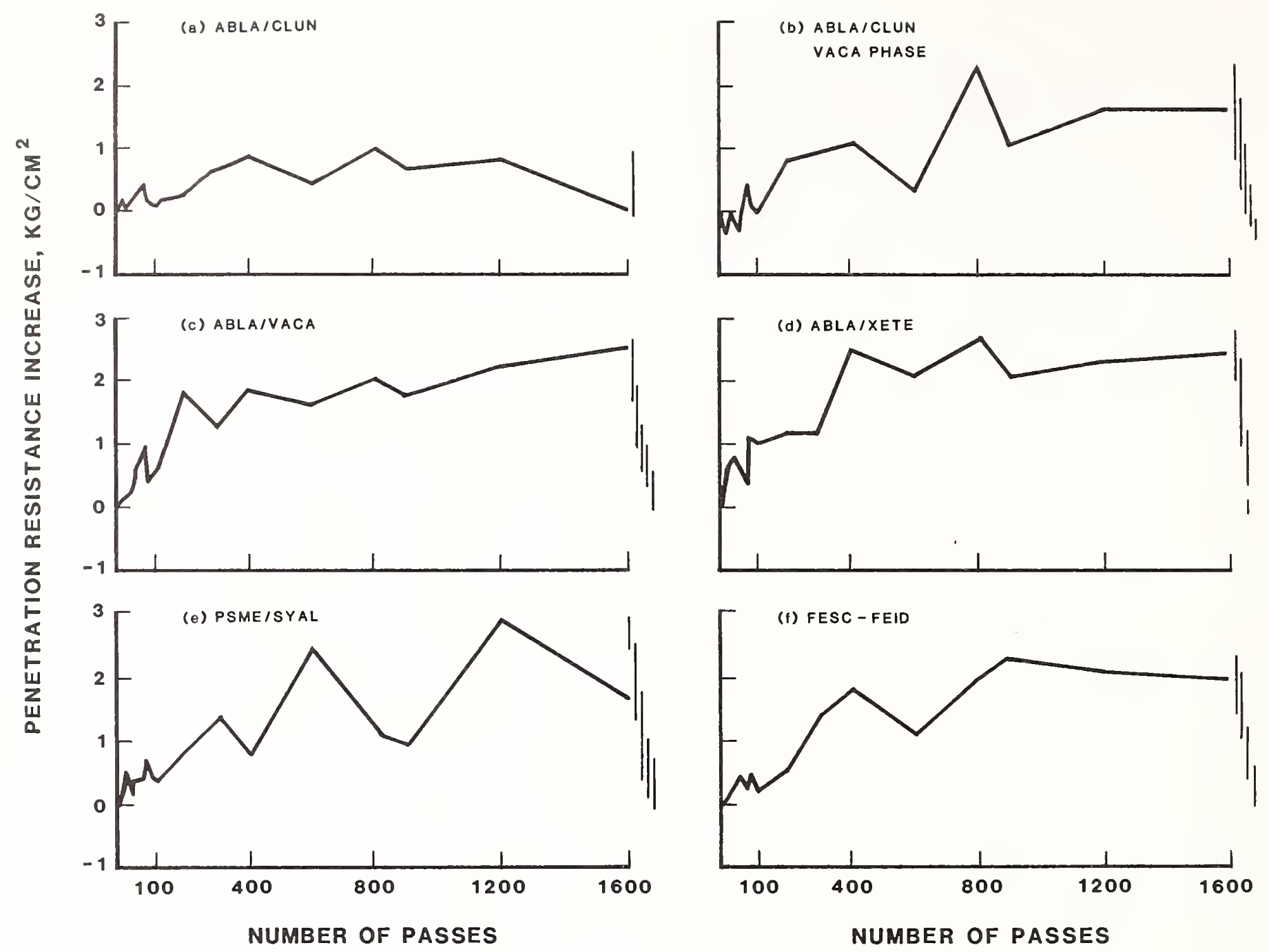

Figure 17. - The relationship between number of passes and increase in penetration resistance (treatment value minus control value). Lines at the right of each graph connect values that are not significantly different (Duncan's multiple range test, $\alpha=0.05$ ). 
Table 10. - Mean increase in penetration resistance $\left(\mathrm{kg} / \mathrm{cm}^{2}\right)$ (treatment value minus control value) after various amounts of trampling for each habitat type and for all types combined ${ }^{1}$

\begin{tabular}{|c|c|c|c|c|c|c|c|}
\hline \multirow{2}{*}{$\begin{array}{c}\text { Number } \\
\text { of } \\
\text { passes }\end{array}$} & \multicolumn{6}{|c|}{ Habitat type ${ }^{2}$} & \multirow{2}{*}{$\begin{array}{c}\text { All } \\
\text { habitat } \\
\text { types }\end{array}$} \\
\hline & $\begin{array}{l}\text { ABLAI } \\
\text { CLUN }\end{array}$ & $\begin{array}{l}\text { ABLA/CLUN. } \\
\text { VACA phase }\end{array}$ & $\begin{array}{l}\text { FESC. } \\
\text { FEID }\end{array}$ & $\begin{array}{l}\text { PSMEI } \\
\text { SYAL }\end{array}$ & $\begin{array}{l}\text { ABLAI } \\
\text { VACA }\end{array}$ & $\begin{array}{l}\text { ABLA/ } \\
\text { XETE }\end{array}$ & \\
\hline 5 & $0.18 \mathrm{bc}$ & $-0.25 a$ & $0.01 a b$ & $0.06 a b$ & $0.18 \mathrm{bc}$ & $0.59 c$ & 0.16 \\
\hline 15 & $.03 a$ & $\mathrm{Oa}$ & $.10 a$ & $.49 a$ & $.20 \mathrm{a}$ & $.64 \mathrm{a}$ & .29 \\
\hline 25 & $.21 \mathrm{a}$ & $-.03 a$ & $.25 a$ & $.21 a$ & $.30 \mathrm{a}$ & $.73 a$ & .32 \\
\hline 40 & $.23 b$ & $-.35 a$ & $.38 b$ & $.39 b$ & $.50 b$ & $.66 \mathrm{~b}$ & .37 \\
\hline 75 & $.36 a$ & $.40 a$ & $.21 \mathrm{a}$ & $.44 a$ & $.96 a$ & $.35 a$ & .47 \\
\hline 80 & $.16 a b$ & $.05 a$ & $.38 \mathrm{ab}$ & $.66 \mathrm{bc}$ & $.43 a b$ & $1.04 \mathrm{c}$ & .52 \\
\hline 100 & $.06 a b$ & $\mathrm{Oa}$ & $.16 a b$ & $.35 a b$ & $.60 \mathrm{bc}$ & $1.00 \mathrm{c}$ & .43 \\
\hline 200 & $.28 \mathrm{a}$ & $.85 a b$ & $.51 \mathrm{a}$ & $.84 a b$ & $1.79 b$ & $1.16 a b$ & .97 \\
\hline 300 & $.64 a$ & $.94 a$ & $1.39 a$ & $1.35 a$ & $1.28 \mathrm{a}$ & $1.14 \mathrm{a}$ & 1.19 \\
\hline 400 & $.83 a b$ & $1.10 \mathrm{ab}$ & $1.78 \mathrm{bc}$ & $.75 a$ & $1.91 \mathrm{bc}$ & $2.53 \mathrm{c}$ & 1.59 \\
\hline 600 & $.43 a$ & $.33 a$ & $1.06 a b$ & $2.43 \mathrm{c}$ & $1.65 \mathrm{bc}$ & $2.10 \mathrm{c}$ & 1.52 \\
\hline 800 & $.93 a$ & $2.33 a$ & $1.93 a$ & $1.16 a$ & $2.08 a$ & $2.68 a$ & 1.89 \\
\hline 900 & $.71 a$ & $1.05 a b$ & $2.28 \mathrm{~b}$ & $.98 \mathrm{a}$ & $1.80 \mathrm{ab}$ & $2.03 a b$ & 1.59 \\
\hline 1,200 & $.81 a$ & $1.63 \mathrm{ab}$ & $2.08 \mathrm{~b}$ & $2.89 \mathrm{~b}$ & $2.29 \mathrm{~b}$ & $2.31 b$ & 2.16 \\
\hline 1,600 & $.03 a$ & $1.68 b$ & $1.93 b$ & $1.65 b$ & $2.58 b$ & $2.45 b$ & 1.89 \\
\hline $\begin{array}{c}\text { All } \\
\text { amounts }\end{array}$ & $.38 a$ & $.63 a$ & $.93 b$ & $.94 b$ & $1.17 \mathrm{bc}$ & $1.33 \mathrm{c}$ & .97 \\
\hline
\end{tabular}

'Any two values in the same row followed by the same letter are not significantly different (Duncan's multiple range test, $\alpha=0.05$ ).

${ }^{2} \mathrm{Habitat}$ types are:

ABLA/CLUN = Abies lasiocarpa/Clintonia uniflora

ABLA/CLUN.VACA = Abies lasiocarpa/Clintonia uniflora-Vaccinium caespitosum phase

FESC.FEID = Festuca scabrella-F . idahoensis

PSME/SYAL = Pseudotsuga menziesii/Symphoricarpos albus

ABLAIVACA = Abies lasiocarpa/Vaccinium caespitosum

ABLAIXETE = Abies lasiocarpa/Xerophyllum tenax

\section{CONCLUSIONS AND MANAGEMENT IMPLICATIONS}

Before discussing conclusions and management implications, it is important to reemphasize that these results apply to only the first-year effects of trampling. They are useful for understanding the initial effects of recreation use on undisturbed sites. The results presented here-as well as those of all the other experimental trampling studies reviewed-cannot be extended to sites where use occurs year after year. That will only be possible after evaluating the effects of several years of trampling and recovery.

The first-year results corroborated the following:

1. For most habitat types there is a curvilinear relationship between trampling intensity and both vegetation loss and soil compaction. The additional impact caused by heavier trampling decreases as trampling intensity increases. This has significant implications for managing the distribution of human use.

2. The grassland was much more resistant to vegetation loss than any of the forested habitat types. Of the forested types, those suffering the most cover loss were those with large proportions of erect, leafy-stemmed forbs. Mosses and Xerophyllum tenax (beargrass) were the major resistant plants in the forested types. Conse- quently, ABLA/XETE was the most resistant forested habitat type.

3. In contrast to vegetation loss and soil compaction, mineral soil was exposed only after a large amount of trampling. As surveys of existing campsites show (Cole $1982 \mathrm{c})$, all but the most infrequently used recreation sites will suffer vegetation loss, but only the most frequently used sites will experience significant baring of mineral soil. This suggests that selecting a site with resistant vegetation is important at low to moderate use levels, but where use is heavy it would be better to select sites less prone to exposure of mineral soil-sites with relatively thick organic horizons and low surface erosion potential.

4. Variations in trampling frequency had considerably less effect on vegetation loss than the total amount of trampling, differences between habitat types, and even local variations in species distribution within habitat types. Consequently, trying to influence whether a given number of visits are concentrated in time or spread throughout the use season will, in most cases, have little effect on how much vegetation is lost.

The information generated from this study can be most usefully applied in deciding how to distribute use spatially in order to minimize impacts. As these results show, impact is dependent upon both amount of use and 
where that use occurs. These relationships are complicated by the fact that the importance of both differences in amount of use and differences between habitat types varies with use intensity. In the forested habitat types, differences in amount of use only affect vegetation loss profoundly if use is less than about 300 passes per season. At higher use levels, differences in amount of use have little effect on cover. Differences in the susceptibility of habitat types to vegetation loss, after one season of use, are most pronounced at use levels of 300 to 900 passes.

Managers can influence the spatial distribution of use in two ways that can reduce impact. First, they can influence the vegetation types on which people camp, and second, they can influence whether camping occurs on sites that have been used frequently, infrequently, or never before.

The results of this study show that, in the study area, camping will cause less vegetation loss in a grassland than in a forest. This corroborates the results of a study of existing sites in the Bob Marshall Wilderness (Cole 1983). If camping occurs in forest, it is best to camp in a type with lots of Xerophyllum tenax. If frequent use of sites is likely, sites might best be located in a forested type like ABLA/CLUN. The fragility of vegetation becomes irrelevant with heavy trampling because most vegetation is eliminated from any site. Nevertheless, the thick organic horizons of the ABLA/CLUN type make it less prone to mineral soil exposure and severe soil compaction.

The apparent effect of local differences in species composition on amount of vegetation loss suggests that care about where visitors walk, build a fire, and set up a tent can have a great influence on amount of impact. If visitors can recognize particularly fragile species (see table 8) and avoid trampling them, vegetation loss could be minimized. Again, this is only likely to be effective on infrequently used campsites.

For vegetation loss and soil compaction, aggregate impact in any local area-a concern for both the severity and areal extent of impact-will generally be minimized when use is directed to whichever site has already been most frequently used. The following example illustrates this point. After treatment, the 100-pass lane of the ABLA/CLUN type (a $16-\mathrm{ft}^{2}\left[1.5-\mathrm{m}^{2}\right]$ area) loses 61 percent cover (table 4). The next increment of 100 passes will be less damaging if applied to the 100-pass lane rather than an unused lane. Two hundred passes on one lane would remove 74 percent cover over a $1.5-\mathrm{m}^{2}$ area$12 \mathrm{ft}^{2}\left(1.11 \mathrm{~m}^{2}\right)$ of vegetation would be lost; 100 passes each along two lanes would remove 61 percent cover over a $32-\mathrm{ft}^{2}\left(3-\mathrm{m}^{2}\right)$ area-a loss of $20 \mathrm{ft}^{2}\left(1.83 \mathrm{~m}^{2}\right)$ of vegetation. In other words, less vegetation will be lost when use is concentrated on one site as opposed to being distributed over more sites.

The exception to this is the FESC-FEID grassland where it would be best to keep total use on any site below 1,200 passes. At this level of use, no cover loss occurs. Of course, trampling at this level year after year might cause pronounced changes. We will be in a position to evaluate this possibility after further seasons of trampling.
The curve relating mineral soil exposure to amount of use appears to be a straight line. That is, any incremental increase in use has about the same effect, regardless of how much use the site has already received. This suggests that aggregate impacts for mineral soil exposure will be about the same whether use is concentrated or spread among a number of sites.

Although impacts appear to usually be minimized by concentrating use on a few sites, minimizing amount of ecological change is only one goal of management.

Esthetic concerns and the provision of opportunities for solitude and primitive and unconfined recreation are also important. It might be logical, for example, for management to decide that a campsite is acceptable if vegetation cover exceeds 50 percent and mineral soil exposure is less than 5 percent. We can see from tables 4 and 9 that to achieve this, use could be no more than 40 passes in ABLA/CLUN, 80 passes in PSME/SYAL, 100 passes in ABLA/CLUN-VACA, 150 passes in

ABLA/VACA, 700 passes in ABLA/XETE, and 1,200 passes in FESC-FEID sites.

Obviously, to make such predictions useful it is necessary to convert number of passes into a unit of use managers can apply. This cannot be done exactly, but by using a number of assumptions and some observations of camping activities it is possible to develop a reasonable conversion.

I counted numbers of tramples associated with building a fire and cooking a simple meal. In one-half hour of meal preparation, one person took about 500 steps within the immediate cooking area-an area of about $100 \mathrm{ft}^{2}\left(10 \mathrm{~m}^{2}\right)$. From this, I estimated that in an overnight stay, one person would take a minimum of 1,500 steps in this area; 500 at breakfast, 500 at dinner, and 500 during the other hours in camp. A number of studies undertaken in diverse wildernesses (for example,

Heberlein and Dunwiddie 1979; Lucas 1980; Leonard and others 1978) have shown that the most common party size is two and median and mean party size is usually three or four. If we take three as an average number, I would estimate a minimum of about 4,000 steps in the central $100 \mathrm{ft}^{2}\left(10 \mathrm{~m}^{2}\right)$ of the campsite. This is slightly less than 3 times 1,500 because of work-sharing in any cooking effort. Pressures exerted will be higher than this because impacts caused by standing, sitting, and lying are not included. Leney (1974) has shown that these activities do have a significant impact, although they are less destructive than moving about. Liddle (1975b) states, for example, that the vertical force applied by a standing man is about $2.8 \mathrm{lb} / \mathrm{in}^{2}\left(200 \mathrm{~g} / \mathrm{cm}^{2}\right)$ compared with a force of $800 \mathrm{lb} / \mathrm{in}^{2}\left(57,000 \mathrm{~g} / \mathrm{cm}^{2}\right)$ applied when in motion. Consequently, 4,000 steps per overnight stay by a typical party of three should be considered a conservative estimate.

The next problem is to relate this number of steps to number of passes in the lanes during the experiment. The treatments were administered in lanes that are $1 \mathrm{ft}$ $(0.3 \mathrm{~m})$ wide and $16.4 \mathrm{ft}(5 \mathrm{~m})$ long. Most people took an average of seven steps in each lane, so each step occurs in a 1- by 2.3 -ft $(0.3$ - by $0.714-\mathrm{m})$ area $\left(2.3 \mathrm{ft}^{2} ; 0.214 \mathrm{~m}^{2}\right)$. Therefore, during each pass, each $0.214-\mathrm{m}^{2}$ area is stepped on once. If we assume that 4,000 steps 
(1 night's use) are equally distributed throughout the central $100 \mathrm{ft}^{2}\left(10 \mathrm{~m}^{2}\right)$ of the campsite, then each $0.214 \mathrm{~m}^{2}$ area of the central campsite is trampled 87 times - the equivalent of 87 passes. This should be a conservative estimate, but let us assume that 75 to 150 passes will simulate the amount of trampling that occurs in 1 night of use by a typical party of three in the central $100 \mathrm{ft}^{2}$ $\left(10 \mathrm{~m}^{2}\right)$ of a campsite. Peripheral parts of the campsite would receive less use.

We tested these estimates by measuring vegetation response to actual camping on two of these vegetation types. Two people spent 1 night each on previously undisturbed sites near the trampling plots in the ABLA CLUN and ABLA/XETE types. Cover measurements, similar to those taken on trampling plots, were taken on nine quadrats systematically dispersed in a $100-\mathrm{ft}^{2}$ $\left(10-\mathrm{m}^{2}\right)$ area around a fire ring and nine around a tent site in each type. Measurements were taken before and after the 8-week trampling period; the night of camping occurred in the middle of this period.

Relative cover around the fire ring after 1 night of camping was 45 percent in ABLA/CLUN and 78 percent in ABLA/XETE. From table 4 and figure 10, this level of impact corresponds most closely with 100 passes in each of these types. The relative cover of the most abundant species around the fire ring was comparable to that found after 75 to 200 passes, depending on the species. Thus, the estimate of 75 to 150 passes as simulating the effect of a typical party in the central part of the campsite appears realistic.

Relative cover around and under the tent was 92 percent in ABLA/CLUN and 95 percent in ABLA/XETE. In both cases this corresponds most closely with the effect of 15 passes. For the most abundant species, relative cover was comparable to that found after 5 to 25 passes, depending on the species. Thus, the effect of 5 to 25 passes appears to simulate the effect of a typical party around the tent.

A large party of, say, 12, although four times as large, would probably not trample any given area four times as much. Per capita impacts on any square meter will be less than with a small party because tasks are shared. I estimate that the central area would be trampled three times as much as with a party of three, an intensity equivalent to about 250 to 400 passes. Because people in a large party must spread out more, however, this high level of trampling on the campsite occurs over a much larger area (i.e., the effects of the 250 to 400 passes will apply to an area perhaps two to three times as large as $\left.100 \mathrm{ft}^{2}\left[10 \mathrm{~m}^{2}\right]\right)$.
Using these estimates, acceptable use frequencies for the average party are: no use for ABLA/CLUN; 1 night of use for PSME/SYAL, ABLA/CLUN-VACA, and ABLA/VACA; 5 to 8 nights for ABLA/XETE; and 10 to 15 nights for the FESC-FEID grassland. Campsites used by large parties would only be acceptable in

ABI.A/XETE (2 to 3 nights of use) and FESC-FEID (3 to 4 nights of use).

Clearly, such predictions should be treated cautiously and conservatively. Cumulative changes from prolonged trampling will also probably be more severe, making desirable use frequencies even lower. Nevertheless, the estimates do compare favorably with measures of vegetation loss on campsites in similar vegetation types receiving estimated amounts of use (Cole and Fichtler 1983).

In addition to corroborating the appropriateness of management suggestions derived from earlier studies of existing campsites (Cole 1982c, 1983; Cole and Fichtler 1983), this study provides more precise quantification of use levels, for individual habitat types, at which dispersal or concentration is likely to be appropriate. Except in the grassland, concentration is always better at minimizing ecological change, particularly vegetation loss. If objectives such as allowing no more than 50 percent vegetation loss are developed, however, dispersal can be desirable, particularly where use levels are not high and vegetation is resistant (for example, in the FESC-FEID and ABLA/XETE habitat types).

Exactly what these use thresholds are will depend upon stated objectives. The previous example, using an objective of no more than 50 percent vegetation loss and 5 percent soil exposure, shows how this can be done.

But there is no magic in these objectives. Managers may want to maintain more or less cover than this. The point is that we are getting closer to a point where we can predict quantitatively the effects of alternative use configurations on campsite conditions.

In assessing the applicability of these results elsewhere, it is worth reiterating that the FESC-FEID grassland is the most resistant vegetation type and ABLA/XETE is the most resistant forested type studied experimentally. The graphs in figures 1 and 10 can be used in areas with similar vegetation types to assess the likely effects of initial use of undisturbed sites. For some unstudied ecosystem types, such as deserts, however, there are no available estimates of the effects of given amounts of use. 


\section{REFERENCES}

Bayfield, Neil G. Recovery of four montane heath communities on Cairngorm, Scotland, from disturbance by trampling. Biological Conservation. 15: 165-197; 1979.

Bell, Katherine L.; Bliss, Lawrence C. Alpine disturbance studies: Olympic National Park, U.S.A. Biological Conservation. 5: 25-32; 1973.

Bowles, Jane M.; Maun, M. Anwar. A study of the effects of trampling on the vegetation of Lake Huron sand dunes at Pinery Provincial Park. Biological Conservation. 24: 273-283; 1982.

Bray, J. R.; Curtis, J. T. An ordination of the upland forest communities of southern Wisconsin. Ecological Monographs. 27: 325-349; 1957.

Campbell, Shannon E.; Scotter, George W. Subalpine revegetation and disturbance studies, Mount Revelstoke National Park. Edmonton, AB: Canadian Wildlife Service; 1975. 99 p.

Cole, David N. Reducing the impact of hikers on vegetation: an application of analytical research methods. In: Ittner, R., and others, eds. Conference proceedingsrecreational impact on wildlands. R-6-001-1979. [Portland, OR]: U.S. Department of Agriculture, Forest Service, Pacific Northwest Region; 1979: 71-78.

Cole, David N. Wilderness campsite impacts: effect of amount of use. Research Paper INT-284. Ogden, UT: U.S. Department of Agriculture, Forest Service, Intermountain Forest and Range Experiment Station; 1982a. 34 p.

Cole, David N. Vegetation of two drainages in Eagle Cap Wilderness, Wallowa Mountains, Oregon. Research Paper INT-288. Ogden, UT: U.S. Department of Agriculture, Forest Service, Intermountain Forest and Range Experiment Station; 1982b. 42 p.

Cole, David N. Controlling the spread of campsites at popular wilderness destinations. Journal of Soil and Water Conservation. 37: 291-295; 1982c.

Cole, David N. Campsite conditions in the Bob Marshall Wilderness, Montana. Research Paper INT-312. Ogden, UT: U.S. Department of Agriculture, Forest Service, Intermountain Forest and Range Experiment Station: 1983. $18 \mathrm{p}$.

Cole, David N.; Fichtler, Richard K. Campsite impact on three western wilderness areas. Environmental Management. 7: 275-288; 1983.

Cole, David N.; Schreiner, Edward G. S. Impacts of backcountry recreation: site management and rehabilitation - an annotated bibliography. General Technical Report INT-121. Ogden, UT: U.S. Department of Agriculture, Forest Service, Intermountain Forest and Range Experiment Station; 1981. 58 p.

Dale, D.; Weaver, T. Trampling effects on vegetation of the trail corridors of north Rocky Mountain forests. Journal of Applied Ecology. 11: 767-772; 1974.

Douglas, George W.; Nagy, John A. S.; Scotter, George W. Effects of human and horse trampling on natural vegetation, Waterton Lakes National Park. Edmonton, AB: Canadian Wildlife Service; 1975. 129 p.

Edmond, D. B. The influence of animal treading on pasture growth. Proceedings of the International Grassland Congress. 10: 453-458: 1966.
Harrison, Carolyn. Recovery of lowland grassland and heathland in southern England from disturbance by seasonal trampling. Biological Conservation. 19: 119 $130 ; 1981$.

Hartley, Ernest Albert. Man's effects on the stability of alpine and subalpine vegetation in Glacier National Park, Montana. Durham, NC: Duke University; 1976. 258 p. Ph.D. dissertation.

Heberlein, Thomas A.; Dunwiddie, Peter. Systematic observation of use levels, campsite selection, and visitor characteristics at a high mountain lake. Journal of Leisure Research. 11: 307-316; 1979.

Hollander, Myles; Wolfe, Douglas A. Nonparametric statistical methods. New York: John Wiley and Sons; 1973. $503 \mathrm{p}$.

Holmes, Daniel O.; Dobson, Heidi E. M. Ecological carrying capacity research: Yosemite National Park. Part I. The effects of human trampling and urine on subalpine vegetation, a survey of past and present backcountry use and the ecological carrying capacity of wilderness. PB-270-955. 'Springfield, VA: U.S.

Department of Commerce, National Technical Information Service; 1976. 247 p.

Hylgaard, T.; Liddle, M. J. The effect of human trampling on a sand dune ecosystem dominated by Empetrum nigrum. Journal of Applied Ecology. 18: 559-569; 1981.

Jones, David Henry. The effect of pedestrian impact on selected soils. Glasgow, Scotland: University of Glasgow; 1978. 154 p. M.S. thesis.

Kellomäki, Seppo; Saastamoinen, Varpu-Leena. Trampling tolerance of forest vegetation. Acta Forestalia Fennica. 147: 5-19; 1975.

Kuss, Fred R. Hiking boot impacts on woodland trails. Journal of Soil and Water Conservation. 38: 119-121; 1983.

Landals, Maureen; Scotter, George W. Visitor impact on meadows near Lake O'Hara, Yoho National Park. Edmonton, AB: Canadian Wildlife Service; 1973. 184 p.

Landals, Maureen; Scotter, George W. An ecological assessment of the Summit Area, Mount Revelstoke National Park. Edmonton, AB: Canadian Wildlife Service; 1974. $197 \mathrm{p}$.

Leney, Fiona M. The ecological effects of public pressure on picnic sites. Journal of the Sports Turf Research Institute. 50: 47-51; 1974.

Leonard, R. E.; Echelberger, H. E.; Schnitzer, M. Use characteristics of the Great Gulf Wilderness. Research Paper NE-428. Broomall, PA: U.S. Department of Agriculture, Forest Service, Northeastern Forest Experiment Station; 1978. 9 p.

Liddle, M. J. A theoretical relationship between the primary productivity of vegetation and its ability to tolerate trampling. Biological Conservation. 8: 251-255; $1975 \mathrm{a}$.

Liddle, M. J. A selective review of the ecological effects of human trampling on natural ecosystems. Biological Conservation. 7: 17-36; 1975 b.

Lucas, Robert C. Use patterns and visitor characteristics: attitudes and preferences in nine wilderness and other roadless areas. Research Paper INT-253. Ogden, UT: U.S. Department of Agriculture, Forest Service, Intermountain Forest and Range Experiment Station; 1980. 89 p. 
Lull, Howard W. Soil compaction on forest and range lands. Miscellaneous Publication 768. Washington, DC: U.S. Department of Agriculture, Forest Service; 1959. $33 \mathrm{p}$.

Lunt, Herbert A. The effects of forest litter removal upon the structure of the mineral soil. Journal of Forestry. 35: 33-36; 1937.

Lutz, H. J. Soil conditions of picnic grounds in public forest parks. Journal of Forestry. 43: 121-127; 1945.

Mueggler, W. F.; Stewart, W. L. Grassland and shrubland habitat types of western Montana. General Technical Report INT-66. Ogden, UT: U.S. Department of Agriculture, Forest Service, Intermountain Forest and Range Experiment Station; 1980. 154 p.

Nagy, John A. S.; Scotter, George W. A quantitative assessment of the effects of human and horse trampling on natural areas, Waterton Lakes National Park. Edmonton, AB: Canadian Wildlife Service; 1974. 145 p.

Pfister, Robert D.; Kovalchik, Bernard L.; Arno, Stephen F.; Presby, Richard C. Forest habitat types of Montana. General Technical Report INT-34. Ogden, UT: U.S. Department of Agriculture, Forest Service, Intermountain Forest and Range Experiment Station; 1977. $174 \mathrm{p}$.

Rogova, T. V. Influence of trampling on vegetation of forest meadow and whortleberry-moss-pine forest cenoses. Soviet Journal of Ecology. 7: 356-359; 1976.

Saunders, Paul Richard; Howard, Gordon E.; StanleySaunders, Barbara Ann. Effect of different boot sole configurations on forest soils. Extension/Research Paper RPA 1980-3. Clemson, SC: Clemson University, Department of Recreation and Park Administration; 1980. $11 \mathrm{p}$.

Schreiner, Edward George. Vegetation dynamics and human trampling in three subalpine communities of
Olympic National Park, Washington. Seattle: University of Washington; 1974. 150 p. M.S. thesis.

Schreiner, Edward. Long term experimental trampling on plant communities in Denali National Park. Progress Report. McKinley Park, AK: Denali National Park; 1980. 86 p.

Siegel, Sidney. Nonparametric statistics for the behavioral sciences. New York: McGraw-Hill; 1956. $312 \mathrm{p}$.

Singer, Steven W. Vegetation response to single and repeated walking stresses in an alpine ecosystem. New Brunswick, NJ: Rutgers University; 1971. 69 p. M.S. thesis.

Steel, Robert G. D.; Torrie, James H. Principles and procedures of statistics. New York: McGraw-Hill; 1960. $481 \mathrm{p}$.

Studlar, Susan Moyle. Trampling effects on bryophytes: trail surveys and experiments. The Bryologist. 83: 301-313; 1980.

Wagar, J. Alan. The carrying capacity of wildlands for recreation. Forest Science Monograph No. 7. Washington, DC: Society of American Foresters; 1964. 23 p.

Washburne, Randel F.; Cole, David N. Problems and practices in wilderness management: a survey of managers. Research Paper INT-304. Ogden, UT: U.S. Department of Agriculture, Forest Service, Intermountain Forest and Range Experiment Station; 1983. 56 p.

Weaver, T.; Dale, D. Trampling effects of hikers, motorcycles, and horses in meadows and forests. Journal of Applied Ecology. 15: 451-457; 1978.

Willard, Beatrice E.; Marr, John W. Effects of human activities on alpine tundra ecosystems in Rocky Mountain National Park, Colorado. Biological Conservation. 2: 257-265; 1970 . 


\section{APPENDIX 1: SOIL PROFILES}

Soil Profile at the Abies lasiocarpa Clintonia uniflora Habitat Type Plot

Oi $\quad 11-9 \mathrm{~cm}(4.3-3.5 \mathrm{in})$.

Oe $\quad 9-0 \mathrm{~cm}(3.5-0 \mathrm{in})$.

E $\quad 0-6 \mathrm{~cm}(0-2 \mathrm{in})$. Grayish brown (10YR 5/2) silt loam, light gray (10YR 7/1) dry; weak very fine to medium crumb structure: very friable (moist), nonsticky and nonplastic (wet); many very fine and fine, common medium, and few coarse roots; noncalcareous; slightly acid; clear smooth boundary.

Bo $\quad 6-31 \mathrm{~cm}(2-12 \mathrm{in})$. Dark brown (7.5YR 4/4) silt loam, pink (7.5YR 7/4) dry; weak very fine to fine and moderate medium crumb structure; very friable to friable (moist), sticky and plastic (wet); common fine and few medium to coarse roots: noncalcareous; slightly acid; abrupt smooth boundary.

2Bt $\quad 31-75 \mathrm{~cm}(12-30 \mathrm{in})$. Dark gray (10YR 4/1) silty clay loam, light gray (10YR 7/1) dry; moderate very fine to fine subangular blocky structure; friable (moist), slightly sticky and plastic (wet); common fine roots; clay skins common thin to common thick on ped faces; noncalcareous; slightly acid; abrupt smooth boundary.

3C $\quad 75-80 \mathrm{~cm}(30-32 \mathrm{in})$. Grayish brown (10YR 5/2) sandy loam, light gray (10YR 7/1) dry; moderate very fine to fine subangular blocky structure; very friable to friable (moist), slightly sticky and slightly plastic (wet); very few smooth ped faces (possibly stress cutans); noncalcareous; slightly acid; abrupt smooth boundary.

$4 \mathrm{Btb} \quad 80-97+\mathrm{cm}(32-38+\mathrm{in})$. Reddish brown (10YR $5 / 3)$ silty clay, light gray (10YR 7/1) dry; strong coarse angular blocky and massive structure; very firm (moist), very sticky and plastic (wet); few fine roots; clay skins common thin to common thick on ped faces; noncalcareous; slightly acid.

Location: SE $1 / 4$ of $\mathrm{SW}^{1 / 4}$ of Sec. $36, \mathrm{~T}, 17 \mathrm{~N} ., \mathrm{R}, 13 \mathrm{~W}$.

Classification: (Andeptic) Eutric Glossoboralf, coarse-

loamy over fine, mixed, frigid

Parent material: Ash over lacustrine sediments

Physiographic position: On stream terrace, in slight concavity at the foot of the side slope

Elevation: 4,400 feet

Slope: $0-4$ percent

Remarks: I called horizon Bo ash because it had a dis. tinctive color and boundary and a high silt content and apparently low bulk density (felt light and fluffy) compared to the underlying horizon. I have assigned this soil to the Glossoboralf great group because it probably has a frigid temperature regime and less than 60 percent tase saturation in the argillic horizon. However, it has no albic tongues into the argillic horizon, characteristic of a Glossoboralf, and furthermore, horizon Bo is apparently ash. Therefore, I have assigned this soil to a new subgroup: (Andeptic) Eutric Glossoboralf. Colors are for the moist soil unless otherwise indicated.
Soil Profile at the Abies lasiocarpa/Clintonia unifloraVaccinium caespitosum Phase Habitat Type Plot

Oi $\quad 6-4.5 \mathrm{~cm}(2.4-1.8 \mathrm{in})$.

Oe $4.5-0 \mathrm{~cm}(1.8-0 \mathrm{in})$.

A $\quad 0-10 \mathrm{~cm}(0-4 \mathrm{in})$. Dark yellowish brown (10YR $3 / 4)$ cobbly sandy loam, light yellowish brown (10YR 6/4) dry; weak very fine to fine crumb structure; very friable (moist), nonsticky and nonplastic (wet); many very fine to fine and few medium roots; noncalcareous; very strongly acid; 85 percent angular gravel to cobbles; clear wavy boundary.

CA $10-45 \mathrm{~cm}(4-18$ in). Strong brown (7.5YR 4/6) cobbly sand, brown (7.5YR 5/4) dry; very weak very fine crumb and single grain structure; loose (moist), nonsticky and nonplastic (wet); many very fine to fine and few medium roots; noncalcareous; very strongly acid; 95 percent angular gravel to cobbles; abrupt wavy boundary.

C $\quad 45-80+\mathrm{cm}(18-31+$ in). Strong brown (7.5YR 4/6) cobbly sand, strong brown (7.5YR 5.5/6) dry; single grain; loose (moist), nonsticky and nonplastic (wet); common very fine to fine and few medium roots; noncalcareous; 90 percent angular gravel to cobbles.

Location: SW $1 / 4$ of SE $1 / 4$ of Sec, $20, T, 16$ N., R. 12 W.

Classification: Typic Udorthent, sandy-skeletal, mixed, frigid

Parent material: Glacial outwash

Physiographic position: Broad, flat terrace (about $1 / 2$ mile wide)

Elevation: 4,200 feet

Slope: $0-3$ percent

Remarks: Colors are for the moist soil unless otherwise indicated.

Soil Profile at the Abies lasiocarpa/Vaccinium caespitosum Habitat Type Plots

Oi $\quad 3.5-3 \mathrm{~cm}(1.4-1.2 \mathrm{in})$.

Oe $\quad 3-0 \mathrm{~cm}(1.2-0 \mathrm{in})$.

E $\quad 0-2 \mathrm{~cm}(0-1$ in). Dark grayish brown (10YR $4 / 2$ ) cobbly fine sandy loam, light gray (10YR 7/2) dry; very weak very fine crumb structure; loose (moist), nonsticky and slightly plastic (wet); common very fine and few fine roots; noncalcareous; strongly acid: 10 percent angular to subrounded gravel, 10 percent subrounded cobbles; abrupt smooth boundary.

Bo 2-16 cm (1-6 in). Dark yellowish brown (10YR 4/4) cobbly silt loam, light yellowish brown (10YR 6/4) dry; moderately weak fine crumb structure; very friable (moist), slightly sticky and slightly plastic (wet); common very fine and fine, few coarse roots; noncalcareous; slightly acid; 10 percent angular to subrounded gravel. 10 percent subrounded cobbles; clear smooth boundary.

Bo2C1 $16-31 \mathrm{~cm}(6-12 \mathrm{in})$. Yellowish brown (10YR $5 / 4)$ stony silt loam, very pale brown (10YR 7/3) dry; very weak very fine crumb and moderate very fine to fine subangular blocky structure; very friable and friable (moist), slightly sticky 
and slightly plastic (wet); few very fine and fine roots; noncalcareous; slightly acid; 10 percent subrounded gravel, 30 percent subrounded cobbles, and 20 percent subrounded stones; clear wavy boundary.

2C1 $31-49 \mathrm{~cm}(12-19 \mathrm{in})$. Light brownish gray (10YR 6/2) stony sandy loam, white (10YR 8/2) dry; very weak fine crumb and moderate very fine subangular blocky structure; loose to friable (moist), nonsticky and nonplastic (wet): few very fine roots restricted to rock faces; noncalcareous; medium acid; 10 percent subrounded gravel, 30 percent subrounded cobbles, and 20 percent subrounded stones; abrupt smooth boundary.

2C2 $49-95+\mathrm{cm}(19-37+$ in). Light brownish gray (10YR 6/2) stony sandy loam, white (10YR 7.5/2) dry; moderate fine to medium angular blocky structure; firm (moist), nonsticky and nonplastic (wet); no roots; many, fine, discontinuous, horizontal, tubular pores within blocks; noncalcareous; medium acid; 10 percent subrounded gravel, 30 percent subrounded cobbles, and 20 percent subrounded stones.

Location: NW $\mathrm{N}^{1 / 4}$ of $\mathrm{NE}^{1 / 4}$ of Sec. 19, T. 17 N., R. 15 W. Classification: Andic Dystrochrept, loamy-skeletal. mixed, frigid

Parent material: Ash over glacial till, outwash, and lacustrine deposits

Physiographic position: Hummocky raised bench above glacially-carved valley

Elevation: 4,400 feet

Slope: $0-7$ percent

Remarks: I called the Bo horizon an ash layer because it had a distinctive color and boundary and a high silt content (estimated at 60 percent), low coarse fragment content, and apparently low bulk density (felt light and fluffy) compared to adjacent horizons. Colors are for the moist soil unless otherwise indicated.

Soil Profile at the Abies lasiocarpa/Yerophyllum tenax Habitat Type Plots

Oi $\quad 0.7-0.5 \mathrm{~cm}(0.3-0.2 \mathrm{in})$.

Oe $0.5-0 \mathrm{~cm}(0.2-0 \mathrm{in})$.

A $0-4 \mathrm{~cm}(0-2 \mathrm{in})$. Very dark grayish brown (10YR $3 / 2$ ) silt loam, dark grayish brown (10YR 4/2) dry; moderately weak very fine to fine crumb structure; very friable (moist), slightly sticky and nonplastic (wet): many very fine and few fine roots; noncalcareous; very strongly acid; 5 percent angular to subrounded gravel; abrupt smooth boundary.

Bo 4-28 cm (2-11 in). Dark yellowish brown (10YR 4/6) silt loam, light yellowish brown (10YR 6/4) dry; very weak very fine crumb structure; very friable to loose (moist), nonsticky and nonplastic (wet); common very fine, few fine and medium roots; noncalcareous; slightly acid; 3 percent angular gravel, 12 percent subrounded gravel; abrupt wavy boundary.

2C $28-81+\mathrm{cm}(11-32+\mathrm{in})$. Brown (7.5YR 5/4) cobbly sand, light brownish gray (10YR 6/2) dry; single grain; loose (moist), nonsticky and nonplastic (wet); common very fine and few fine roots; noncalcareous; slightly acid; 10 percent angular and rounded gravel, collectively, and 75 percent subrounded gravel and cobbles, collectively.

Location: $\mathrm{SE}^{1 / 4}$ of $\mathrm{SW}^{1 / 4}$ of Sec. 36, T. 17 N., R. $13 \mathrm{~W}$.

Classification: Andic Dystrochrept, sandy-skeletal. mixed, frigid

Parent material: Ash over glacial outwash

Physiographic position: Broad stream terrace

Elevation: 4,400 feet

Slope: $0-2$ percent

Remarks: I called horizon Bo ash because it had a distinctive color and boundary and a high silt content (estimated at 55 percent), low coarse fragment content, and apparently low bulk density (felt light and fluffy) compared to the underlying horizon. Colors are for the moist soil unless otherwise indicated.

Soil Profile at the Pseudotsuga menziesii/ Symphoricarpos albus Habitat Type Plots

Oi $\quad 6-4.5 \mathrm{~cm}(2.4-1.8 \mathrm{in})$.

Oe $\quad 4.5-0 \mathrm{~cm}(1.8-0 \mathrm{in})$.

A $\quad 0-9 \mathrm{~cm}(0-4 \mathrm{in})$. Very dark grayish brown (10YR $3 / 2$ ) finely gravelly silt loam, light brownish gray (10YR 6/2) dry; moderately weak very fine crumb structure; very friable (moist), slightly sticky and nonplastic (wet): many very fine, few fine, and common medium roots; noncalcareous; very strongly acid; 30 percent angular gravel; clear wavy boundary.

E $9-29 \mathrm{~cm} \mathrm{(4-11} \mathrm{in).} \mathrm{Brown} \mathrm{(10YR} \mathrm{5/3)} \mathrm{finely} \mathrm{grav-}$ elly loam, light gray (10YR 7/2) dry; moderately weak very fine to fine crumb structure with a few moderately weak very fine subangular blocks; very friable (moist), slightly sticky and nonplastic (wet); many very fine, few fine, and common medium roots; noncalcareous; medium acid; 40 percent angular gravel: clear wavy boundary.

2E $29-42 \mathrm{~cm}(11-17$ in). Brown (10YR 5/3.5) cobbly sandy loam, very pale brown (10YR 7/3) dry: moderately weak to moderate very fine to fine subangular blocky structure; friable (moist), nonsticky and nonplastic (wet); common very fine, fine, and coarse roots; noncalcareous; medium acid; 25 percent angular gravel, 25 percent channery sandstone, and 20 percent subrounded cobbles; gradual irregular boundary.

2Bt1 42-90 cm (17-35 in). Yellowish brown (10YR 5/4) cobbly clay, light yellowish brown (10YR 6/4) with common fine to medium, faint yellowish brown (10YR 5/4) mottles dry; moderate and strong very fine to medium angular blocky structure; firm to extremely firm (moist), sticky and plastic (wet): many thin clay skins on ped and rock faces; common very fine, few fine and medium roots all restricted to rock and ped faces; noncalcareous; slightly acid; 25 percent angular gravel, 25 percent channery sandstone, and 20 percent subrounded cobbles, at $70 \mathrm{~cm}$ changing to 10 percent angular gravel, 15 percent channery sandstone, and 55 percent subrounded cobbles; gradual irregular boundary. 
2Bt2 90-99+ cm $(35-39+$ in). Yellowish brown (10YR $5 / 4)$ cobbly clay marginal to sandy clay, very pale brown (10YR 7/3) dry; moderate very fine to fine angular blocky structure; firm (moist), slightly sticky and plastic (wet); common thin clay skins on ped and rock faces; few very fine roots restricted to rock faces; noncalcareous; slightly acid; 10 percent angular gravel, 15 percent channery sandstone, and 55 percent subrounded cobbles.

Location: $\mathrm{NE}^{1 / 4}$ of $\mathrm{NW}^{1 / 4}$ of Sec. 32, T. 16 N., R. $12 \mathrm{~W}$.

Classification: Eutric Glossoboralf, clayey-skeletal, mixed, frigid

Parent material: Colluvium over glacial till mixed with residual sandstone

Physiographic position: Side slope about $100 \mathrm{~m}$ above a stream terrace

Elevation: 4,200 feet

Slope: $20-25$ percent to the SW

Remarks: High bulk density below $42 \mathrm{~cm}$ may restrict water movement. Sandstone flagstones in the $2 \mathrm{Bt} 2$ horizon could be cut with a spade and broke easily in the hand. Colors are for the moist soil unless otherwise indicated.

Soil Profile at the Festuca scabrella- $F$. idahoensis Habitat Type Plots

Oe $\quad 3-0 \mathrm{~cm}(1.2-0 \mathrm{in})$.

A $\quad 0-19 \mathrm{~cm}(0-7$ in). Black (10YR 2/1) gravelly silt loam, very dark grayish brown (10YR 3/2) dry; very weak medium crumb and moderate fine to medium subangular blocky structure; very friable to friable (moist), nonsticky and slightly plastic (wet); many very fine and few fine roots; noncalcareous; neutral; 45 percent angular to subrounded gravel; clear wavy boundary.

Bw $\quad 19-27 \mathrm{~cm}(7-11$ in). Very dark grayish brown (10YR 3/2) gravelly loam, brown (10YR 4.5/3) dry; moderate fine to medium subangular blocky structure breaking to very fine subangular blocks; very friable to friable (moist), slightly sticky and slightly plastic (wet); common very fine and few fine roots; noncalcareous; neutral; 45 percent angular to subrounded gravel; clear wavy boundary.

CBw 27-41 cm (11-16 in). Dark grayish brown (10YR 4/2) gravelly loam, brown (10YR 5/3) dry; moderately weak fine crumb and moderately weak fine subangular blocky structure; very friable (moist), slightly sticky and slightly plastic (wet); many very fine and common fine roots; noncalcareous; neutral; 45 percent angular to subrounded gravel; clear irregular boundary.

Ck1 41-73 cm (16-29 in). Dark grayish brown (10YR 4/2) gravelly silt loam, brown (10YR 5/3) dry; very weak medium crumb structure breaking to single grain; very friable (moist), slightly sticky and slightly plastic (wet); many very fine and common fine roots; bulk of soil noncalcareous with a few white flecks strongly effervescent; neutral; 35 percent angular to subrounded gravel; abrupt wavy boundary.

Ck2 73-95+ cm (29-37+ in). Dark brown (10YR 4/3) gravelly loam, brown (10YR 5.5/3) dry; very weak fine subangular blocky structure breaking to very fine subangular blocks and single grains; friable (moist), slightly sticky and slightly plastic (wet); common very fine and few fine roots; violently effervescent pockets in the soil matrix and white coatings on the bottoms of coarse fragments; 50 percent gravel and 10 percent angular cobbles.

Location: SE $1 \frac{1}{4}$ of SE $1 / 4$ of Sec. 15, T. 15 N., R. 14 W.

Classification: Typic Haploboroll, loamy-skeletal, mixed, frigid

Parent material: Glacial till

Physiographic position: Spur ridge about 50 feet wide, with side slopes of about 15 percent

Elevation: 4,400 feet

Slope: $0-2$ percent

Remarks: Colors are for the moist soil unless otherwise indicated. 
APPENDIX 2: MEAN COVER AND FREQUENCY VALUES

Mean Cover and Frequency Values for Species on the Abies lasiocarpa/Clintonia uniflora Habitat Type Plot ${ }^{1}$

\begin{tabular}{|c|c|c|}
\hline Species & Cover & Frequency \\
\hline & ----- & ent ---- \\
\hline \multicolumn{3}{|l|}{ SHRUBS AND SUBSHRUBS } \\
\hline Amelanchier alnifolia & 2 & 7 \\
\hline Berberis repens & 22 & 99 \\
\hline Linnaea borealis & 2 & 21 \\
\hline Pachistima myrsinites & 5 & 50 \\
\hline Rhamnus alnifolia & 1 & 6 \\
\hline Rosa gymnocarpa & 1 & 7 \\
\hline Rubus idaeus & 1 & 3 \\
\hline Rubus parviflorus & 2 & 15 \\
\hline Spiraea betulifolia & 8 & 59 \\
\hline Symphoricarpos albus & 7 & 28 \\
\hline \multicolumn{3}{|l|}{ GRAMINOIDS } \\
\hline Bromus vulgaris & 2 & 38 \\
\hline Calamagrostis rubescens & + & 1 \\
\hline Elymus glaucus & + & 1 \\
\hline \multicolumn{3}{|l|}{ FORBS } \\
\hline Adenocaulon bicolor & 8 & 56 \\
\hline Arnica cordifolia/A. latifolia & 24 & 87 \\
\hline Aster conspicuus & 1 & 18 \\
\hline Calypso bulbosa & + & 1 \\
\hline Clintonia uniflora & 9 & 47 \\
\hline Disporum trachycarpum & + & 3 \\
\hline Epilobium angustifolium & 1 & 21 \\
\hline Fragaria vesca & 2 & 29 \\
\hline Fragaria virginiana & 3 & 49 \\
\hline Galium triflorum & 2 & 44 \\
\hline Osmorhiza chilensis & 3 & 62 \\
\hline Pyrola chlorantha & + & 7 \\
\hline Smilacina stellata & 18 & 84 \\
\hline Thalictrum occidentale & 36 & 96 \\
\hline Veratrum viride & 1 & 3 \\
\hline Viola orbiculata & 4 & 62 \\
\hline Xerophyllum tenax & 2 & 4 \\
\hline $\begin{array}{l}\text { MOSSES } \\
\text { (mainly Rhytidiopsis) }\end{array}$ & 3 & 16 \\
\hline Mean total plant cover & 93 & \\
\hline
\end{tabular}

Cover is the mean percent cover of sixty-eight 2- by 5-dm subplots Frequency is the percent of these subplots in which the species was found. $A+$ indicates cover less than 0.5 percent.
Mean Cover and Frequency Values for Species on the Abies lasiocarpa/Clintonia uniflora.Vaccinium caespitosum Habitat Type Plot ${ }^{1}$

\begin{tabular}{lll}
\hline Species & Cover Frequency \\
\hline &
\end{tabular}

SHRUBS AND SUBSHRUBS

Amelanchier alnifolia

Arctostaphylos uva-ursi

Berberis repens

Linnaea borealis

Lonicera utahensis

Rhamnus alnifolia

Rosa gymnocarpa

Spiraea betulifolia

Symphoricarpos albus

Vaccinium globulare

$\begin{array}{rr}1 & 3 \\ 8 & 62 \\ 19 & 84 \\ 45 & 97 \\ 3 & 13 \\ + & 1 \\ + & 1 \\ 11 & 57 \\ 1 & 4 \\ 5 & 19\end{array}$

GRAMINOIDS

Bromus vulgaris

Calamagrostis rubescens

Carex concinnoides

Carex geyeri

FORBS

Antennaria racemosa

Arnica cordifolia

Aster conspicuus

Aster foliaceus

Campanula rotundifolia

Chimaphila umbellata

Cirsium hookeriana

Clintonia uniflora

Disporum trachycarpum

Fragaria vesca

Fragaria virginiana

Galium boreale

Galium triflorum

Goodyera oblongifolia

Hieracium albiflorum

Osmorhiza chilensis

Pyrola secunda

Senecio pseudaureus

Smilacina stellata

Thalictrum occidentale

Viola adunca

$\begin{array}{rr}2 & 16 \\ 13 & 76\end{array}$

$1-10$

212

Mean total plant cover

$\begin{array}{rr}4 & 32 \\ 1 & 3 \\ + & 1 \\ 1 & 21 \\ + & 1 \\ 9 & 82 \\ + & 1 \\ + & 3 \\ + & 7 \\ 1 & 6 \\ 8 & 76 \\ 3 & 54 \\ + & 4 \\ + & 6 \\ 1 & 9 \\ 2 & 40 \\ + & 4 \\ + & 1 \\ 1 & 4 \\ 2 & 7 \\ + & \end{array}$

${ }^{1}$ Cover is the mean percent cover of sixty-eight 2-by 5 -dm subplots. Frequency is the percent of these subplots in which the species was found. $\mathrm{A}+$ indicates cover less than 0.5 percent. 
Mean Cover and Frequency Values for Species on the

Abies lasiocarpa/Vaccinium caespitosum

Habitat Type Plots ${ }^{1}$

\begin{tabular}{|c|c|c|c|c|}
\hline \multirow[b]{2}{*}{ Species } & \multicolumn{2}{|c|}{ Plot 1} & \multicolumn{2}{|c|}{ Plot 2} \\
\hline & Cover & Frequency & Cover & Frequency \\
\hline & \multicolumn{4}{|c|}{ 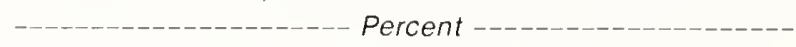 } \\
\hline \multicolumn{5}{|l|}{ SHRUBS AND SUBSHRUBS } \\
\hline Arctostaphylos uva-ursi & 22 & 93 & 4 & 38 \\
\hline Berberis repens & + & 1 & - & - \\
\hline Linnaea borealis & - & - & + & 6 \\
\hline Rosa acicularis & 2 & 16 & 1 & 7 \\
\hline Spiraea betulifolia & 5 & 46 & 2 & 18 \\
\hline Vaccinium caespitosum & 33 & 99 & 47 & 100 \\
\hline \multicolumn{5}{|l|}{ GRAMINOIDS } \\
\hline Calamagrostis rubescens & 15 & 91 & 11 & 88 \\
\hline Carex concinnoides & + & 10 & + & 4 \\
\hline Carex geyeri & 3 & 25 & 1 & 3 \\
\hline \multicolumn{5}{|l|}{ FORBS } \\
\hline Achillea millefolium & 2 & 29 & + & 7 \\
\hline Antennaria racemosa & - & - & 3 & 13 \\
\hline Arnica cordifolia & 1 & 3 & 1 & 7 \\
\hline Calochortus apiculatus & + & 1 & + & 1 \\
\hline Campanula rotundifolia & - & - & + & 6 \\
\hline Chimaphila umbellata & - & - & 1 & 9 \\
\hline Fragaria virginiana & + & 1 & 5 & 63 \\
\hline Hedysarum occidentale & 11 & 68 & 1 & 7 \\
\hline Hieracium albiflorum & 1 & 13 & 1 & 12 \\
\hline Lupinus argenteus & 11 & 63 & 7 & 43 \\
\hline Melampyrum lineare & 6 & 57 & 6 & 88 \\
\hline Penstemon procerus & + & 1 & + & 6 \\
\hline Viola adunca & + & 3 & + & 1 \\
\hline Xerophyllum tenax & 13 & 37 & 20 & 65 \\
\hline \multicolumn{5}{|c|}{$\begin{array}{l}\text { MOSSES } \\
\text { (mainly Brachythecium; some } \\
\text { Polytrichum and }\end{array}$} \\
\hline Rhytidiadelphus) & 13 & 74 & 32 & 93 \\
\hline \multicolumn{5}{|l|}{$\begin{array}{l}\text { LICHENS } \\
\text { (mainly Cladonia; some }\end{array}$} \\
\hline Peltigera) & 5 & 60 & 5 & 50 \\
\hline Mean total plant cover & 90 & & 90 & \\
\hline
\end{tabular}

Cover is the mean percent cover of sixty-eight 2- by $5-\mathrm{dm}$ subplots. Frequency is the percent of these subplots in which the species was found. A + indicates cover less than 0.5 percent. 
Mean Cover and Frequency Values for Species on the Abies lasiocarpa/Xerophyllum tenax Habitat Type Plots ${ }^{1}$

\begin{tabular}{|c|c|c|c|c|}
\hline \multirow[b]{2}{*}{ Species } & \multicolumn{2}{|c|}{ Plot 1} & \multicolumn{2}{|c|}{ Plot 2} \\
\hline & Cover & Frequency & Cover & Frequency \\
\hline \multicolumn{5}{|l|}{ SHRUBS AND SUBSHRUBS } \\
\hline Berberis repens & - & - & + & 1 \\
\hline Lonicera utahensis & + & 1 & - & - \\
\hline Pachistima myrsinites & 2 & 9 & + & 3 \\
\hline Spiraea betulifolia & 1 & 15 & 1 & 15 \\
\hline Vaccinium globulare & 22 & 81 & 8 & 31 \\
\hline Vaccinium scoparium & 55 & 100 & 52 & 100 \\
\hline \multicolumn{5}{|l|}{ GRAMINOIDS } \\
\hline Calamagrostis rubescens & 1 & 19 & 1 & 10 \\
\hline Carex concinnoides & 3 & 29 & 2 & 35 \\
\hline Carex geyeri & + & 6 & + & 6 \\
\hline \multicolumn{5}{|l|}{ FORBS } \\
\hline Chimaphila umbellata & - & - & 1 & 6 \\
\hline Fragaria virginiana & - & - & + & 1 \\
\hline Goodyera oblongifolia & 1 & 6 & + & 3 \\
\hline Hieracium albiflorum & 1 & 38 & 1 & 32 \\
\hline Melampyrum lineare & 2 & 57 & + & 12 \\
\hline Xerophyllum tenax & 22 & 53 & 35 & 84 \\
\hline \multicolumn{5}{|l|}{$\begin{array}{l}\text { MOSSES } \\
\text { (mainly Brachythecium and }\end{array}$} \\
\hline Dicranum; some Polytrichum) & 56 & 100 & 34 & 100 \\
\hline \multicolumn{5}{|l|}{$\begin{array}{l}\text { LICHENS } \\
\text { (mainly Cladonia; some }\end{array}$} \\
\hline Peltigera) & 27 & 97 & 39 & 97 \\
\hline Mean total plant cover & 93 & & 94 & \\
\hline
\end{tabular}

${ }^{1}$ Cover is the mean percent cover of sixty-eight 2. by $5 \cdot \mathrm{dm}$ subplots. Frequency is the percent of these subpiots in which the species was found. A + indicates cover less than 0.5 percent. 
Mean Cover and Frequency Values for Species on the Pseudotsuga menziesii/Symphoricarpos albus Habitat Type Plots ${ }^{1}$

\begin{tabular}{|c|c|c|c|c|}
\hline \multirow[b]{2}{*}{ Species } & \multicolumn{2}{|c|}{ Plot 1} & \multicolumn{2}{|c|}{ Plot 2} \\
\hline & Cover & Frequency & Cover & Frequency \\
\hline & \multicolumn{4}{|c|}{ 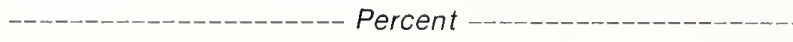 } \\
\hline \multicolumn{5}{|l|}{ SHRUBS AND SUBSHRUBS } \\
\hline Amelanchier alnifolia & 2 & 7 & 3 & 10 \\
\hline Berberis repens & 10 & 82 & 22 & 99 \\
\hline Linnaea borealis & 1 & 4 & - & - \\
\hline Rosa gymnocarpa & 1 & 13 & 1 & 6 \\
\hline Spiraea betulifolia & 16 & 74 & 12 & 60 \\
\hline Symphoricarpos albus & 16 & 35 & 4 & 19 \\
\hline \multicolumn{5}{|l|}{ GRAMINOIDS } \\
\hline Calamagrostis rubescens & 34 & 96 & 28 & 87 \\
\hline Carex concinnoides & 1 & 3 & - & - \\
\hline Carex geyeri & - & - & 1 & 4 \\
\hline \multicolumn{5}{|l|}{ FORBS } \\
\hline Achillea millefolium & + & 1 & - & - \\
\hline Arnica cordifolia & 13 & 93 & 18 & 96 \\
\hline Aster conspicuus & 3 & 29 & 2 & 21 \\
\hline Aster foliaceus & - & - & + & 3 \\
\hline Castilleja miniata & + & 3 & - & - \\
\hline Clematis columbiana & + & 1 & + & 3 \\
\hline Disporum trachycarpum & + & 6 & + & 4 \\
\hline Epilobium angustifolium & - & - & + & 1 \\
\hline Erythronium grandifiorum & 1 & 15 & + & 3 \\
\hline Fragaria vesca & + & 1 & 1 & 4 \\
\hline Fragaria virginiana & 8 & 93 & 10 & 82 \\
\hline Galium boreale & - & - & + & 1 \\
\hline Goodyera oblongifolia & 1 & 18 & + & 1 \\
\hline Hedysarum occidentale & 1 & 4 & - & - \\
\hline Hieracium albiflorum & + & 4 & + & 4 \\
\hline Lithospermum ruderale & - & - & + & 1 \\
\hline Lupinus wyethii & + & 4 & + & 10 \\
\hline Osmorhiza chilensis & 2 & 57 & + & 6 \\
\hline Pyrola secunda & + & 3 & - & - \\
\hline Smilacina racemosa & - & - & + & 1 \\
\hline Thalictrum occidentale & 5 & 47 & 8 & 54 \\
\hline Viola adunca & 1 & 19 & + & 6 \\
\hline $\begin{array}{l}\text { MOSSES } \\
\text { (mainly Brachythecium) }\end{array}$ & 9 & 31 & 3 & 19 \\
\hline Mean total plant cover & 81 & & 81 & \\
\hline
\end{tabular}

${ }^{1}$ Cover is the mean percent cover of sixty-eight 2 -by $5-\mathrm{dm}$ subplots. Frequency is the percent of these subplots in which the species was found. A + indicates cover less than 0.5 percent. 
Mean Cover and Frequency Values for Species on the

Festuca scabrella.F. idahoensis Habitat Type Plots'

\begin{tabular}{|c|c|c|c|c|}
\hline \multirow[b]{2}{*}{ Species } & \multicolumn{2}{|c|}{ Plot 1} & \multicolumn{2}{|c|}{ Plot 2} \\
\hline & Cover & Frequency & Cover & Frequency \\
\hline \multicolumn{5}{|l|}{ SHRUBS AND SUBSHRUBS } \\
\hline Berberis repens & + & 7 & - & - \\
\hline Rosa acicularis & 1 & 9 & - & - \\
\hline \multicolumn{5}{|l|}{ GRAMINOIDS } \\
\hline Agropyron spicatum & 11 & 47 & - & - \\
\hline Carex filifolia & 8 & 44 & + & 3 \\
\hline Carex rossii & 2 & 15 & - & - \\
\hline Carex vallicola & + & 3 & - & - \\
\hline Festuca idahoensis & 27 & 88 & 43 & 100 \\
\hline Festuca scabrella & 76 & 100 & 58 & 100 \\
\hline Koeleria cristata & 4 & 32 & 10 & 81 \\
\hline Poa scabrella & 2 & 16 & - & - \\
\hline \multicolumn{5}{|l|}{ FORBS } \\
\hline Achillea millefolium & 8 & 65 & 14 & 93 \\
\hline \multicolumn{5}{|l|}{ Antennaria microphyllal } \\
\hline A. umbrinella & + & 3 & 2 & 37 \\
\hline Arenaria congesta & - & - & 9 & 88 \\
\hline Arnica sororia & 3 & 32 & 1 & 19 \\
\hline Balsamorhiza sagittata & 2 & 9 & - & - \\
\hline Campanula rotundifolia & 1 & 10 & + & 10 \\
\hline Castilleja lutescens & - & - & + & 4 \\
\hline Chrysopsis villosa & - & - & 5 & 49 \\
\hline Clematis hirsutissima & - & - & 2 & 15 \\
\hline Collinsia parviflora & + & 9 & - & - \\
\hline Crepis atrabarba & - & - & 1 & 22 \\
\hline Eriogonum umbellatum & + & 3 & 1 & 4 \\
\hline Gaillardia aristata & - & - & + & 6 \\
\hline Galium boreale & 1 & 15 & - & - \\
\hline Geranium viscosissimum & 5 & 25 & - & - \\
\hline Hieracium albertinum & - & - & 2 & 21 \\
\hline Lithophragma parviflora & + & 4 & + & 1 \\
\hline Lithospermium ruderale & + & 1 & 1 & 1 \\
\hline Lomatium macrocarpum & - & - & 1 & 13 \\
\hline Lupinus sericeus & 9 & 79 & 26 & 100 \\
\hline Penstemon confertus/P. procerus & 2 & 12 & 1 & 9 \\
\hline Potentilla arguta & + & 1 & - & - \\
\hline Potentilla gracilis & 5 & 34 & + & 1 \\
\hline Solidago missouriensis & 10 & 49 & 7 & 74 \\
\hline Mean total plant cover & 95 & & 94 & \\
\hline
\end{tabular}

${ }^{1}$ Cover is the mean percent cover of sixty-eight 2 - by $5-\mathrm{dm}$ subplots. Frequency is the percent of these subplots in which the species was found. A + indicates cover less than 0.5 percent. 

Cole, David N. Recreational trampling effects on six habitat types in western Montana. Research Paper INT-350. Ogden, UT: U.S. Department of Agriculture, Forest Service, Intermountain Research Station; 1985. 43 p.

This study examined the response of six vegetation types in western Montana to experimental trampling. All of the forest types showed a curvilinear relationship between amount of trampling and loss of vegetation cover, loss of plant species, and soil compaction. A grassland was more resistant to vegetation loss. These results can be used to evaluate the likely effects of different use levels on campsites and to identify the most durable locations for campsites.

KEYWORDS: ecological impact, trampling, wilderness, backcountry management, habitat types 
The Intermountain Research Station, headquartered in Ogden, Utah, is one of eight Forest Service Research stations charged with providing scientific knowledge to help resource managers meet human needs and protect forest and rarge ecosystems.

The Intermountain Station's primary area includes Montana, Idaho, Utah, Nevada, and western Wyoming. About 231 million acres, or 85 percent, of the land area in the Station territory are classified as forest and rangeland. These lands include grasslands, deserts, shrublands, alpine areas, and well-stocked forests. They supply fiber for forest industries; minerals for energy and industrial development; and water for domestic and industrial consumption. They also provide recreation opportunities for millions of visitors each year.

Several Station research units work in additional western States, or have missions that are national in scope.

Field programs and research work units of the Station are maintained in:

Boise, Idaho

Bozeman, Montana (in cooperation with Montana State University)

Logan, Utah (in cooperation with Utah State University)

Missoula, Montana (in cooperation with the University of Montana)

Moscow, Idaho (in cooperation with the University of Idaho)

Ogden, Utah

Provo, Utah (in cooperation with Brigham Young University)

Reno, Nevada (in cooperation with the University of Nevada)

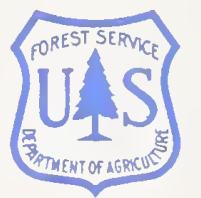

